\title{
Evaluation of techniques for disseminating parent -child interaction therapy
}

Amy D. Herschell

West Virginia University

Follow this and additional works at: https://researchrepository.wvu.edu/etd

\section{Recommended Citation}

Herschell, Amy D., "Evaluation of techniques for disseminating parent -child interaction therapy" (2003). Graduate Theses, Dissertations, and Problem Reports. 1875.

https://researchrepository.wvu.edu/etd/1875

This Dissertation is protected by copyright and/or related rights. It has been brought to you by the The Research Repository @ WVU with permission from the rights-holder(s). You are free to use this Dissertation in any way that is permitted by the copyright and related rights legislation that applies to your use. For other uses you must obtain permission from the rights-holder(s) directly, unless additional rights are indicated by a Creative Commons license in the record and/ or on the work itself. This Dissertation has been accepted for inclusion in WVU Graduate Theses, Dissertations, and Problem Reports collection by an authorized administrator of The Research Repository @ WVU.

For more information, please contact researchrepository@mail.wvu.edu. 
Evaluation of Techniques for Disseminating Parent-Child Interaction Therapy

\author{
Amy D. Herschell \\ Dissertation submitted to the \\ College of Arts and Sciences \\ at West Virginia University \\ in Partial Fulfillment of the Requirements for \\ the degree of
}

\title{
Doctor of Philosophy in
} Child Clinical Psychology

Cheryl B. McNeil, Ph.D., Chair Kevin T. Larkin, Ph.D. Tandy J. McClung, Ph.D. Daniel W. McNeil, Ph.D.

Tracy L. Morris, Ph.D.

Department of Psychology

Morgantown, West Virginia 2003

Keywords: Dissemination, Empirically Supported Treatments, Child Therapy 


\begin{abstract}
Evaluation of Techniques for Disseminating Parent-Child Interaction Therapy
\end{abstract}

Amy D. Herschell

Considerable advancements have been made in the last decade in developing, identifying, and evaluating empirically supported treatment programs (ESTs). Less progress has been made in the dissemination of these promising programs. This trend may be due, in part, to a lack of systematic studies investigating methods to distribute ESTs successfully so that both skills and knowledge are acquired. More information is needed regarding the effectiveness of existing treatment dissemination modalities (e.g., treatment manuals, workshops) as well as therapist characteristics that might impact training success.

The purposes of the current investigation were to: (a) evaluate a treatment manual as a method for dissemination of one child EST, (b) evaluate two workshop formats for delivering information relevant to an EST, and (c) provide preliminary data on therapist characteristics which may be associated with successful adoption of an EST. Toward these goals, 42 community-based, masters- and doctoral-level clinicians participated in the current study. Participants were assigned to one of two training groups (didactic or experiential). Behavior observation and self-report data were collected to assess three levels of training outcome: knowledge, skill, and satisfaction across four data points.

Results suggest that reading a treatment manual is useful but not sufficient. Significant improvements were noted in participants' knowledge and skill measures after reading; however, additional training was necessary for participants to reach mastery of knowledge and skills. Results also indicate that for the knowledge, skill, and satisfaction variables assessed, experiential and didactic training were equally effective. Concerning though is that after a two day intensive training, few participants demonstrated mastery of skills. In terms of therapist characteristics predicating success, degree type, but not theoretical orientation, was associated with training success. Participants with a MSW degree were significantly more likely that those with MA/MS degrees to reach skill mastery. Limitations of this study include selection and number of participants, frequent assessment, assessment of basic skills, and a lack of standardized and validated dependent variables. Several directions are highlighted to address these limitations. Findings indicate that ESTs like Parent-Child Interaction Therapy can be widely disseminated. Additional research clearly is needed; however, this study offers a unique contribution to the literature in that it is one of the first efforts to systematically examine techniques for disseminating ESTs. 


\section{Acknowledgements}

This manuscript represents the work of outstanding groups of people in both West Virginia and California. The project spanned two years and included the collaborative effort of numerous individuals to whom I am grateful.

This project could not have been completed without the mentorship of Drs. Cheryl McNeil and Anthony Urquiza. Over the course of my graduate training and including this project, Cheryl has offered meaningful academic guidance and remained a source of encouragement and support. She has an amazing skill in constructively motivating students to remain focused and productive. While encouraging me to remember "the big picture" and answer the "so what" she has pushed my critical thinking. Anthony has an inspiring way of making those around him feel capable and confident. His unyielding support and guidance made the completion of this project possible.

I also was fortunate to have a constructive and supportive dissertation committee guiding this project. Drs. Kevin Larkin, Tandy McClung, Daniel McNeil, and Tracy Morris provided their remarkable expertise and experience. Their comments and revision suggestions have substantially contributed to the betterment of this project as well as my research conceptualization, design, analysis, and writing skills.

Several individuals were instrumental in the design and execution of this research. Jean McGrath, Nancy Zebell, Alissa Porter, and Eric Vargas of the CAARE Center, University of California, Davis Medical Center helped to make this a practical and feasible project. Data collection took place in training and clinical facilities throughout California, which made for logistical and equipment challenges that could have halted this research project if it were not for such a quick-thinking, creative, and pragmatic group. I sincerely appreciate all the compromises made and efforts undertaken, from the inclusion of additional participants to role-playing for the two hundredth time. I also appreciated the statistical expertise and consultation provided by Dr. Susan Timmer as well as the support of several colleagues at the CAARE Center including Drs. Dawn Blacker, Katherine Elliott, and Georganna Sedlar. Kimberly Lee served as a research assistant on this project and coded a substantial portion of the data. Her hard work and dedication certainly deserve recognition and are appreciated.

I also would like to thank the individuals who participated in this project. Data collection was time and labor intensive for each of four sessions that participants completed. Without the patience and persistence of these participants, the study could not have been finished. 
Table of Contents

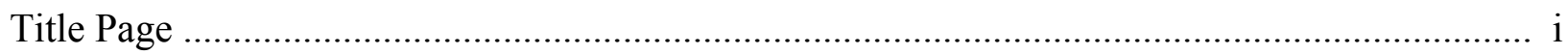

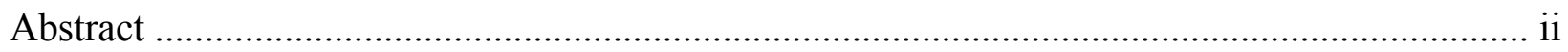

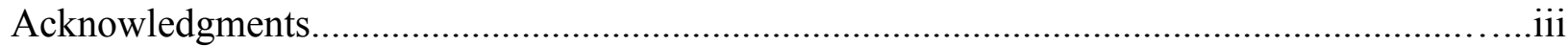

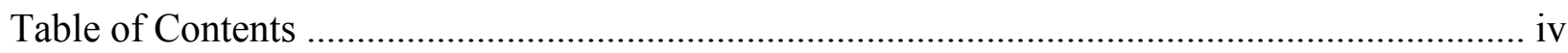

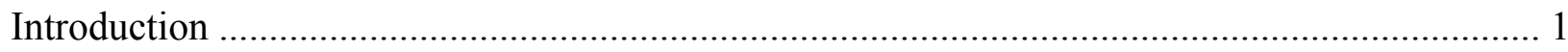

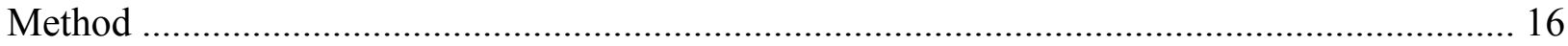

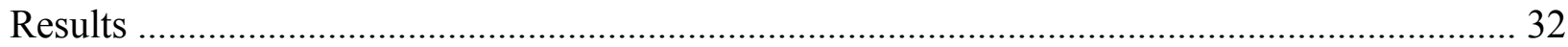

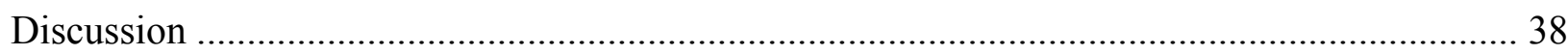

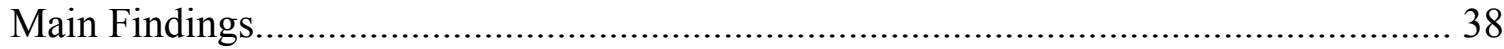

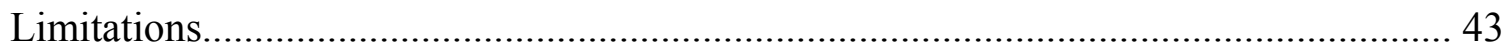

Suggestions for Future Research............................................................................. 45

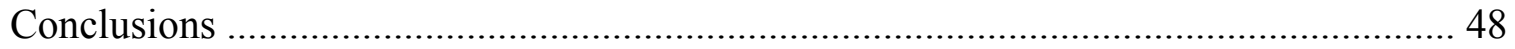

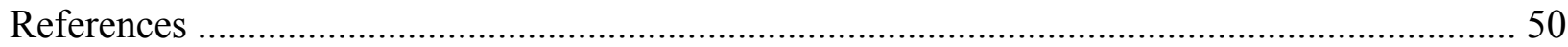

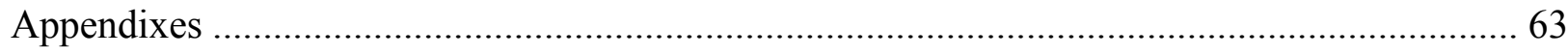

A - Training Activities/Functions/Expectations for Contracts Related to Parent-Child Interaction Therapy Training................................................................................63

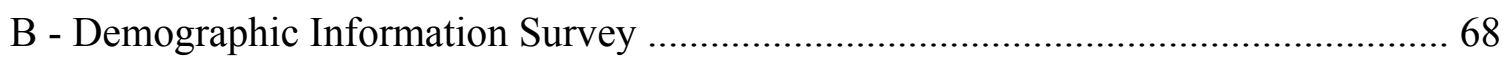

C - Attitudes Towards Treatment Manuals ................................................................. 76

D - Sample Scoring of CDI Skill Acquisition ……………….................................... 78

E - Dyadic Parent-Child Interaction Coding System (DPICS) Abbreviated Definitions. 79

F - Confederate Procedures and Situations ............................................................. 80

G - Procedures and Instructions for Coding Coaching Statements ............................... 81

$\mathrm{H}$ - Knowledge of Behavioral Principles as Applied to Children (KBPAC) - Forms A and $\mathrm{B}$ and Accompanying Answer Keys ............................................................ 84

I - CDI and DPICS Knowledge Questionnaire and Accompanying Answers - Forms A, B, $\mathrm{C}, \mathrm{D}$

J - CDI and DPICS Knowledge Questionnaire Pilot Study ..........................................106

K - Modified Therapist Attitude Inventory (Modified TAI) ............................................ 110

L - Satisfaction with Training .................................................................................. 112 
M - Training Treatment Integrity PCIT Fundamentals Day 1 114

N - Training Treatment Integrity PCIT Fundamentals Day 2 - Experiential Group ..... 117

O - Training Treatment Integrity PCIT Fundamentals Day 2- Didactic Group ..............119

P - Sample Reminder Letter to Participants ...................................................................121

Tables

1 - Participating Agencies Information Summary ............................................................ 122

2- Dependent Variable Summary ………………….................................................... 125

3 - Participants' Attitudes Toward Behaviorally Oriented Therapies ...................................... 126

4 - Training Integrity Percentages for each Training Day and Format ...................................... 127

5 - Basic Demographic Characteristics of Combined, Didactic, and Experiential Groups .........128

6 - Educational and Training Experience Characteristics of Combined, Didactic, and Experiential

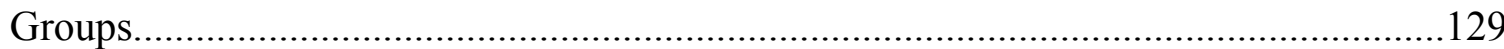

7 - Current Professional Characteristics of Combined, Didactic, and Experiential Groups.........132

8 - Interest in Upcoming PCIT training of Combined, Didactic, and Experiential Groups.........135

9 - Experience with Treatment Manuals of Combined, Didactic, and Experiential Groups........137

10 - Attitudes Toward Behaviorally Oriented Treatments of Combined, Didactic, and

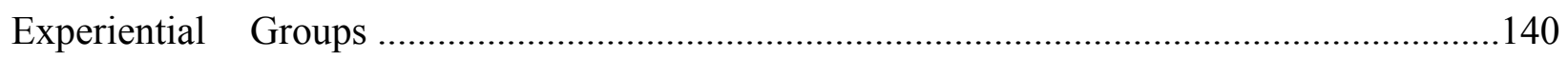

11 - Comparison of Pre-Training Skill Variables of Combined, Didactic, and Experiential Groups.

12 - Comparison of Pre-Training Knowledge Variables of Combined, Didactic, and Experiential

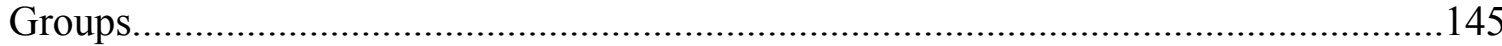

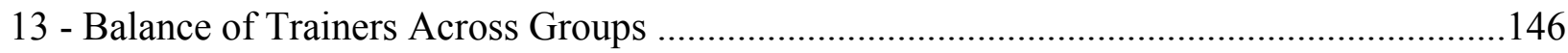

14- Assessment Procedures Summary ……………………................................................147

15 - Comparison of Knowledge Scores Pre-training and After Reading the PCIT Manual .......149

16 - Comparison of Skills Scores Pre-training and After Reading the PCIT Manual..................150

17 - Comparison of Assessment Point Three Knowledge Variables of Combined, Didactic, and

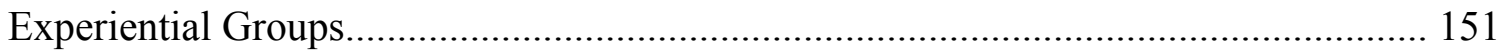

18 - Comparison of Assessment Point Three Skill Variables of Combined, Didactic, and Experiential Groups

19 - Comparison of Training Groups on Skill Acquisition at Assessment Points Three and Four 
20 - Comparison of Training Groups on Knowledge Gain at Assessment Points

Three and Four

21 - Comparison of Training Groups on Satisfaction at Assessment Points

Three and Four.

22 - Intercorrelations Between Pre-training Therapist Variables and Post-training Knowledge, Skills, and Satisfaction.

23 - Intercorrelations Between Pre-training Attitudes Toward and Experience with Treatment Manuals and Post-training Knowledge, Skills, and Satisfaction. .159

24 - Intercorrelations Between Attitudes Toward Behaviorally Oriented Therapy (BOT) and Post-training Knowledge, Skills, and Satisfaction

25 - Intercorrelations Between Pre- and Post-training Knowledge, Skills, and Satisfaction.......161

26 - Results of Logistic Regressions Predicting PCIT Knowledge Mastery by Degree Type and

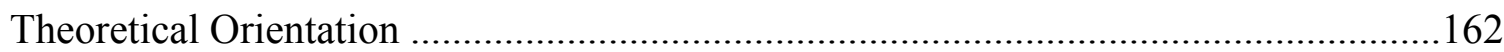

27 - Results of Logistic Regressions Predicting CDI Skill Mastery by Degree Type and Theoretical Orientation .163

28 - List of Variables Examined in Exploratory Analyses .164

29 - Description of Participants' MSW and MA/MS Programs by Graduate School and Specialty Area .166

Figure 1 - Sample Agency Assessment Schedule 168 
Evaluation of Techniques for Disseminating Parent-Child Interaction Therapy As many prominent psychologists (e.g., Crits-Christoph, 1996; Fowler, 1999; Hayes, 1998; Pelham, 1999; Persons, 1997; Weisz, 2000) have argued, and professional organizations have supported (e.g., American Psychological Association's 1999 emphasis on "giving away of psychology;" Association for Advancement of Behavior Therapy's 2001 meeting's theme "Dissemination of Effective Treatments for Psychological Disorders"), dissemination of empirically supported treatments (ESTs) is critically important to psychology and is one of the most challenging (but necessary) tasks now and in the near future. Substantial progress has been made in the development and identification of ESTs; however, few gains have been made in the dissemination of these programs. Perhaps this lack of progress has been due, in part, to the absence of empirical work devoted to systematically examining success or failure of EST dissemination techniques. The purposes of the current investigation are to: (a) investigate the effectiveness of a treatment manual for disseminating an EST, (b) evaluate the effects of didactic versus experiential workshop formats on participant outcomes, and (c) provide preliminary information on therapist characteristics associated with successful adoption of an EST.

Empirically Supported Treatments in Child Clinical Psychology

It is estimated that 12 to $22 \%$ of children experience mental, emotional, or behavioral difficulties significant enough to warrant a diagnosis (Costello, 1989). Fortunately, progress has been made in the development and evaluation of treatments for these various disorders. Collectively, recent meta-analytic reviews of treatment outcome literature on general child treatments (e.g., Casey \& Berman, 1985; Kazdin, Bass, Ayers, \& Rodgers, 1990; Weisz, Weiss, Alicke, \& Klotz, 1987; Weisz, Weiss, Han, Granger, \& Morton, 1995), as well as treatment for specific childhood disorders (e.g., Brestan \& Eyberg, 1998; Kaslow \& Thompson, 1998; Ollendick \& King, 1998; Pelham, Wheeler, \& Chronis, 1998), demonstrate this progress. Lonigan, Elbert, and Bennett-Johnson (1998) report that when general meta-analytic reviews are summarized, information from over 300 outcome studies conducted between 1952 and 1993, involving children aged 2 to 18 years, indicated that children in intervention groups scored 76 to $81 \%$ higher on outcome measures than did children in control groups.

The American Psychological Association's (APA) Society of Clinical Psychology (Division 12) recently recognized the multitude of empirical support for therapies and need for dissemination as demonstrated in the formation of Task Force on Promotion and Dissemination 
of Psychological Procedures in 1993 (APA, 1993), their initial report in 1995 (Task Force on Promotion and Dissemination of Psychological Procedures, 1995), and subsequent report additions in 1996 and 1998 (Chambless et al., 1996; 1998). Reflecting these and other treatment developments and advancements, the Surgeon General recently released the first ever report on mental health indicating that the efficacy of mental health treatments has been well documented, and that a range of treatments exist for each disorder (Satcher, 2000).

In considering childhood disorders, disruptive behaviors disorders (i.e., oppositional defiant disorder, conduct disorder, attention-deficit hyperactivity disorder, disruptive behavior disorder, not otherwise specified) represent the majority (51 to $58 \%$ ) of referrals to child mental health facilities (Kazdin, Bass et al., 1990; Tynan \& Chew, 1999). Without intervention, it is likely that antisocial and aggressive behavior in children characteristic of behavior disorders will result in a long-term (perhaps life-long) pattern of difficult behavior requiring supportive intervention (Campbell, Shaw, \& Gilliom, 2000; Wolf, Braukmann, \& Ramp, 1987). Disruptive behavior disorders most commonly are treated with eclectic, psychodynamic, and general counseling (Kazdin, Siegel, \& Bass, 1990; Schmidt \& Taylor, 2002), all of which have little empirical support compared to available behaviorally-oriented ESTs.

\section{Parent Child Interaction Therapy}

Parent-Child Interaction Therapy (PCIT; Eyberg \& Calzada, 1998; Hembree-Kigin \& McNeil, 1995) is a treatment program designed to treat children aged 2 through 6 exhibiting behavior consistent with a disruptive behavior disorder. PCIT incorporates two discrete phases, Child-Directed Interaction (CDI) and Parent-Directed Interaction (PDI). CDI emphasizes the quality of the parent-child relationship. PDI concentrates on establishing a structured and consistent discipline program. The treatment protocol is assessment-driven and is not timelimited; progress in the parent-child interactions is coded at each session, and treatment is completed when parents have mastered the skills of CDI and PDI and the child's behavior is within normal limits.

For each phase of treatment, CDI and PDI, parents attend one didactic session during which the therapist describes the skills of the interaction and provides the rationales for their use. Following the initial didactic session, parents and their child attend weekly coaching sessions together. During these coaching sessions, parents typically wear a bug-in-the-ear hearing device and are coached on their use of the skills by a therapist who is observing the parent-child 
interaction from behind a one-way mirror. Coaching is somewhat unique to PCIT, and requires therapists to be extremely active, directive, and assertive. This direct style of therapy is advantageous for several reasons including: (a) parent skill acquisition should occur more rapidly because the therapist can provide frequent, immediate, and specific feedback to shape behavior, (b) parent errors can be corrected quickly before they are practiced over an extended period, (c) general skills can be adapted to the individual needs of each parent-child dyad, and (d) therapists can observe the child's behavior with the parent and provide feedback regarding the interaction (Hembree-Kigin \& McNeil, 1995).

During CDI, parents are taught to use praise, reflection, imitation, description, and enthusiasm at high rates, and to avoid questions, commands, and criticism while conducting special playtime with their child. Once the parent's CDI skill level meets a predetermined set of criteria, the second phase of PCIT is initiated. Mastery of CDI skills is defined as the parent exhibiting the following verbal behaviors in a five-minute structured behavior observation: 25 to 50 descriptions and reflections, 15 praises ( 8 of which must be labeled praises), and no more than 3 commands, criticisms, or questions. All negative child behaviors must be appropriately ignored. During PDI, parents are taught to issue clear, developmentally appropriate, direct commands and to provide consistent consequences for both their child's compliance and noncompliance.

For most families, the full course of treatment is completed in 8 to 14 weekly, one-hour sessions. A comprehensive PCIT treatment program includes: a pretreatment assessment of child and family functioning, feedback, teaching and coaching of parents in behavioral play therapy skills, teaching and coaching of parents in behavior management skills, teaching generalization skills, and a post-treatment assessment of child and family functioning. Follow-up assessments are recommended, and booster sessions are provided, if needed. Traditionally, booster sessions are scheduled at 1, 3, 6, and 12 months after treatment completion; however, few endeavors have systematically examined the impact of these session on maintenance of treatment gains with one notable exception (Eyberg, Edwards, Boggs, \& Foote, 1998). Eyberg and colleagues explored the content and timing of booster sessions in an effort to reduce drop-out; however, a randomized control group design study has not been completed, but is needed to better understand the maintenance of treatment gains. 
Outcome research on PCIT has demonstrated clinically and statistically significant improvements in the interactional styles of parents and in the behavior problems of children at home and at school (Eisenstadt, Eyberg, McNeil, Newcomb, \& Funderburk, 1993; McNeil, Eyberg, Eisenstadt, Newcomb \&, Funderburk, 1991; Schuhmann, Foote, Eyberg, Boggs, \& Algina, 1998). In addition to finding that PCIT is efficacious in helping them manage their child's behavior, parents report high levels of satisfaction with the content and process of PCIT, less distress as their child's behavior improves, and more confidence in their ability to control their child's behavior (Schuhmann et al.). The effects of PCIT have been shown to generalize to the behavior of untreated siblings of referred children (Brestan, Eyberg, Boggs, \& Algina, 1997), to the psychological functioning of the parent (Eyberg \& Robinson, 1982), and across time (Eyberg et al., 2001), leading to improved behavior on observational and rating scale measures. Examinations of PCIT have included comparisons of treated children to wait list controls (Brestan et al., Schuhmann et al.), normal classroom controls, untreated classroom controls (McNeil et al.), modified treatment groups (Nixon, 2000), treatment dropouts (Edwards, Eyberg, Rayfield, Jacobs, \& Hood, 2002), and control groups varying in severity of disruptive behavior (Funderburk et al., 1998). Each comparison has demonstrated the short-term superiority of treatment over various control conditions.

\section{Criteria for Establishment as an Empirically Supported Treatment}

As previously mentioned, in the early 1990's APA heightened its focus on identifying ESTs and formed the Task Force on Promotion and Dissemination of Psychological Procedures (APA, 1993). The Task Force's 1995 report (Task Force on Promotion and Dissemination of Psychological Procedures, 1995) increased the visibility of ESTs and established criteria for determining if treatments should be considered empirically supported. In reviewing treatment outcome literature, criteria were applied to determine if interventions were "well established," "probably efficacious," or "in need of additional empirical support." The 1995 Task Force considered a treatment to be "well established" if it was supported by two group design studies that were conducted by different researchers or by a large series of single case design studies. Each study had to demonstrate sufficient efficacy, include treatment manuals, and clearly specify sample characteristics. In order for a treatment to be considered "probably efficacious," it had to be supported by two group design studies demonstrating treatment effects superior to a wait-list control group, or by a small series of single-subject design studies. Treatments in "probably 
efficacious" category could have support from the same investigator or have flawed samples. On the 1995 list of empirically supported treatments, 3 child treatments were considered wellestablished (behavior modification for enuresis and encopresis, and parent training programs for children with oppositional behavior) compared to 17 adult treatments, and 2 techniques applied to adults and children (behavior modification for individuals with developmental disabilities, and token economies).

Since the initial development of these criteria, several groups have completed additional literature reviews including the Section on Clinical Child Psychology (currently APA Division 53). Results from this review were presented at the 1996 APA convention and published as a series of papers in The Journal of Clinical Child Psychology Volume 27 (Ollendick, 1998). More recently, Chorpita and colleagues (2002) completed a review as part of a statewide dissemination effort. Consistent across these reviews are that parent-training programs, like PCIT, are considered "well-established." It should be noted; however, that PCIT is not independently considered "well-established." This is because the intervention's developer, Sheila Eyberg, or students of Dr. Eyberg have conducted the majority of PCIT studies. Treatments cannot be considered "well established" if their empirical support comes from the lab of the developer or those she has trained. It also should be noted that the research data that supports the efficacy of PCIT was completed with families of children experiencing disruptive behavior problems, not with families with children experiencing disruptive behavior problems and who also have a a history of physical abuse.

PCIT was chosen as the focus of the current investigation for several reasons. First, the program has a substantial level of empirical support. Over 30 controlled studies have demonstrated PCIT's efficacy (see Herschell, Calzada, Eyberg, \& McNeil, 2002 for a review). Second, PCIT was designed for the treatment of disruptive behavior disorders. These disorders represent the most common referral problem to mental health centers (Kazdin, Bass et al., 1990; Tynan \& Chew, 1999), and a major societal concern if left untreated (Wolf et al., 1987). Currently, these disorders most often are treated with strategies that are not empirically supported, and for which the efficacy is unknown (Kazdin, Siegel et al., 1990; Schmidt \& Taylor, 2002). Third, the structure of PCIT is consistent with a Hanf (1969) two-stage treatment model (positive behavioral exchange followed by a structured, consistent behavior management program). This model also is employed in other commonly used disruptive behavior disorder 
treatment programs (e.g., Barkley, 1989; Webster Stratton, 1994) with similar levels of empirical support (see Brestan \& Eyberg, 1998 for a review) which may lend to this study's generalizabillity. Fourth, PCIT has a widely available treatment manual (Hembree-Kigin \& McNeil, 1995) as well as an accompanying coding manual (Eyberg \& Robinson, 1983). Also, PCIT is very skill focused, behaviorally oriented, and complex, which may make it difficult to disseminate. Coaching requires therapists not only to know and apply specific therapy skills themselves, but also to instruct parents (rather quickly) on how to implement strategies as a therapist would utilize them. It will be useful to examine dissemination techniques for distributing PCIT because its' successful implementation requires a typically new knowledge as well as skill base. Some other therapies (e.g., Barkley) may require a therapist to learn new knowledge that is implemented using more common therapy skills. Finally, PCIT is not widely disseminated. Despite mounting empirical support since its development in the 1970's, the use of PCIT primarily has remained in the university setting (Herschell et al.).

\section{Methods of Dissemination}

Because PCIT is used primarily in university settings, most training in PCIT also is conducted in those same settings (e.g., Auburn University, West Virginia University, University of Florida). To aid in dissemination, a treatment manual has been developed (Hembree-Kigin \& McNeil, 1995). Additionally, workshops have been conducted at national conferences (e.g., American Psychological Association, Association for Advancement of Behavior Therapy) as well as trainings at medical centers (e.g., Columbia University Medical Center, University of California, Davis Medical Center) and community mental health centers (e.g., CARE Center in Santa Rosa, California; Family Life Center in Columbus, Kansas). Formal assessment of these trainings has not yet been conducted.

Interestingly, two postgraduate learning formats, written materials (e.g., treatment manuals) and workshops are those that psychology has relied on and whose success as dissemination techniques have been repeatedly questioned and criticized (e.g., Addis, 2002). Considering that it has been estimated (Durbin, 1972) that the average half-life of a doctorate in psychology is 10 to 12 years, indicating that within this time span a psychologist's knowledge base may be half as complete as it was at the time of licensure, it seems particularly important for postgraduate education in psychology to be effective. 


\section{Utilization of Research Findings in Community Settings}

Historically, disseminating innovative clinical techniques and research findings through the use of printed materials has been unsuccessful. As discussed by Backer, Liberman, and Kuehnel (1986), a study conducted in 1971 (Garvey \& Griffith) demonstrated that half of all research articles were read by no more than 200 persons. Similarly, Cohen (1979) estimated that clinical psychologists read only two to four research articles per month and Norris and Larsen (1976) found that less than $10 \%$ of 1,100 mental health workers in "real-world" settings used printed materials to help them manage client needs. Continuing education, typically delivered in didactic workshop formats, has suffered a similar historical fate. In a follow-up survey of 1, 623 participants attending continuing education courses, only $26 \%$ of 393 respondents reported offering new services as a result of the training they received (Beisser, 1976).

As is demonstrated by these and other investigations (e.g., Barlow, 1981; MorowBradley, \& Elliott, 1986; O’Donohue, Curtis, \& Fisher, 1985), low rates of clinical innovations and research utilization in community settings is a fairly consistent finding in the early dissemination literature. Unfortunately, more recent studies have demonstrated similar findings despite substantial efforts to disseminate research on ESTs. For example, as discussed by Persons (1997), an extraordinary success rate of $70 \%$ has been reported for conditioning therapy in the treatment of children experiencing enuresis; however, less than 5\% of American primary physicians prescribe this therapy (Rushton, 1989), and only $25 \%$ of 196 members of the American Association for Marriage and Family Therapy chose it to treat enuresis. Instead, the large majority (75\%) chose individual psychotherapy, family therapy, or play therapy as their preferred treatment method for enuresis (Wagner \& Hicks-Jimenez, 1986). Furthermore, research-supported techniques still are in the minority of techniques used to prepare children for medical procedures (O’Bryne, Peterson, \& Saladana, 1997) and to treat disruptive behavior disorders (Kazdin, Siegel et al., 1990; Schmidt \& Taylor, 2002). In addition, Peterson (1997) suggested that only $10 \%$ of effective behavioral techniques are used by the general public, some of which often are used incorrectly (e.g., time-out). Similar patterns have been well documented in the adult anxiety disorder (e.g., Barlow, Levitt, \& Bufka, 1999; Goisman et al., 1993; Goisman, Warshaw, \& Keller, 1998) and substance abuse research literature (e.g., Miller et al., 1995). Additionally, Addis and Krasnow (2000) demonstrated that $76.9 \%$ of practicing psychologist respondents had heard of treatment manuals (a hallmark of ESTs discussed later); 
however, $47 \%$ never used treatment manuals in clinical work, and less than $50 \%$ reported having ample knowledge of the contents or applicability of manuals.

Authors have suggested that ESTs are not widely used because of specific dissemination obstacles (e.g., Addis, Wade, \& Hatgis, 1999; Hoagwood, Hibbs, Brent, \& Jensen, 1995; Persons, 1995; Strosahl, 1998). The validity of two theorized barriers will be investigated in the current investigation. First, it has been suggested that ESTs are theoretically limited and may only be successful with those who adhere to behavioral or cognitive-behavioral orientations because most ESTs were developed from these orientations. Another theorized barrier to be examined is the assertion that the majority of clinicians are masters-level professionals who may not have the training background necessary for flexible and adherent implementation of ESTs (Addis \& Krasnow, 2000).

ESTs primarily have been developed from behaviorally and cognitive-behaviorally oriented treatment approaches. Hallmarks of these theoretical approaches such as systematically monitoring client progress, documenting sessions' content and gains, and taking an actuarial approach to treatment have been accused of "manualizing" therapy. It has been suggested and some preliminary data (Addis \& Krasnow, 2000) support that acceptance of treatment manuals (a significant part of ESTs) is related to theoretical orientation and job setting. Practitioners reporting adherence to a cognitive-behavioral orientation and/or working in an academic setting had a significantly more positive attitude toward treatment manuals than practitioners reporting adherence to a psychodynamic theoretical orientation and/or working in a non-academic setting. This is particularly concerning considering that approximately $57 \%$ of 891 clinicians in Addis and Krasnow's investigation reported their theoretical orientation to be something other than cognitive-behavioral (24\% of whom reported a pychodynamic orientation) and only $9 \%$ were employed in an academic setting. Practitioners in private practice (the most common work setting reported) had more negative attitudes about treatment manuals than any other group examined. It seems that individuals who have the most exposure to treatment manuals (behaviorally or cognitively-behaviorally oriented academics) also are those who view them positively. Questions remain on whether therapists exposed to an EST will report similar favorable attitudes and success with treatment regardless of their reported theoretical orientation.

While a theoretical orientation consistent with an EST may be helpful for its adoption, it remains an empirical question whether this consistency is necessary. Parents have been taught, 
and successfully applied, behavioral techniques for managing disruptive behavior without lengthy instruction in theoretical issues for years. Interestingly, in a study in which parents' were taught behavioral techniques and not the behavioral theory behind the technique application, parents' post-test performance suggested significant increases in behavioral principles knowledge (McLoughlin, 1985). The same may be true of therapists; knowledge of behavioral techniques may improve knowledge of behavioral principles and, in turn, may help adoption of ESTs.

Some have mentioned educational level as a barrier to EST dissemination, indicating that masters-level practitioners may not have the educational background to successfully and flexibly implement ESTs (e.g., Addis \& Krasnow, 2000). Supporting these claims is the literature demonstrating correlations between level of degree and patient outcomes. Practitioners in outpatient settings with higher degrees (doctoral-level) tended to have fewer clients drop out of therapy, better client outcomes, and higher client satisfaction than practitioners with lesser degrees (masters-level) (Stein \& Lambert, 1995). Also interesting is that one outcome study, which used a treatment manual (Henry, Schacht, Strupp, Butler, \& Binder, 1993), demonstrated that therapists who had less prior supervision improved after training; although, that was not true for therapists who had more prior supervision, indicating that masters-level (those with less supervision) may have the most to benefit from ESTs.

\section{Treatment Manuals as a Dissemination Technique}

Recent attention to ESTs has brought a plethora of treatment manuals with the assumed intention of using them as a dissemination tool. These written sources have been essential to the evaluation of innovative interventions due to their research-oriented, session-by-session account of therapy activities. They also have sparked quite a debate. Some authors have advocated for treatment manuals, arguing that they can enhance clinical outcomes by specifying procedures so that adherence and competence can be assessed (Addis, 2002), and by capitalizing on an actuarial approach to treatment decisions (Wilson, 1996a; 1996b; 1997a; 1997b; 1998). Unnecessary variability also can be reduced, and accountability, development of practice guidelines, and formulation of specific treatment recommendations for clinical practice can be improved (Marques, 1998). Additionally, treatment manuals can act as a bridge between research and clinical practice by operationalizing clinical techniques that have been demonstrated to be efficacious and effective (Davison, 1998). 
Conversely, other authors maintain that treatment manuals neglect the idiographic study of the individual patient, and de-emphasize and stunt clinical innovation (Davison, 1998; Davison \& Lazarus, 1994; 1995). Treatment manuals also have received criticism for: (a) overlooking possible limitations in existing research, (b) neglecting the importance of client and therapist variability, (c) ignoring the role of common factors in psychotherapy, (d) disregarding the need to adapt therapeutic procedures for the problems of the individual client or patient, (e) overemphasizing techniques, and (f) relying on diagnostic categories (Garfield, 1996; 1998; Lambert, 1998; Silverman, 1996).

Empirical examinations of manuals have reported mixed results. Some have suggested that the use of a treatment manual is associated with positive and improved outcomes (e.g., DeRubeis \& Feeley, 1990; Foley, O’Malley, Rounsaville, Prusoff, \& Weissman, 1987; Frank, Kupfer, Wagner, McEachran, \& Cornes, 1991; Jacobson et al., 1989; Schulte, Kunzel, Pepping \& Schulte-Bahrenberg, 1992). Other research, however, has suggested that the use of a treatment manual is associated with negative effects and outcomes (e.g., Castonguay, Goldfried, Wiser, Raue, \& Hayes, 1996; Henry et al., 1993; Najavits \& Strupp, 1994; Rounsaville, Chevron, \& Weissman, 1984). Studies conducted on treatment manuals have focused on their impact on therapy rather than the manuals' effectiveness as a dissemination technique. Therefore, the studies have included training in addition to the manual.

Addis and Krasnow (2000) have maintained that, "Despite the interest in dissemination of empirically supported treatments, currently there are no standard practices for dissemination and no guidelines for teaching clinicians how to use a manual in their existing practices (Addis et al., 1999). Moreover, there has been little exploration of the receptivity of organizations to the dissemination of manuals or the training involved (Strosahl, 1995; Strosahl, Hayes, Bergan, \& Romano, 1998). (p. 338)" Additionally, Kendall (1998) suggested that systematically examining client and therapist characteristics that may impact dissemination progress is necessary. Workshops as a Dissemination Technique

Clinical practitioners receive a significant amount of their training through continuing education (CE) courses, typically delivered in a didactic workshop format (Addis, 2002). In fact, as reported in the 1998 results of State and Provincial Mandatory continuing professional education requirements survey (APA, 2000), CE is required by 40 of 50 states $(80 \%)$ with the number of required credits ranging from 10 per year (or 20 per 2 years) to 100 every 2 years. The 
quality of CE, however, has been described as chaotic (Davison, 1998), and the APA Task Force on Promotion and Dissemination of Psychological Procedures specifically excluded conference workshops, the typical CE modality, as a training resource on their list of ESTs and accompanying training opportunities (Sanderson \& Woody, 1995; Woody \& Sanderson, 1998). Interestingly, information on where to obtain manuals was provided.

Currently, little is known about the effectiveness of psychology CE or about effective means for disseminating ESTs through CE (Addis, 2002; Calhoun, Moras, Pilkonis, \& Rehm, 1998). In large part, research has focused on medical rather than psychological CE. Comprehensive reviews of medical CE (MCE) completed by Davis, Thomson, Oxman, and Haynes (1992) and Davis and colleagues (1999), indicate that the traditional workshop does relatively little to change the behavior of participants. Instead, extended formats which incorporate more experiential activities are necessary.

Davis and colleagues (1999) reviewed 14 studies conducted from 1983-1998 on the effect of MCE on physician performance and health care outcomes. A main conclusion was that "While these (didactic) interventions may change other elements of competence, such as knowledge, skills, or attitudes, or may act as predisposing elements to change, didactic lectures by themselves do not play a significant role in immediately changing physician performance or improving patient care" (Davis et al., 1999, p. 870). Additionally, it was noted that utilization of interactive techniques (e.g., case discussion, role-play, or hands-on practice sessions) and sequencing sessions was associated with greater skill acquisition. In a previous review, in which Davis et al. (1992) examined 50 MCE studies, consistent results were found indicating that MCE is more effective when it incorporates practice-based strategies. A review of limited psychology CE investigations by VandeCreek, Knapp, and Brace (1990) reported very similar conclusions. The traditional workshop is insufficient for practitioners to acquire skills. Instead, CE courses successful at facilitating skill acquisition were those that identified a target audience, included participants who expressed a desire to learn and who had identified current skills or knowledge inadequacies, made learning objectives clear, required active participation, and provided opportunities for supervised practice beyond the period of training. Assessment of Skill Acquisition, Knowledge Gain, and Satisfaction

In the dissemination of ESTs, a clear difference should be delineated between knowledge gain and skill acquisition. Literature supports that knowledge may be gained from simple 
exposure to materials or unstructured and unsupervised activities; however, skills, particularly therapy skills, generally are acquired through use of targeted goals, practice, feedback (e.g., Alberts \& Edelstein, 1990; Beutler \& Kendall, 1995; Beutler, Machado, \& Nuefeldt, 1994; Luborsky, 1990), and supervision (Holloway \& Neufeldt, 1995). Knowledge alone does not necessarily lead to behavior change as has been demonstrated in multiple literatures including health psychology (e.g., Inham \& Bennett, 1990), sexual abuse prevention skills training with individuals with developmental disabilities (e.g., Lumley, Miltenberger, Long, Rapp, \& Roberts, 1998), and abduction prevention training with preschool children (e.g., Carroll-Rowan \& Miltenberger, 1994). Similarly, in treatment outcome studies, performance on a written test of knowledge showed no relationship with therapist in-session performance in cognitive-behavioral training (Shaw, 1984), and high performance on tests of knowledge actually was associated with low performance of therapy skills (Chevron \& Rounsaville, 1983). Therefore, in considering dissemination of ESTs, tests of knowledge may be necessary, but not sufficient to demonstrate competent application of skills. Hawkins and Sinha (1998) examined knowledge gain after a training on a theoretically complex therapy (dialectical behavior therapy). Results of a posttraining examination indicated that therapists did master the content of the training; however, performance of the taught therapy skills was not assessed. Therefore, studies like this one offer a beginning to understanding successful dissemination methods for distributing knowledge, yet, assessment of performance is critical to understanding successful dissemination methods for distributing applied therapy techniques.

Also critical to understanding success or failure of a dissemination technique is its acceptability. Wolf (1978) suggested that social validity significantly impacts the relationship between treatment recommendations and implementation. In order for treatments to be implemented they must be acceptable first to those applying them, (in this case) therapists. Measures of satisfaction, although less frequently employed in scientific evaluations, are arguably as important as more objective measures of change in determining effectiveness (Eyberg, 1993). After all, if therapists are unsatisfied with a treatment approach, it is unlikely they will use it in clinical practice or recommend it to clients or colleagues. 


\section{UC Davis Medical Center PCIT Training Contract}

In an effort to disseminate innovative and empirically supported treatments, the California Governor's Office of Criminal Justice Planning (OCJP) in May 2000 awarded the Child \& Adolescent Abuse, Resource, and Evaluation Center (CAARE Center), UC Davis Medical Center, $\$ 650,000$ to develop PCIT programs in 13 agencies across the state of California. Each of the agencies selected to receive PCIT training specialized in the treatment of children with histories of maltreatment (i.e., physical abuse, sexual abuse, neglect, or a combination of the three). While PCIT was originally developed to treat children exhibiting disruptive behavior, it also has been successfully applied to children with histories of maltreatment (Urquiza \& McNeil, 1996). This success may be due to the high comorbidity between physical abuse and disruptive behavior (see Kolko, 1992 and Wolfe, 1987 for reviews). Each of the 13 participating agencies initially selected 2 therapists who would receive PCIT training and be responsible for training other staff members at his or her agency; however, later each agency was invited to send additional staff members to receive training in PCIT and participate in the current study.

Training was conducted in five phases: program development, PCIT fundamentals, intensive skill building, advanced skill building, and consultation and supervision. Also included in training were quality assurance, quarterly regional meetings, and one PCIT national conference. All of these components occurred over the course of one year and took place at the CAARE Center as well as at agency sites.

Phase one, program development, included individualized assistance and consultation in building a PCIT program. Consultation was provided on practical aspects of establishing and maintaining a PCIT program such as participating in training, securing an ongoing referral base, acquiring a stable funding source, and acquiring and installing equipment. Approximately three months later, Phase two, PCIT fundamentals, included a two consecutive day workshop at each agency site or region. An overview of PCIT was provided as well as detailed information regarding CDI. All study participants received the same content and format of information on day one. During the second day of PCIT fundamentals, study participants received either experiential or didactic training depending on their group assignment. They received the same content of information presented in differing formats, which is discussed in detail in the procedures section. 
Phase three, PCIT intensive skill building, was conducted at the CAARE Center. Participants refined their CDI skills, learned the second component of PCIT, PDI, and received individualized feedback on their skill use with clients. Phase four, advanced skill building also was conducted at the CAARE Center. The goal of phase four was for therapists to expand their skills and knowledge so that mastery of PCIT was obtained. Toward that end, continued coaching instruction, supervision on therapists' cases, and individualized feedback on PCIT therapy skills was provided.

Finally, phase five, PCIT consultation, supervision, and training, focused on therapists being able to successfully and independently implement a PCIT program at their agency. Therefore, this phase concentrated on teaching skills related to teaching and supervising novice PCIT therapists. Also included in this phase was continued clinical consultation on challenging cases, changing program needs, management of procedures related to PCIT, and issues related to successful program implementation. Please see Appendix A for additional details regarding the broader training program of which this study is a part.

\section{Present Study}

The present study focused on phases one and two of the larger training project. More specifically, four assessments of participants took place: one prior to initiation of training phase one (assessment one), one at the end of training phase one and beginning of phase two (assessment two), one at the middle of phase two (assessment three), and one at the end of phase two (assessment four). As described in Figure 1, immediately after completing pre-training assessment, training phase one was initiated. Phase one included information relevant to program development, not therapy. Afterward, participants were provided with the PCIT and DPICS manuals. Approximately three months later, assessment two occurred. Immediately thereafter, day one of PCIT fundamentals began. Assessment three occurred at the end of that day. Participants received differing workshop formats on the second consecutive workshop day. Assessment four occurred at the end of the second day.

The OCJP training project offered a unique opportunity to evaluate the application of an empirically supported, university-based treatment program in "real-world" settings. A critically important part of successful EST dissemination is the training of therapists and determination of effective training techniques. Toward that end, there were three purposes for the present study. The first purpose was to evaluate the effectiveness of a treatment manual as a method for 
disseminating an EST. Participants were provided the PCIT and DPICS manuals immediately after completing program development. Assessments occurred prior to supplying the manual as well as prior to beginning phase two to determine if simply reading the manuals improved participants' skills, knowledge, and satisfaction. The second purpose of the proposed study was to compare experiential versus didactic workshop formats for delivering information relevant to PCIT. This was examined by comparing outcomes of participants who received two different workshop formats (experiential and didactic). Finally, the current study provided preliminary data on therapist characteristics that may be associated with successful adoption of an EST. Therapist characteristics were assessed prior to the initiation of any training and were examined to determine if any might predict or be associated with successful implementation of PCIT.

It was predicted that the treatment manual would not be a sufficient method of dissemination. It was suspected that after reading a manual, an increase in knowledge would be evident; however, it was suspected that skills would not be mastered. As some have suggested (Alberts \& Edelstein, 1990; Beutler \& Kendall, 1995; Beutler et al., 1994; Luborsky, 1990), knowledge can be gained from exposure to materials; however skill acquisition requires a more active process.

It also was predicted that participants involved in an experiential training would demonstrate more improved outcomes than participants involved in a didactic training. More specifically, it was hypothesized that participants in the experiential group would demonstrate gains in skills, knowledge, and satisfaction whereas participants in the didactic group would experience gains in only knowledge and satisfaction, not skills. As VandeCreek et al. (1990) indicated in a review of the psychology CE literature and Davis et al. (1999) demonstrated in a review of the medical CE literature, practice-based, experiential learning formats facilitate the acquisition of skills. Also, research on therapy skills (e.g., Alberts \& Edelstein, 1990; Beutler \& Kendall, 1995) indicates that skills generally are acquired through use of targeted goals, practice, and feedback.

Finally, it was predicted that specific therapist characteristics would be associated with training success. It was suspected that that participants who reported a behavioral orientation (Addis \& Krasnow, 2000) or who had a doctoral- (rather than masters-) level degree (Stein \& Lambert, 1995) would demonstrate significantly higher levels of skill acquisition and knowledge gain at the final assessment point (assessment four) than participants who did not report those 
characteristics. Others (Addis \& Krasnow) have suggested that individuals who work in an academic setting, have experience with treatment manuals, and report a positive attitude towards manuals may demonstrate higher success at acquiring therapy knowledge and skills compared to those who report contrary opinions and experiences.

\section{Method \\ Setting and Participants}

\section{Setting}

PCIT fundamentals trainings were conducted in conference and mental health centers throughout California. Participants were asked to attend regional or local trainings depending on their geographic location and distance from other agencies. Data were collected at eleven phase one and eight phase two trainings. The same number of agencies participated in each phase of training; however, two agencies in southern California and two agencies in northern California were geographically close to one another and scheduled phase two training together. The average number of attendees at phase one meetings was six, with a range of four attendees in the smallest training and ten attendees in the largest training. The average number of attendees at phase two trainings was six, with a range of two attendees in the smallest training and nine attendees at the largest training. For each of the trainings, there were two groups (experiential and didactic). Participants were matched to group at each of the trainings so that group size was consistent across trainings. Therefore, any difference in number of people in attendance was balanced across experiential and didactic groups. This also was done so that participant characteristics that might be correlated with individual agencies would be balanced across experimental group conditions.

\section{Participant Selection}

Initially, it was proposed that as part of the OCJP Project, 26 therapists from 13 agencies would be selected to receive training. Because two of the agencies had received training in PCIT prior to this project, it was proposed that those agencies would be excluded from participation in the current study. It was proposed that the remaining 22 therapists from 11 agencies would be asked to voluntarily participate as an experiential group, and 22 therapists from the same 11 agencies would be asked to voluntarily participate as a didactic group. Instead, in order to increase the potential number of participants, agencies were invited to send as many therapists as possible to participate in training. From the 11 agencies considered for inclusion, data originally 
were collected on 61 therapists; however 13 people participated in only phase one of training and were, therefore, not considered in the current project. Of the thirteen people who participated in only phase one, the following reasons were given for discontinuing participation: (a) One agency originally sent 10 people to phase one; however, afterward the agency executive director selected three to participate in the year-long training, excluding seven people from participation; (b) After significant administrative changes, three participants resigned from one agency; (c) Two practicum students completed training with an included agency and sought employment elsewhere; and (d) one person from another agency decided not to participate in the OCJP training project due to time constraints. No person who participated in the OCJP training project declined participation in the current study.

Of the remaining 48 participants, 6 were selected for exclusion from the experiential group so that the groups could be balanced for number and educational level. Of the participants selected for exclusion, five participants possessed a doctoral degree (4 Ph.D., 1 Psy.D) and one participant had received a Masters in Social Work. Participants were selected for exclusion in a two-step process. First, the participant numbers for all participants in the experiential group with a doctoral degree were determined and written on pieces of paper. Each piece of paper was placed in a box. Next, 5 numbers were randomly drawn from the box by a research assistant. Participants with matching participant numbers were excluded from this project. Similarly, all participant numbers for participants in the experiential group with Masters in Social Work were identified, written on pieces of paper, and placed in a box. The same research assistant selected one piece of paper from the box. The participant whose participant number matched the number drawn from the box was excluded from this project.

Participants were matched to group by agency. Phone contacts were made with each of the agencies prior to initiating training. It was recommended that persons invited to participate in training (after the initial two persons were selected and placed in the experiential group), be as similar as possible to the original two persons selected. It was necessary to place the initial two persons in the experiential group because of OCJP's contract obligations. OCJP, the funding source, had been informed of the experiential type of training that would be offered. Additional people were included in the training, in part, to increase the number of participants in this study; however, it was after the agencies had identified two trainees and OCJP had been informed of those trainees. Agencies also were encouraged to include clinicians whose primary responsibility 
was direct service delivery. Participating agencies all specialized in the treatment of children who have experienced maltreatment; however, agencies were quite diverse, serving various cultural groups in differing regions. A summary of basic information about each agency is provided in Table 1. This information was obtained from proposals submitted to OCJP requesting funds for PCIT training and in multiple interactions with participants from each agency.

\section{Measures}

Information was obtained to assess four domains: participant characteristics, skill acquisition, knowledge gain, and satisfaction. Measures also were used to assess training integrity as discussed below. Table 2 includes a summary of dependent variables to be discussed as well as information pertaining to their reliability assessment.

\section{Participant Characteristics}

Demographic Information Survey. Several variables have been hypothesized to affect adoption of ESTs including therapist theoretical orientation and training background (Addis \& Krasnow, 2000). A demographic information survey was developed to include these variables as well as details regarding age, ethnicity, gender, postgraduate training experiences, applicability of training to clinical practice, preferred learning formats, satisfaction with currently used interventions, interest in PCIT training, attitudes toward treatment manuals, and attitudes toward a behavioral orientation. The developed survey is included in Appendix B. Participants completed this measure once prior to training (assessment one).

Eleven items were included on the Demographic Information Survey that was developed by the researcher to assess participants' attitudes toward behaviorally oriented therapies. While the attitudes toward behavioral therapies inclusion was designed as a single measure of positive and negative attitudes, when the items were subjected to a reliability analysis, the alpha coefficient was unacceptably low $(\alpha=.45)$, suggesting poor internal consistency. In order to determine whether the scale actually contained more than one conceptually distinct measure of attitudes, a principle components factor analysis with varimax rotation was performed on the eleven items. The varimax rotation maximizes the conceptual distinctness of the solution without forcing orthogonality on it. This process yielded four factors with eigenvalues greater than 1 , accounting for $67 \%$ of the variance. When four factors were considered, items were widely spread across factors, with four items loading primarily on factor 1; three items primarily loading 
on factor 2; three items primarily loading on factor 3; and two items primarily loading on factor 4. Two of the four factors had eigenvalues greater than or equal to 2 , accounted for $43 \%$ of the variance, and were conceptually distinct. Therefore, a two factor solution appeared to be a reasonable estimate of the potential number of factors.

A second principal component factor analysis with a varimax rotation was conducted in which a two-factor solution was specified. Two items (items 1 and 10) had loadings of less than .45 on any one factor, and therefore were excluded, leaving 9 items. The two factors accounted for $43 \%$ of the variance in 9 of the original 11 items, and were interpreted based on their item content. Table 3 reveals that Factor $1(\alpha=.75)$ consisted of items highlighting participants' negative ideas about behavior therapies. This factor was labeled Negative Ideas. Factor $2(\alpha=$ .68) consisted of items that revealed more positive ideas about behavior therapies, and was therefore named Positive Ideas. Ratings of items loading greater than .45 on each factor were summed to create factor scores for each participant, where higher scores on the Negative Ideas factor indicated more negative attitudes toward behavior therapies and higher scores on the Positive Ideas factor indicated more positive attitudes toward behavior therapies. These factor analyses should be considered with extreme caution given the low sample size. They were conducted as an exploratory measure and offered to provide some information for a measure created by the examiner.

Attitudes toward Treatment Manuals. This 17-item self-report questionnaire was designed to assess attitudes toward treatment manuals (Addis \& Krasnow, 2000). More specifically, items were included to assess positive and negative aspects of using treatment manuals. These aspects were derived from a review of the literature on treatment manuals as well as information interviews with New England practitioners. Addis and Krasnow used this measure in a survey of 2,970 licensed psychologists; however, they did not report its psychometric properties, with the exception of factor analysis completed to examine the instrument's structure as described below. Practitioners completing this questionnaire were asked to rate their agreement with each of 17 items on a five-point Likert scale ranging from 1 (strong disagreement) to 5 (strong agreement). Sample items include: 1. Manuals make therapists more like technicians than caring human beings, 2. Following a treatment manual will enhance therapeutic outcomes by ensuring that the treatment being used is supported by research (see Appendix C). 
Considering the 19 items of the scale, Addis and Krasnow (2000) completed a principalcomponents analysis, which yielded a three factor solution. Given that one of the three factors accounted for only $6 \%$ of the variance, a two-factor solution was considered more reasonable. A second principal components analysis with a specified two-factor solution was completed, which accounted for $52 \%$ of the variance and yielded two factors: Negative Process and Positive Outcome. The negative process factor represents therapists' concern for freedom and flexibility in sessions as well as concern for the potential negative effects of manuals on the therapeutic relationship. Conversely, the Positive Outcome factor represents therapists' belief that manuals can enhance treatment outcomes (Addis \& Krasnow, 2000). Both factor scores were considered in the current study. Participants were asked to complete this measure, which is included in Appendix C, two times: once at assessment point one and once at assessment point four. Skill Acquisition

Dyadic Parent-Child Interaction Coding System. The Dyadic Parent-Child Interaction Coding System (DPICS; Eyberg \& Robinson, 1983) was designed to assess the quality of parentchild interactions through observations of dyads in three standardized laboratory situations (CDI, PDI, clean-up). The DPICS measures 24 categories of parent and child behaviors through frequency counts. Normative data are available (Eyberg \& Robinson) as well as ample studies documenting this coding system's reliability and validity (e.g., Aragona \& Eyberg, 1981; Eyberg \& Matarazzo, 1980; Robinson \& Eyberg, 1981). Numerous treatment outcomes studies have used this system to measure treatment gains (e.g., Eisenstadt et al., 1993; McNeil et al., 1991). Reliability ratings for parent behaviors reportedly range from .67 to 1.0, with a mean of .91 (Robinson \& Eyberg). In terms of validity, the DPICS has been demonstrated to distinguish between pre- and post-treatment data (e.g., Robinson \& Eyberg), various methods of treatment (Eyberg \& Matarazzo), and interaction patterns between different family populations (Aragona \& Eyberg).

Although there are 24 categories of behavior measured by the DPICS, in the current study only eight behaviors were considered: unlabeled and labeled praise, critical, reflective, and descriptive statements, indirect and direct commands, and questions. These eight codes were chosen because they are used clinically to determine if a person has reached mastery criteria in CDI. In order to advance to the second stage of PCIT as well as reach mastery of CDI, an adult must demonstrate the following behaviors in the 5-minute CDI observation: 25-50 descriptions 
and reflections (reflecting at least half of all child verbalizations), 15 praises ( 8 of which must be labeled), and no more that 3 critical statements, commands, or questions (Eyberg \& Calzada, 1998).

One total score was derived based on therapist performance in each of the eight behavior categories as compared to mastery criteria in CDI skills. Participants received one point toward their total score for each of the categories in which they reached mastery. Total scores ranged from 0 to 7. Examples of scoring appear in Appendix D. An abbreviated definition list for the codes to be used in the current investigation are included in Appendix E. Please see Eyberg and Robinson (1983) for a more detailed account of coding rules. The instructions for the structured role play are described in the procedures section of this manuscript and outlined in Appendix F. This scoring system was used at each of the four assessment points.

Coaching skills. Participants were asked to view a videotape of Amy Herschell interacting with a child and "coach" Ms. Herschell in appropriate use of CDI skills. Participant coaching statements were audio taped so that they could be heard in combination with Ms. Herschell and the child on the tape. The child was a 6 year-old, Caucasian male with a history of child maltreatment who was clinic referred for exhibiting externalizing behavior problems. Using a point system, each coaching statement was assigned a value. The point system is included in Appendix $\mathrm{G}$ and was developed after observing multiple coaching sessions involving different coaches. Each coaching statement was given a score of -1 through 3 based on the sophistication of the statement. Coaching errors were scored as a -1 whereas advanced coaching statements were scored as a 3. Four tapes were developed. Participants were asked to coach one tape at each assessment point. The order in which participants received the tapes was randomized. Additional information regarding coaching skills assessment is provided in the procedures section of this manuscript.

Knowledge Gain

The Knowledge of Behavioral Principles As Applied to Children. The Knowledge of Behavioral Principles As Applied to Children (KBPAC; O’Dell, Tarler-Benlolo, \& Flynn, 1979) is a 50-item multiple-choice test designed to assess understanding of the application of behavioral principles to children. Behavioral vocabulary is avoided in this questionnaire. Instead, practical problem situations are presented to which the respondent is asked to select the response which would most likely produce a desirable effect. Behavioral principles assessed include: 
reinforcement, punishment, schedules, shaping, differential attention, extinction, and counting and recording behavior. Questions are based on behavioral principles found in four texts: “Parents Are Teachers” (Becker, 1971), “Managing Behavior 2” (Hall, 1971), "Living with Children" (Patterson \& Guillon, 1968), and "Families" (Patterson, 1971).

This 50 -item test requires 30 to 60 minutes to complete. Because of the length of time required for completion, 10- and 25-item forms of the questionnaire were developed (Furtkamp, Giffort, \& Schiers, 1982). Initially, both the 10- and 25-item forms demonstrated promising psychometric properties including satisfactory internal consistency as well as consistent means and standard deviations; however, in a subsequent examination (Sturmey, Newton, Milne, \& Burdett, 1987), one of the 10-item forms was found to be significantly easier than the second form. Therefore, the 25-item Forms A and B are included as instruments in the proposed study (see Appendix H). Less time consuming than the original version, the 25-item Forms A and B have demonstrated internal consistency as well as means, standard deviations, and standard errors comparable to the full 50-item version (Sturmey et al.). Using Cronbach alpha as a measure of internal consistency, coefficients ranging from .42 to .84 have been reported for various samples. For two samples evaluated by Sturmey et al. paired sample t-test revealed no significant differences $(p>.05)$ between Forms A and B. Sensitivity to change also has been demonstrated by independent groups t-tests (Sturmery et al.). The KBPAC has been used in multiple studies to assess various populations including psychiatric nurses, psychiatrists, occupational therapists, physiotherapists, clinical psychologists, general nurses, parents participating in behavior management training, teachers, and college students taking various psychology courses (e.g., Furtkamp et al., McLoughlin, 1985; O’Dell et al., 1979; Sturmey et al.).

In the current study, participants were asked to complete one form of this measure at pretraining (assessment point one) and one form at assessment point four. Each participant completed both Forms A and B which are included in Appendix H. The order in which participants received the questionnaire was randomized.

CDI and DPICS Knowledge Questionnaire. Four versions of a 20-item quiz were developed to assess participants' knowledge of CDI and DPICS information. Each version contained 10 items on CDI knowledge and 10 items on DPICS knowledge. The CDI section contained an equal number of items targeting didactic and coaching skills whereas the DPICS 
section contains an equal number of items targeting definitions and application of definitions to particular scenarios. These questionnaires are included in Appendix I.

Four forms were developed with the intention of each being equal in difficulty level and content. These forms were independently, informally reviewed by a doctoral-level, PCIT clinician to assess their face validity. Additionally, prior to using them in this study, a pilot study was conducted using the forms. Ten PCIT clinicians completed the forms. A detailed report of this preliminary study is included in Appendix $\mathrm{J}$.

Each participant in the current study completed all questionnaires, one at each assessment point. Each questionnaire yielded three scores: CDI Knowledge, DPICS Knowledge, and Total PCIT Knowledge. The order in which participants received the questionnaires was randomized. Participant Satisfaction

Modified Therapy Attitude Inventory. The original Therapy Attitude Inventory (TAI; Eyberg, 1974) was designed to assess consumer satisfaction with parent training, parent-child treatments, and family therapy (Eyberg, 1993). On a 5-point Likert scale ranging from 1 (poor) to 5 (excellent), respondents are asked to rate 10 questions regarding their satisfaction with treatment. In a recent study examining the psychometric properties of the TAI (Brestan, Jacobs, Rayfield, \& Eyberg, 1999), a reliability coefficient (Cronbach's alpha) was reported as .91 and stability over a four-month period also was high (.85). Eisenstadt et al. (1993) reported a similar reliability coefficient (Cronbach's alpha) of .88. Additional empirical examinations have demonstrated the reliability of this measure (e.g., Eyberg \& Matarazzo, 1980). In terms of validity, low to moderate correlations (.36-.49) were reported between the TAI scores and changes during treatment as measured by the Eyberg Child Behavior Inventory and behavioral observation of child compliance (Brestan et al.). It was suggested that satisfaction ratings were more closely linked to child problem behavior change rather than the level of behavior problems evident at post-treatment.

In the current study, the TAI was modified to assess therapists' (rather than parents') satisfaction with PCIT. The original 10 items and response choices remained. Changes were made only to sentence structure so that items would be appropriate for therapists rather than parents. Also, the words "Compared to other approaches I have used" were added to the beginning of each sentence. Information was provided about therapists' perceptions of PCIT with regard to practicality (e.g., time efficiency), acceptability, and efficacy (see Appendix K). 
Data from this form should be interpreted cautiously considering that the form was modified for the current study, and with these modifications the form's psychometric properties are unknown. Participants were asked to complete this questionnaire at three assessment points: two, three, and four.

Satisfaction with Training. A 19-item questionnaire was developed to assess participants' satisfaction with training (see Appendix L). Three areas of training were assessed including the content of training, format of training, and presenters. Fifteen of the 19 questions were rated on a 5-point Likert scale ranging from 1 (strongly disagree or poor) to 5 (strongly agree or excellent). Of the remaining four questions, two were open-ended, and two asked for the participants' preference of six training methods. These remaining four questions were not considered in the total satisfaction score. Considering that this satisfaction measure was developed by the examiner for the current study and its psychometric properties are unknown, the scores should be interpreted with caution. Participants were asked to complete this measure twice: once at assessment point three and once at assessment point four.

\section{Training Integrity}

Training Integrity Checklists. Training integrity checklists were used to assess the accuracy of trainers' implementation of each day of training (see Appendixes M, N, \& O). These checklists verified that trainers implemented training in a manner consistent with the stated research goals. Trainers were informed that checklists would be completed each day as well as the points covered on the checklists. A score of $90 \%$ or greater was considered accurate implementation of the training curriculum. This score was calculated by dividing the total number of "true" responses by the total number of criteria applicable for that day. These forms were modified from the original proposal to include more specific information. Items were added that provided a check of inclusion of important and detailed content information. Two research assistants were trained in how to complete these forms and did so as described below.

Training integrity data were obtained for 38\% (3 of 8) of trainings on day one, $25 \%$ ( 2 of 8) of didactic trainings on day two, and 38\% (3 of 8) of experiential trainings on day two. As is evident in Table 4, for day one total training integrity scores ranged from $92 \%$ to $100 \%$, and averaged $98 \%$; content training integrity scores ranged from $91 \%$ to $100 \%$, and averaged $97 \%$, format training integrity scores were equal to $100 \%$. For day two didactic training, the total training integrity scores ranged from $94 \%$ to $100 \%$, and averaged $97 \%$; content training integrity 
scores ranged from $92 \%$ to $100 \%$, and averaged $96 \%$, format training integrity scores were equal to $100 \%$. For day two experiential training, total, content, and format scores were equal to $100 \%$. Reliability and Response Measurements

Training coders. Two advanced undergraduate students were recruited by the investigator to serve as primary research assistants. These two qualified persons were found through recruitment efforts at the University of California, Davis and were senior psychology and human development majors. Each of the two research assistants received training in PCIT as well as in scoring all measures used in this study by Amy Herschell. Specific attention was directed toward training research assistants in scoring measures related to CDI skills, coaching skills, and CDI and DPICS knowledge. In total, training took approximately 65 hours to complete. Four additional CAARE Center research assistants assisted in scoring, coding and entering data for the study; however, these research assistants participated in activities that took a lesser degree of training such as data entry, scoring the KBPAC Questionnaires, and treatment integrity scoring.

CDI skills were coded according to the DPICS. Ms. Herschell conducted training in DPICS with the assistance of CAARE Center research staff members Susan Timmer, Ph.D., and Eric Vargas, B.A. Dr. Timmer and Mr. Vargas collaborated regarding DPICS training due to their expertise in this coding system. Training in DPICS consisted of didactic instruction as well as videotape coding. Once the research assistants obtained $85 \%$ reliability on practice videotape coding, their coding was considered to meet mastery criteria and acceptable for coding videotaped sessions. Due to the complexity of the coding system, obtaining mastery coding levels took as long as 40 hours to achieve.

One research assistant also was trained in scoring the participants' audio taped coaching skills assessment. Similar to training in DPICS, instruction in scoring the coaching tapes involved didactic training and practice scoring. Instruction also involved observation of live PCIT coaching sessions, providing feedback on coaching tapes of non-participating therapists, and practicing CDI skills with children so that the research assistant had a better understanding of PCIT and ability to differentiate types and quality of coaching statements. Once reliability had reached kappa levels of .80, the research assistants were asked to code audiotapes for the current study. Training required approximately 10 hours.

In order to score CDI and DPICS knowledge questionnaires, it was proposed that research assistants would be provided a detailed answer key (see Appendix I) as well as didactic 
training and practice in coding "mock" questionnaires that would be completed by four clinicians: two who were and two who were not considered trained to mastery level in PCIT. It was anticipated that proficiency in scoring would take approximately 4 hours of training; however, after several attempts to train research assistants to score these measures, it was determined that this would not be possible. Because the questionnaires included open-ended questions, the variety of responses provided by participants was extremely variable and scoring required a high level of sophistication in PCIT skills as well as theoretical knowledge and general therapy skills. Therefore, a research assistant re-assigned participant numbers to all questionnaires so that the investigator was blind to the participant number and assessment point for each questionnaire. After this re-assignment was complete, Amy Herschell scored each of the questionnaires. Twenty-five percent of the questionnaires were scored twice for reliability purposes. Final scores were obtained before returning the original participant numbers and assessment points to the questionnaires.

To evaluate if PCIT fundamentals training was consistent with stated research goals and across multiple training dates, research assistants were asked to view videotaped training sessions and complete training integrity checklists (see Appendix M, N, \& O). Training in completion of these checklists was taught through didactic instruction and practice in scoring previously conducted, videotaped workshops. Again, once reliability levels of .80 were obtained, research assistants were asked to complete checklists for the purpose of this study. It took approximately 8 hours of training to reach proficiency in completing these checklists.

Research assistants were unaware of the participant's group assignment as well as the study's hypotheses. In order to minimize observer drift, research assistants received weekly, onehour, booster-training sessions on coding and scoring procedures throughout the duration of the study. Additionally, reliability data were obtained throughout the coding period.

Interobserver reliability. In order to evaluate reliability, a second person coded at least $25 \%$ of all behavior observation data collected. In obtaining reliability data, several techniques were used to ensure independent coding including: (a) intentionally recording incorrect codes and later changing them, (b) slating the clip board opposite to the first observer so that recorded responses could not be seen, (c) covering recorded marks, (d) only recording responses after the first coder had marked impressions, and (e) sitting as far from the first rater as possible so that the responses could not be viewed. Additionally, some coding was completed at separate times to 
ensure independence.

Interobserver reliability on the DPICS was calculated by determining percentage agreement (the number of agreed divided by the number of agreed and disagreed responses). Thirty-one percent of the data were double coded. The first rater was one of two research assistant coders while the second coder was Amy Herschell. Data coded by Amy Herschell were used only for reliability purposes and were not included in the data analysis. The overall percent agreement for DPICS coding was $85 \%$. The overall percent agreement for coder one was $89 \%$ and the overall percent agreement for coder two was $83 \%$. Because coder one obtained higher agreement scores than coder two, she coded the majority of DPICS data included in the study.

Interrater reliability for coaching scores, CDI and DPICS knowledge scores, and training integrity videotapes was calculated by using intraclass correlations (Howell, 1997; Shrout \& Fleiss, 1979). Twenty-five percent of coaching assessments, CDI and DPICS Knowledge scores, and training integrity videotapes were double-coded. The following intraclass correlations were revealed: total coaching scores (.98), CDI Knowledge (.99), and training integrity videotapes (.94).

Interobserver reliability on child confederate behavior coding was calculated using intraclass correlations for the continuous variable, child verbalizations, and Cohen's Kappa statistic for the categorical variable, child specified behavior. Cohen's Kappa was used to help control for the agreement that could have occurred by chance in the six-category variable of child-specified behavior (Howell, 1997). Data were double coded for $25 \%$ of those scored. A child verbalizations intraclass correlation of .84 revealed good reliability across coders. A Kappa of .67 revealed low to adequate reliability in child specified behavior coding. The kappa statistic likely represents a conservative estimate considering that only two categories (the top two) of the six categories used for coding child specified behavior were utilized and therefore considered in the kappa statistic computation (in spite of the fact that there were six categories in total).

In order to ensure accurate data entry, a user-friendly database was designed in Microsoft ACCESS in which to enter data. All data were double entered into the ACCESS database that was programmed to inform persons entering data if there was a data entry error. After all data were entered into the ACCESS system, data were transferred and analyzed in SPSS. 


\section{Participants}

The participants were all practicing clinicians in community agencies specializing in the treatment of children with histories of physical abuse, sexual abuse, and neglect, and who were participating in PCIT training though the OCJP Project. After agreeing to participate in the current research project, participants were assigned to one of two groups: a didactic or experiential group. Table 5 presents basic demographic information for the two groups. Several variables were examined including gender, age, ethnicity, and if participants spoke a second language. An examination of this table reveals that participants were diverse in terms of age and ethnicity. Also revealed is that $45 \%$ of participants spoke a second language, and that $19 \%$ of participants used English as that second language. Additionally, Table 5 shows that the groups were not significantly different on any of these variables. It should be noted, however, that participant gender was approaching statistical significance $\chi^{2}(1, \mathrm{~N}=42)=3.11, p=.08$ in that more men were in the experiential than in the didactic group. Independent samples $t$-tests were completed on continuous demographic variables, and Pearson's Chi square analyses were completed on categorical demographic variables.

The educational and training experiences of participants were examined in Table 6 . The large majority (86\%) of participants had a masters-level degree, two participants $(5 \%)$ received a doctoral degree and four participants (10\%) received only a bachelor level degree. Participants reported attending graduate programs with diverse theoretical orientations, although, the modal theoretical orientation during their graduate training was a family systems orientation. On average, participants had been out of school for $8.03(\mathrm{SD}=7.66)$ years, and earned $259.58(\mathrm{SD}=$ 274.99) hours of postgraduate continuing education credits. Participants reported receiving training on topics related to the OCJP training including child development (24\%), child maltreatment (69\%), disruptive behavior disorders (26\%), and empirically supported treatments (26\%). Though not significantly different, postgraduate training in empirically supported treatments was near statistical significance $\chi^{2}(1, \mathrm{~N}=41)=3.45, p=.06$ as more participants in the didactic as compared to the experiential group had received that type of training. Participants on average had worked $9.54(\mathrm{SD}=7.40)$ years with general clinical populations, $8.67(\mathrm{SD}=$ 7.48) years with children with disruptive behavior disorders, and $7.69(\mathrm{SD}=6.45)$ years with child maltreatment populations. No statistically significant differences were found between groups on any variables. 
Participants' current professional activities are explored in Table 7, interest in PCIT training reported by participants is summarized in Table 8, experience with treatment manuals is examined in Table 9, and attitudes toward behaviorally oriented therapies are described in Table 10. Comparisons also were explored between the groups pre-training scores on the ChildDirected Interaction Skills (Table 11); Coaching Skills (Table 11), and Knowledge Variables (Table 12). Similar to previous comparisons, no statistically significant differences were found between groups on any of these variables.

\section{Procedure}

\section{Participant Training}

Six trainers were involved in PCIT fundamentals training on day one: Anthony Urquiza, Ph.D., Nancy Zebell, Ph.D., Jean McGrath, Ph.D., Amy Herschell, M.A., Eric Vargas, B.A., and Alissa Porter, M.S. Drs. Urquiza, Zebell, and McGrath as well as Ms. Herschell conducted training related to therapy. Mr. Vargas specialized in training of DPICS coding, PCIT equipment installation, and technical assistance, and Ms. Porter focused on organizing training efforts such as coordinating training participants and scheduling follow-up visits. PCIT fundamentals training day one included all study participants. Therefore, each participant received the same training experience. All presentation materials were presented didactically, and participants had no scheduled opportunity during the day to practice skills discussed.

The same six trainers were involved in day two of PCIT fundamentals training. During this second day, participants were divided into two groups: an experiential and didactic group. Each group received the same content of information as indicated on training integrity checklists (Appendices M, N, \& O); however, the format for which the information was delivered differed. Members of the experiential group were required to participate in role-plays, practice coding videotapes individually, and receive feedback on their performance. In contrast, the didactic group reviewed session videotapes, discussed PCIT skills, and coded videotapes as a group. As

previously mentioned, each training day was videotaped, $38 \%$ of day one trainings and $31 \%$ of day two trainings were coded for training integrity.

In order to control for trainer effects, trainers rotated between the experiential and didactic groups. Three trainers played more active roles on the second day of the eight trainings conducted (Nancy Zebell, Jean McGrath, and Amy Herschell) than the other trainers involved (Anthony Urquiza, Eric Vargas, and Alissa Porter). During each of these days, each primary 
trainer was assigned to one of three roles: primary didactic, primary experiential, or rotating between the two groups. The order in which primary trainers completed these roles was randomized. Table 13 highlights the role of primary trainers at the eight trainings. Anthony Urquiza attended two of the eight trainings on day two. His participation was balanced across the two groups as is evident in Table 13. Secondary trainers Eric Vargas and Alissa Porter assisted when necessary to ensure that the two training groups (experiential and didactic) had two trainers present at all times.

\section{Assessment Schedule}

Prior to the initiation of training, the experimenter visited each agency to explain the study to participants, receive signatures on informed consent forms, and conduct the pre-training assessment (assessment one). This was considered the start of phase one, program development. As indicated in Table 14, pre-training assessment included participant characteristics, skills, and knowledge. After completion of pre-assessment, participants were provided with and asked to read pages 1 to 69 of the textbook, Parent-Child Interaction Therapy (Hembree-Kigin \& McNeil, 1995), and an abbreviated DPICS manual (Eyberg \& Robinson, 1983). The abbreviated manual included only the definitions relevant to CDI mastery criteria. In order to help determine if therapists read the assigned materials, they were asked to keep a reading log and were provided forms for this purpose. Additionally, participants were given a verbal and written reminder that: (a) the second assessment would occur prior to the start of PCIT fundamentals training (training phase two), (b) the assessment would include information relevant to the CDI portion of PCIT, and (c) the speed of training would be dependent on participants' skills and knowledge. Therefore, if participants were prepared, training would progress at a faster pace. Also, each participant was phoned one week prior to PCIT fundamentals to remind him or her of the assessment, to stress the importance of reading assigned materials, and to address any concerns regarding study participation. Once it was determined that a phone call one week prior to training was insufficient in motivating participants to read the assigned materials, a letter (see Appendix P) was mailed two weeks prior to training, which was followed by the phone call initiated one week prior to training.

Prior to the start of training phase two, PCIT fundamentals, participants were asked to complete assessments of skills, knowledge, and satisfaction as detailed in Table 14. This same assessment occurred at the end of that same day of training. A final assessment was conducted at 
the end of the second day of training and included measures of participant characteristics, skills, knowledge, and satisfaction (see Table 14).

Skill assessment. Acquisition of CDI skills was measured by requiring each participant to interact with a confederate for a five-minute, videotaped, structured behavioral observation. This was meant to be analogous to the parent-child assessment conducted the beginning of each PCIT treatment session. The confederate, Eric Vargas, a 30-year old, male followed the same procedure for each participant as detailed in Appendix F. Essentially, each participant interacted with Mr. Vargas for 5-minutes, 30-seconds. The first 30 seconds was not coded and was considered a warm-up period during which the participant had a short period to become more comfortable in the role-play setting. During subsequent minutes, the confederate acted in ways to elicit target behaviors (i.e., using praise, reflection, imitation, and description while avoiding commands, criticism, and questions) from participants. For example, during one one-minute interval, the confederate made frequent verbalizations so that the participant had the opportunity to use the reflection skill. The order in which the confederate engaged in each specified behavior was randomized. In order to ensure that the confederate randomized and engaged in each behavior for one minute, he wore a tape recorder with an ear piece that fit in one ear and he was provided with a pre-recorded audiotape. The audiotape prompted Mr. Vargas to engage in randomized specified behaviors. Each 5-minute behavior observation was videotaped and later coded by research assistants who reached DPICS mastery level. Each video was first coded to assess participant behavior. Eighty-eight percent of tapes were coded a second time to determine if Mr. Vargas had engaged in specified behaviors as well as to determine his number of verbalizations to assist in determining if participants met mastery criteria for the CDI skill reflection (i.e., participants must reflect half of the confederate's verbalizations to reach CDI mastery criteria for reflection).

Acquisition of coaching skills was assessed by asking participants to view a videotape of Amy Herschell interacting with a child and to "coach" Ms. Herschell in the use of CDI skills. Four videotapes were developed. Ms. Herschell interacted with the same child in each of the four tapes. The child was a six year old, Caucasian male who was clinic referred for experiencing a disruptive behavior disorder and a history of child maltreatment. During these tapes, Ms. Herschell approximated common parent behaviors including use of skills such as praise, reflection, imitation, description, and enthusiasm as well as questions, commands, and criticism. 
Also, Ms. Herschell allowed a slight pause after each verbalization so that the coach had the opportunity to make a statement without interrupting or talking over Ms. Herschell. Commonly in coaching, the therapist develops a "coaching rhythm" with the parent in which the parent says something, the coach responds, the parent makes another statement, and the coach responds. Allowing a brief pause was an effort to approximate what would naturally happen in a coaching session. Participants were instructed (as detailed in Appendix G) that there would be a 30-second period for them to observe Ms. Herschell and the child. Afterward, they coached Ms. Herschell for 5 minutes as if she was a mother referred for PCIT with her son.

Results

\section{Impact of Reading a Treatment Manual on Participant Knowledge and Skill}

In order to determine if reading a treatment manual was sufficient for participants to evidence significant gains in PCIT knowledge and skills, participants were asked to read pages 1 through 69 of the PCIT treatment manual (Hembree-Kigin \& McNeil, 1995) as well as and an abbreviated DPICS manual (Eyberg \& Robinson, 1983) between assessment points one and two. Paired-comparison $t$-tests were conducted comparing assessment point one to assessment point two mean scores on knowledge (i.e., CDI knowledge, DPICS knowledge, and Total PCIT Knowledge) and skill measures (i.e., unlabeled praise, labeled praise, reflections, descriptions, questions, criticism, indirect commands, direct commands, CDI Mastery Score, Total Coaching Score) for participants who reported reading pages 1 through 69 of the PCIT treatment manual (Hembree-Kigin \& McNeil). In order to control for the potentially high familywise error rate, the Bonferroni inequality was applied. Because 13 comparisons were made, an alpha level of .05/13 (.004) or less was considered to be significant. Twenty-nine of 42 participants (69\%), reported reading the manual; and therefore, were considered in the analyses. It was anticipated that while gains in all knowledge and skill categories might be evident, only gains in knowledge would be statistically significant.

Table 15 presents descriptive statistics and results of paired-comparison $t$-tests on knowledge measures. As predicted, statistically significant increases were evident in Total PCIT Knowledge $t(24)=-3.79, p=.001$ and DPICS Knowledge $t(24)=-3.86, p=.001$; however, no significant increase in CDI Knowledge was revealed for participants from assessment point one to assessment point two. 
In addition to comparing performance on knowledge measures, level of skill development also was assessed. Table 16 summarizes descriptive statistics and results of paired comparison $t$ tests on skill measures. Statistically significant increases were revealed in Labeled Praise $t(26)=$ $-3.63, p=.001$ and Total Coaching Score $t(28)=-4.02, p<.001$. Significant decreases were evident in Questions $t(26)=5.25, p<.001$ and Indirect Commands $t(26)=3.14, p=.004$. Didactic versus Experiential Training

It was anticipated that participants involved in experiential training would evidence better gains than matched comparison participants involved in a didactic training. The sample was divided into two training groups (i.e., didactic and experiential) after the third assessment point. Prior to the third assessment point, participants experienced the same training situation: each participant was expected to read the training manual and attended a one-day didactic training. In order to ensure that groups were equal immediately prior to the experimental manipulation, independent samples $t$-tests were performed to detect differences between groups at assessment point three on knowledge and skill variables. Again, considering the high familywise error rate, the Bonferroni inequality was applied and $p<.004$ was considered significant. Tables 17 and 18 reveal that no group differences were detected applying the Bonferroni technique; however, two variables (labeled praise and reflections) would be considered significantly different using less conservative difference tests. Labeled praise $t(42)=2.01, p=.01$ and reflections $t(42)=2.22, p$ $=.03$ indicate that the experiential groups scored slightly higher with each of these skills at assessment point three.

An analysis of training success was conducted using three 2 X 2 multivariate analysis of variance (MANOVAs) with one nonrepeated factor (Group) and one repeated factor (time). One MANOVA was conducted for skill variables including unlabeled praise, labeled praise, descriptions, questions, criticism, indirect commands, direct commands, CDI mastery score, and total coaching scores at assessment points three and four. A second MANOVA included knowledge variables: CDI knowledge and DPICS knowledge at assessment points three and four. Finally, the third MANOVA included two satisfaction variables: TAI total score and satisfaction with training total scores at assessment points three and four.

An examination of skill variables revealed no group $\mathrm{X}$ time interaction $F(10,23)=1.38$, $p=.25$. A group main effect also was not present $F(10,23)=1.24, p=.32$. A time main effect was present $\mathrm{F}(10,23)=5.93, p<.001$. As is evident in Table 19, univariate analyses reveal 
statistically significant increases in scores on labeled praise $F(1,32)=20.50, p<.001$; descriptions $F(1,32)=9.01, p=005$.; reflections $F(1,32)=14.29, p=.001$; CDI mastery $F(1$, $32)=12.45, p=.001$; and total coaching scores $F(1,32)=37.81, p<.001$. These same univariate analyses revealed statistically significant decreases in scores on questions $F(1,32)=$ $17.99, p<.001$.

Inspection of knowledge variables revealed no group $\mathrm{X}$ time interaction effect $F(3,38)=$ $1.00, p=.40$ or group main $\operatorname{effect} F(3,38)=1.78, p=.17$. A significant time main effect was revealed $F(3,38)=17.71, p<.001$. Univariate tests summarized in Table 20 revealed statistically significant increases in scores on CDI Knowledge $F(1,40)=26.84, p<.001$ and DPICS Knowledge $F(1,40)=33.27, p<.001$.

In examining satisfaction variables, a group $\mathrm{X}$ time interaction effect was not revealed, $F(2,38)=3.20, p=.052$, nor was a group main effect $F(2,38)=.86, p=.43$; however, a significant time main effect was present $F(2,38)=13.10, p<.001$. Table 21 highlights that univariate tests revealed statistically significant increases in scores on the Therapy Attitude Inventory $F(1,39)=14.91, p<.001$ as well as the Satisfaction with training total score $F(1,39)=$ 19.93, $p<.001$ from assessment point three to assessment point four.

\section{Therapist Characteristics Associated with Higher Skill Acquisition}

Analyses were conducted to investigate pre-training predictors of training success at assessment point four. Bivariate correlations were calculated between pre-training measures (assessment point one) and post-training (assessment point four) knowledge, skill, and satisfaction measures (i.e., Knowledge of Behavioral Principles as Applied to Children, Total PCIT Knowledge, CDI Mastery Score, Total Coaching Score, Therapy Attitude Inventory, and Satisfaction with Training). Correlations between pre-training therapist variables (e.g., age, number of years since obtained graduate degree) are reported in Table 22. Significant correlations relevant to the purposes of this study include a moderate positive correlation between age and post-training satisfaction $(r=-.38)$ as well as a moderate negative correlation between years since grad degree and post-training CDI Mastery Score $(r=-.34)$. A moderate negative correlation was revealed between years worked with clinical populations and posttraining CDI Mastery Score $(r=-.33)$. Number of supervision hours was moderately negatively correlated with both the post-training Therapy Attitude Inventory $(r=-.34)$ and post-training Satisfaction with Training $(r=-.34)$. Post-training Knowledge of Behavioral Principles was 
positively correlated with and post-training Total PCIT Knowledge $(r=.50)$ and post-training Total Coaching score $(r=.34)$. Post-training CDI Mastery Criteria was positively correlated with post-training Coaching score $(r=.35)$. Post-training satisfaction measures (Therapy Attitude Inventory and Satisfaction with Training) were strongly correlated ( $r=.64)$ with each other. Listed in Table 23 are correlations between attitude toward and experience with treatment manuals and outcomes. Interestingly, more negative attitudes toward treatment manuals were moderately correlated inversely with CDI Mastery scores $(r=-.31)$, and hearing of treatment manuals was moderately correlated with Knowledge of Behavioral Principles $(r=.33)$. Table 24 depicts correlations between attitudes toward behaviorally oriented therapies and knowledge, skill, and satisfaction outcomes. Strong correlations were revealed between particular ideas about behaviorally oriented therapies (BOTs) and skill measures. Negative correlations were revealed between Total Coaching score and BOTs are practical $(r=-.45)$ and between Total Coaching score and BOTs provide a "cookbook" approach of therapeutic techniques $(r=-.49)$. Negative correlations also were revealed between CDI Mastery score and BOTs provide a "cookbook" approach of therapeutic techniques $(r=-.37)$ as well as CDI Mastery score and BOTs overly simplify complex processes $(r=-.36)$.

Table 25 includes correlations between pre- and post-training scores on knowledge, skill, and satisfaction measures. Positive correlations were revealed between pre-training Knowledge of Behavioral Principles and pre-training Total PCIT Knowledge $(r=.46)$ as well as pre-training Total PCIT knowledge and pre-training coaching scores $(r=.45)$. Pre-training Knowledge of Behavioral Principles was strongly correlated with post-training Knowledge of Behavioral Principles $(r=.66)$ as well as correlated with post-training Total PCIT Knowledge $(r=.43)$. Pretraining coaching score was negatively correlated with post-training satisfaction $(r=-.34)$. Pretraining ratings of how useful PCIT would be were positively correlated with post-training satisfaction measures, the Therapy Attitude Inventory $(r=.41)$ and Satisfaction with Training $(r$ $=.38$ ). In order to identify factors that predict mastery of PCIT concepts, logistic multivariate regression analyses were conducted. Training success was measured by demonstration of mastery on CDI and DPICS knowledge, CDI skills, and Coaching skills. Mastery of CDI and DPICS knowledge was defined as scoring $80 \%$ or higher on the assessment four CDI and DPICS knowledge questionnaire. This criterion was based on the pilot study conducted on the CDI and DPICS knowledge questionnaire in which the average score of five experienced PCIT clinicians 
was $80 \%$. (Please see Appendix $\mathrm{J}$ for additional details.) Mastery of CDI skills was defined as a score of 15 praises, at least 8 of which were labeled; more than 25 descriptions and reflections; and no more that three questions, commands, or criticisms. This CDI mastery criterion was established by Eyberg and Calzada (1998). Mastery of coaching skills was calculated by asking five experienced PCIT clinicians to complete the coaching assessment. The five clinicians who completed the assessment ranged in degree type from bachelors- to doctoral-level, averaged four years of experience conducting PCIT (range 2 to 7 ), and currently see 8 to 10 PCIT clients per week. After completion of the coaching assessment, audiotapes were coded, and scores were obtained for each of the five clinicians. The average coaching score for the experienced PCIT clinicians was 58 (range 47 to 76); therefore, a score of 58 or higher was considered mastery criteria for PCIT coaching.

Two main predictors, theoretical orientation and degree type, were explored because they have been hypothesized in the literature to affect the adoption of ESTs. It was hypothesized that participants reporting having a behavioral or cognitive-behavioral orientation would demonstrate greater training success on measures of PCIT knowledge and skills than participants reporting different theoretical orientation (i.e., non-behavioral or cognitive-behavioral). It also was originally hypothesized that participants who had received a doctoral-level degree would have better outcomes that participants who had obtained a masters-level degree. Neither of the doctoral-level participants met mastery criteria on CDI skills or coaching skills, and only one of the two doctoral-level participants met mastery criteria on PCIT knowledge. Because there were only two doctoral-level participants in the current study, doctoral-level participants were not included. Instead, it was predicted that participants with a Masters degree of Arts or Science (MA/MS) would have better outcomes on measures of PCIT knowledge and skills than participants with a Masters degree in Social Work (MSW). This was predicted because it was assumed that masters-level training in arts and sciences, typically psychology, would be more likely to include skills necessary to implement an empirically supported treatment like PCIT (e.g., focus on the individual, assessment, psychological theory) than would masters-level training in social work.

A multivariate logistic regression analysis was performed to examine if degree type and theoretical orientation predicted mastery of PCIT knowledge. As depicted in Table 26, neither degree type nor theoretical orientation was found to be predictive of mastery of PCIT 
knowledge. In a second logistic regression analysis conducted to examine if degree type and theoretical orientation predicted mastery of CDI skills, type of degree predicted mastery of CDI skills (see Table 27). Participants who had a MSW were 15 times more likely than participants with a MA/MS to reach mastery of CDI skills. Theoretical orientation did not predict mastery of CDI skills as is evident in Table 27. Due to the low number of participants who reached mastery of coaching skills ( 4 of 42,10\%) and mastery of a combination of all three knowledge and skill measures, PCIT knowledge, CDI skills, and coaching, (2 of 42, 5\%) logistic regression analyses were not completed for these variables.

Follow-up analyses were conducted to determine if there were any variables that might have been associated with degree type and therefore might help to explain the finding that degree type predicted CDI mastery. Because this follow-up was intended to be an exploratory analysis (i.e., inclusive of as many explanations as possible), a decision was made to not use the Bonferroni inequality to minimize the Type 1 error rate. Of multiple variables examined using independent samples $t$-tests and chi-squares (please see Table 28 for a listing of examined variables), second language spoken was found to be significantly different between the groups, $\chi^{2}(1, \mathrm{~N}=36)=3.86, p=.05$.

Next, follow-up analyses were conducted to determine differences between seven participants who met CDI Mastery criteria and all other participants. Again, the Bonferroni inequality was not used. Considering that these analyses are exploratory and lack control for type 1 error, they should be interpreted with caution. Of multiple variables examined using independent samples $t$-tests and chi-squares (please see Table 28 for a listing of examined variables), viewing BOTs as scientific and graduate program's theoretical orientation were each found to be significantly different between participants who reached CDI Mastery criteria and participants who did not reach CDI Mastery criteria. Participants who met CDI Mastery criteria were less likely to view BOTs as scientific $\chi^{2}(3, \mathrm{~N}=37)=7.78, p=.05$, and more likely to describe their graduate training programs' theoretical orientation as family systems, interpersonal, or psychodynamic $\chi^{2}(6, \mathrm{~N}=39)=13.21, p=.04$. 


\section{Discussion}

\section{Main Findings}

Impact of Reading a Treatment Manual on Participant Knowledge and Skill

Although not originally hypothesized, reading a treatment manual resulted in significant improvements in participants' knowledge and skills. It initially was expected that significant improvements would be found in knowledge and not skills. Yet, it is important to note that while these improvements in knowledge and skill were statistically significant, they were not clinically significant. Mastery of PCIT knowledge or skills was not obtained after reading the book for any participant. Given these findings, it appears that reading a treatment manual can result in knowledge and skill improvement, but may not be sufficient for successful implementation of certain ESTs. In other words, a treatment manual may serve as a useful "first step" in dissemination that must be followed by more intensive training for effective implementation of an EST like PCIT.

\section{Didactic versus Experiential Training}

It was expected that participants in the experiential group would score better on outcome measures than participants in the didactic group; however, no differences were found between the two groups. This lack of group differences may be due to the fact that the didactic group received more than didactic training. For each of the PCIT concepts role-played in the experiential group, participants in the didactic group viewed a videotape and discussed the concepts through the video case examples. Therefore, the description of the training as "didactic" was misleading, and a better name for the group might have been the "videotape modeling group." Considerable research on a parent training program, the Incredible Years Training Series (e.g., Webster-Stratton, 1990; 1994), has demonstrated that videotape role modeling is an effective training method for parents, teachers, and family service workers (Webster-Stratton, Reid, \& Hammond, 2001). Research on the Incredible Years Training Series has revealed improvements in child, parent, and teacher behavior on both self-report and behavior observation measures after adults attend training groups. Generally, these training groups involve participants viewing 2-minute vignettes and discussing the parent-child interactions on the videotape. A group leader guides participants in problem-solving discussions centered on: (a) playing with children, (b) helping children learn, (c) using praise and encouragement, (d) setting limits, (e) managing disruptive behavior, and (f) finding social supports. Social learning and relational 
theories emphasizing the promotion of attachment and parent-child relationships are the two general theories underlying the Incredible Years program (Webster-Stratton et al., 2001). The training provided in the current study was very similar in method and content to the described Webster-Stratton program. Like Webster-Stratton's research, the current study demonstrated the utility of videotape modeling training.

Perhaps also contributing to a lack of group differences was participation in the assessment. Over the course of a two consecutive day workshop, participants completed three assessments. Each assessment provided an opportunity for participants to practice PCIT skills in situations analogous to PCIT sessions. Therefore, members of the didactic group were able to practice the PCIT skills during the assessment portions of the training. Perhaps the only true difference between the two groups was that the experiential group participants received feedback from trainers on their skill performance during training and the didactic group participants did not receive that type of feedback. Instead, participants in the didactic group received feedback on their suggestions for CDI skills application through the video example.

\section{Improvement Versus Mastery of Knowledge and Skills}

Significant increases were found in participants' knowledge, skills, and satisfaction over time. While it certainly is a positive finding that participation in either the experiential or didactic trainings resulted in improved outcomes and participation reportedly was an enjoyable experience, a concern remains. After a two day intensive training, very few participants demonstrated mastery of skills. Of 42 participants, only $2(5 \%)$ reached mastery level on all three PCIT specific measures (PCIT knowledge, CDI skills, and coaching). Considering these measures individually, only $31 \%$ of participants demonstrated mastery of PCIT knowledge, $17 \%$ demonstrated mastery of CDI skills, and 10\% demonstrated mastery of coaching skills. While it is important to have reasonable expectations for training, the PCIT knowledge and skills measured are the very basics of PCIT and are essential for successful implementation of the program. For example, even parents receiving PCIT are required to demonstrate mastery of CDI skills before moving to the PDI phase of treatment. Also, it seems that the analog assessment sessions in the current study were optimal for demonstration of knowledge and skill because the "parent" and "child" in the role-play assessments were more competent than the average client. Implementing PCIT skills in a clinical setting with extremely challenging children and parents may actually decrease performance. While improvement in knowledge and skills is a positive 
occurrence, mastery should be obtained before implementing the program.

\section{Therapist Characteristics Associated with Higher Skill Acquisition}

Researchers have hypothesized that therapist characteristics such as previous training experiences, current attitudes toward treatment manuals, and theoretical orientation affect EST dissemination (e.g., Addis, 2002; Addis \& Krasnow, 2000; Barlow et al., 1999). Multiple therapist characteristics were examined in the current study; however, all findings should be interpreted cautiously considering the small number of participants in the study (42) and the even smaller number of participants who met mastery criteria (only seven).

Attitudes. The affect of participants' attitudes on their performance was examined by exploring the relationship between therapists' pre-training attitude reports and post-training scores on knowledge, skill, and satisfaction measures. Significant associations were found between extreme negative opinions of treatment manuals and behaviorally oriented therapies and lower scores on CDI mastery and coaching skills. These associations suggest that participants with extreme pre-training negative views are likely to perform poorly on post-training skill assessments This finding supports the conceptual work of Addis and Krasnow (2000) in which they hypothesized that practitioners' attitudes toward manualized treatments would have an impact on acceptance and utilization of ESTs.

Theoretical orientation. An interesting association was found between higher scores on Knowledge of Behavioral Principles and knowledge of treatment manuals. Again, consistent with Addis and Krasnow's expectations, this association supports the idea that persons with increased behavioral or cognitive-behavioral familiarity will be more likely to have knowledge of treatment manuals. Interestingly, reported theoretical orientation was not found in this study to have predictive power for post-training increases in knowledge or skill. This is consistent with Hawkins and Sinha's (1998) finding that theoretical orientation accounted for little variance in performance on examinations assessing treatment knowledge. Examining differences between participants who met CDI Mastery criteria and those who did not revealed that participants who met criteria reported their graduate programs' theoretical orientation to be family systems, interpersonal, or psychoanalytic. However, group differences were not found between participants' current theoretical orientation. A closer inspection revealed that participants who mastered CDI criteria were likely to change theoretical orientations between their graduate training and the time of data collection. Perhaps this change in theoretical orientation indicates 
that participants who met CDI Mastery criteria were open to new (to them), behaviorally oriented treatments like PCIT.

Age. The exploratory correlations revealed a moderate negative association between mastery of CDI skills and age. Another moderate negative association was found between mastery of CDI skills and the years participants worked with clinical populations. This association suggests that younger, less-experienced clinicians may gain CDI skills faster than older, more experienced practitioners. Similarly, in a previous study, fewer supervision hours were associated with positive training outcome (Henry et al., 1993).

Degree type. Interestingly, degree type predicted CDI mastery. Of the seven participants who reached mastery criteria in CDI skills, five of them had a MSW, one had a MA, and one had a bachelor's degree. Neither of the doctoral-level participants met mastery criteria on CDI skills or coaching skills, and only one of the two doctoral-level participants met mastery criteria on PCIT knowledge. While MA/MS participants were more likely than MSW participants to speak a second language, use English as a second language, and report a cultural minority ethnicity, none of these variables predicted CDI mastery. In order to account for why MSW participants were 15 times more likely than MA/MS participants to reach CDI mastery, an examination of participants' graduate programs and graduate programs' accreditation status was conducted.

Table 29 includes the graduate programs from which participants graduated as well as their specialty areas of study. MSW participants were more homogeneous; they all attended university based graduate programs in the United States, and many attended the same programs (e.g., Sacramento State University, University of California, Berkeley). All programs also were terminal degrees, and (arguably) the programs attended by MSW participants are considered to be well-respected. In contrast, the MA/MS participants were heterogeneous in terms of type of school (University versus Professional School), graduate programs attended, and specialty area pursued. MA/MS participants also were more likely to be in various stages of their degree. Some participants pursued a MA/MS as a terminal degree whereas a few other participants with MA/MS degrees were en route to a doctoral degree. Some MA/MS participants also received multiple degrees (e.g., one participant obtained Art Therapy and Counseling Psychology masters degrees). Although, the extent of multiple degrees is not adequately reflected in Table 30 because during data collection participants were instructed to list the highest graduate degree obtained that was most applicable to PCIT training, rather than all degrees obtained. 
No differences were reported by participants in their graduate programs' accreditation status. Future examinations should solicit information concerning participants' licensure status as well as information on the quality of graduate training obtained. In the current study it might have been that MSW participants received a higher quality of graduate training than did MA/MS participants or MSW participants may have been more likely to be licensed, an indicator of competency. Unfortunately, these data do not allow this conclusion to be drawn.

The finding that type of masters-level degree predicts training success is particularly intriguing because previous training studies have primarily included inexperienced therapists or doctoral-level participants, rather than experienced, masters-level participants (Alberts \& Edelstein, 1990). Clearly, there is a need to better study the impact of type and quality of masters-level degree on training because clients are increasingly being served by master- level practitioners (Addis \& Krasnow, 2000) and results of this study suggest differences among practitioners by degree type.

Ethnicity. Thirty-six percent (15 of 42) of participants reported a cultural minority ethnicity. Recently, increasing attention has been paid to the role of culture and EST dissemination (e.g., Bernal \& Scharron-Del-Rio, 2001; Satcher, 2000; Sue, 1999). Considerable debate remains as to the appropriateness of ESTs with culturally diverse groups, which likely has affected the EST dissemination literature. To date, no dissemination studies specifically investigating culturally diverse therapists have been conducted. A large need remains to examine the effectiveness of ESTs and EST dissemination mechanisms with culturally diverse clients.

Like many other ESTs, PCIT was developed by and predominately based on a European American, middle-class, English speaking population. Emerging research on PCIT has suggested that it is useful in treating Hispanic (Calzada \& Eyberg, 2001) and African American families (Capage, Bennett, \& McNeil, 2001; Werba, Eyberg, Boggs, \& Algina, 2000); however, a more complete understanding is necessary. Similarly, a better understanding also is necessary of the ways in which PCIT training might better met the needs of culturally diverse clinicians.

Assessment measures. Also found in these exploratory analyses were positive associations between knowledge measures (i.e., Knowledge of Behavioral Principles and PCIT Knowledge), between skill measures (i.e., CDI Mastery score and coaching score), and between satisfaction measures (i.e., Satisfaction with Training, Therapy Attitude Inventory) supporting the conceptual grouping of these assessments. While this finding is not surprising or directly 
meaningful to the hypotheses, it does support the measurement of three distinct constructs: knowledge, skills, and satisfaction.

\section{Limitations}

The results of the current study should be interpreted with caution for several reasons that are discussed in detail below. Limitations of the study include the selection and number of participants, frequent assessment, assessment of basic skills, and a lack of standardized and validated dependent variables.

\section{Selection and Number of Participants}

Participant selection clearly was a limitation in the current study. Initially, administrators at each agency selected two staff persons to participate in PCIT training. The two people were chosen with the understanding that they would be responsible for training other staff members at their agency. Later, agency administrators were invited to send as many clinicians as feasible to participate in training. It was agreed that the two initial staff persons selected would be provided experiential training, and all other persons would participate in didactic training due to contract obligations with the funding agency. At least initially, members of the didactic group may have felt inferior due to being selected second to participate in training. Because of concerns that this selection bias might have led to stronger therapists in the experiential group, a number of analyses were conducted. As no differences were found between the experiential and didactic group on any knowledge, skill, or satisfaction measures, it appears that this selection bias did not represent such a serious concern as to decrease the overall validity of the two group analyses.

Also concerning is the small number of participants. Having only 21 participants in each group reduced the statistical power for detecting possible group differences as well as reduced the generalizability of findings. Additionally, each training session included only a small number of participants (average 6). This did not approximate general continuing education training very well. Typical continuing education workshops involve many more trainees, resulting in less individual instruction. The present training situation was unusual in that there was a low ratio of trainers to trainees (approximately 2:3).

While concerns remain regarding the selection and number of participants, the current study offered a few improvements to methodological concerns mentioned in critical reviews (Alberts \& Edelstein, 1990). For example, previous training studies have been criticized for including clinicians with little training (Alberts \& Edelstein), whereas other research (e.g., Henry 
et al., 1993) and conceptual discussion has criticized the use of only doctoral-level professionals. It seems that the majority of clients are seen in community mental health centers where doctorallevel psychologists serve as supervisors rather than direct service providers (Addis \& Krasnow, 2000). A strength of the current study is that of masters-level professionals who have considerable work experience were also trained. Addis and Krasnow (2000) also assert that master- level clinicians are responsible for increasing amounts of direct client contact, and acknowledge that masters-level training is different than doctoral-level training. Additionally, while the current study included only 42 participants, it is not uncommon for training studies to have limited sample sizes (e.g., Henry et al. included 16 participants) because of logistical constraints.

\section{Frequent Assessment}

Another limitation for the current study was the large number of assessment points relative to the amount of time spent in training. This may have increased the likelihood of practice effects. Over the course of a two consecutive day workshop, participants completed three assessments. Each assessment involved practicing PCIT skills, and each group participated in the assessment. It may have been that these repeated assessments contributed to a lack of group differences by allowing the didactic group to have some skills practice.

\section{Assessment of Basic Skills}

The current study included assessment of only basic, or low-level, PCIT skills. In fact, only the first phase of PCIT, CDI, was examined. Arguably, CDI is consistent with a wide array of theoretical approaches and palatable to a large number of therapists because it combines developmental, interpersonal, social learning, and behavioral theories. It also involves traditional play therapy techniques and is a positive, strength-based approach to working with families. The skills needed to implement CDI are considered easier to implement than those used in the PDI phase of PCIT. PDI focuses on consistent limit-setting and compliance training, with a strong reliance on behavioral principles. Clinically, observations of therapists who are learning PDI have revealed that it could be considered a more sophisticated, or higher-level, PCIT skill than CDI. Implementation of PDI is complex and novice therapists appear to make many more significant errors. Perhaps an assessment of low-level versus high-level skills would yield more interesting findings on the utility of experiential versus didactic training. Assessment of both 
types of skills (low- and high-level) may indicate a need for experiential training when skills are more complex and difficult to implement successfully. Lack of Standardized and Validated Dependent Variables

Significant attempts were made to find psychometrically sound measures. If appropriate measures were not available, attempts were made to make as few modifications as possible to existing psychometrically sound measures for them to be useful in the current study. If a measure was not found that could be used directly or with slight modifications, attempts were made to ensure that created measures were sound (see CDI \& DPICS Knowledge Questionnaire Pilot Study in Appendix J). However, because it was beyond the scope of this study to standardize and validate new measures, results based on measures created solely for this investigation should be interpreted with caution.

\section{Suggestions for Future Research}

\section{Assessment of Practicing Clinicians and Empirically Supported Treatments}

As suggested by previous researchers (Alberts \& Edelstein, 1990; Henry et al., 1993), the dependent variables used for psychotherapy training studies typically lack strong psychometric properties. Because EST dissemination is an emerging area of study and because of the specific differences between ESTs, measurement of the knowledge and skills necessary for individual EST implementation is relatively new and complicated. Better measures of theoretical orientation, attitudes toward behaviorally and cognitive-behaviorally oriented therapies, as well as knowledge and skill variables specific to any one EST program are needed. Specific to PCIT is the need for a strong measure for assessing knowledge and coaching skill. The current study offers a "first step" in knowledge assessment; however, much could be gained be developing a multiple choice PCIT knowledge questionnaire from the open-ended knowledge questionnaire used in the current study. Coaching is a hallmark of PCIT and is the technique used for the majority of each treatment session; however, its measurement is complex and in its infancy. Multiple Levels of Successful Dissemination Efforts

For a more comprehensive understanding of dissemination, studies should be conducted to examine the multiple levels affected by EST implementation. For example, little is known about the specific agency (organization-level) variables that help to support or hamper therapist efforts to learn and implement ESTs. It has been suggested that agency characteristics such as stability, commitment to training, and adequate financial resources (Barlow et al., 1999) are 
associated with successful adoption of ESTs; however, there has been little systematic investigation of these critical variables. A preliminary report of the Head Start Teaching Center Demonstration Project echoes organization-level concerns in their recommendations to involve program directors and managers in training, ensure trainees are afforded adequate time to implement newly learned skills, and provide training at convenient locations and times with flexible trainers (Head Start Bureau of the Administration on Children, Youth and Families, 2001).

In the current study, 13 therapists participated in phase one of data collection, but were unable to participate in the remaining assessments. From informal reports, it appeared that each of these participants dropped from the larger training project due to agency-related issues such as an agency shifting priorities from staff training to staff billing or an agency reallocating staff resources to another project. In future studies it would be interesting to measure organizational level variables such as agency size, leadership, stability, financial security, commitment to staff continuing education, and ability to offset clinicians' caseloads to accommodate training cases and time in training.

Another level of dissemination deserving additional study is the performance of clients who will be served by trained clinicians. Some studies have been devoted to this topic; however, more are needed. It currently is unknown if the same level of treatment success that has been obtained by using ESTs in university settings can be obtained in community settings. Mixed results have been reported by the few studies examining this question. Wade et al. (1998) as well as Persons et al. (1999) trained clinicians in "real world" settings to conduct ESTs for panic disorder and depression, respectfully. Each found treatment outcomes comparable to those found in efficacy studies. In contrast, Morganstern, Morgan, Labouvie, Blanchard, and MacDonald (1999) found no significant differences on outcome measures for a structured version of the substance abuse EST, a flexibly implemented version of the same EST, and treatment as usual. More studies examining the effect of ESTs on children and families are necessary, particularly considering that relatively fewer studies examine child treatments compared to adult treatments (Herschell, McNeil, \& McNeil, 2002).

Investigation of Dissemination Models

Some dissemination models have proposed a "trainer of trainer" (TOT) concept in which a small number of persons from one agency receive training in an EST, and then are required to 
train others at their agency in that EST. The effects of implementing this type of dissemination model are not clear. Can TOT's deliver the same quality of training as university trainers or is the EST "watered down?" Are the therapists trained by TOTs implementing ESTs with the same level of treatment integrity that was used in the treatment outcome studies to empirically support the use of the treatment? Future research is needed to answer these types of questions concerning the relative effectiveness of various dissemination models.

To begin to address the question of whether the discussed dissemination model is useful, a fifth assessment will be completed with participants from the current study. Assessment of knowledge, skills, and satisfaction will be conducted after the completion of the full year-long, five-phase training model. The current study examined only phases one and two of the five phase project.

\section{Maintenance of Training Gains}

Little is known about what occurs after an intensive training is complete. Investigations need to be conducted to determine if a therapist will continue to use knowledge gained and skills acquired with high treatment integrity. Henggeler and colleagues (Henggeler, Melton, Brondino, \& Scherer, 1997) have begun to document the importance of maintaining a high level of treatment integrity with one finding indicating that high levels of treatment integrity were associated with positive client outcome. Clearly, maintenance of a high level of treatment integrity is important; however, we do not know what level of treatment integrity therapists maintain after training is complete. Some have suggested that therapists will drift towards familiar styles of intervention with more difficult clients, rather than using a recently learned treatment (Barlow et al, 1999).

Study of modifications made to ESTs by practicing clinicians also is necessary to determine if the modifications are improvements (e.g., helping to fit ESTs within a "real-world" setting) or if modifications simply are ineffective deviations from protocol. It may be that such modifications change the efficacy of the EST. As previously mentioned, Henngeler and colleagues (1997) found treatment success to be associated with treatment integrity. An investigation conducted by Morganstern et al. (1999) offer another example of how researchers may begin to study modifications to ESTs. In this study a structured version of the substance abuse EST, a flexibly implemented version of the same EST, and treatment as usual were compared. Interestingly, no differences were found among the three treatments. Additional 
studies comparing the effectiveness of ESTs implemented in community settings with varying degrees of treatment protocol adherence would aid researchers in understanding the importance of treatment integrity as well as the modifications made, and potential rationales for why clinicians make changes to ESTs.

\section{Conclusions}

The current study offers a contribution to the currently scarce dissemination literature in that it is a "first step" in empirically investigating methods of disseminating a child EST to community practitioners. Results tentatively suggest the following regarding PCIT dissemination: (a) reading a treatment manual is useful but not sufficient, (b) training success is not associated with theoretical orientation, (c) for low-level skills, both experiential and didactic training (with videotape modeling) can be useful, and (d) the treatment is accepted by practitioners with a variety of theoretical orientations as demonstrated by reported high satisfaction. Each of these findings cautiously, but optimistically, supports the idea that PCIT can be widely disseminated. Caution must be taken considering that the current study demonstrated that increases in knowledge and skills are likely for a majority of participants; however mastery of knowledge and skills is likely for only a minority of participants after reading a treatment manual and attending two consecutive days of training. Additional instruction and the study of that instruction is necessary to determine how much and what type of training is required for mastery of low- and high-level PCIT skills.

Results also suggest that type of masters degree may be important to training success. Considering that previous dissemination studies have not investigated impact of type of masterslevel degree on training performance, and instead have investigated doctoral- and doctoralversus masters-level training, this finding highlights the need for additional study of masterslevel practitioners.

In summary, the current study offers a beginning to evaluating the success of techniques for disseminating a child EST; however, additional systematic investigations are needed. Future studies should continue to explore therapist characteristics associated with training success, improvements in versus mastery of specific EST knowledge and skills, and the role of masterslevel practitioners in EST delivery. Also new areas of investigation should be explored such as acquisition of low-level versus high-level therapy skills, maintenance of training gains, multiple levels of dissemination (e.g., organizational level), and dissemination models. Hopefully, the 
results and application of findings from such investigations will assist program developers and researchers in transporting ESTs to community-based centers, where the majority of children and families receive services, and where the need for effective services is paramount. It is this type of research that will help to narrow the gap between science and practice. 


\section{References}

Addis, M. E. (2002). Methods for disseminating research products and increasing evidence based practice: Promises, obstacles, and future directions. Clinical Psychology: Science and Practice, 9,421-424.

Addis, M. E., \& Krasnow, A. D. (2000). A national survey of practicing psychologists' attitudes towards psychotherapy treatment manuals. Journal of Consulting and Clinical Psychology, 68, 331-339.

Addis, M. E., Wade, W. A., \& Hatgis, C. (1999). Barriers to dissemination of evidence-based practices: Addressing practitioners' concerns about manual-based psychotherapies. Clinical Psychology: Science and Practice, 6, 430-441.

Alberts, G., \& Edelstein, B. (1990). Therapist training: A critical review of skill training studies. Clinical Psychology Review, 10, 497-511.

American Psychological Association. (1993). Task Force on Promotion and Dissemination of Psychological Procedures. A report to Division 12 board of the American Psychological Association. (Available from the Division 12 of the American Psychological Association. 750 First Street, NE. Washington, DC 20002-4242. USA.).

American Psychological Association. (2000). Results of state provincial mandatory continuing professional education (MCPE) requirements survey. Retrieved April 26, 2002, from http://www.apa.org/ed/mcesurvey.html.

Aragona, J. A., \& Eyberg, S. M. (1981). Neglected children: Mothers' report of child behavior problems and observed verbal behavior. Child Development, 52, 596-602.

Backer, T. E., Liberman, R. P., \& Kuehnel, T. G. (1986). Dissemination and adoption of innovative psychosocial interventions. Journal of Consulting and Clinical Psychology, 54, 111-118.

Barkley, R. A. (1989). Defiant children. New York: Guilford Press.

Barlow, D. H. (1981). On the relation of clinical research to clinical practice: Current issues, new directions. Journal of Consulting and Clinical Psychology, 49, 147-155.

Barlow, D. H., Levitt, J. T., \& Bufka, L. F. (1999). The dissemination of empirically supported treatments: A view to the future. Behaviour Research and Therapy, 37, S147-S162.

Becker, W. C. (1971). Parents are teachers. Champaign, IL: Research Press. 
Bernal, G., \& Scharron-Del-Rio, M. R. (2001). Are empirically supported treatments valid for ethnic minorities? Toward an alternative approach for treatment research. Cultural Diversity and Ethnic Minority Psychology, 7, 328-342.

Beisser, A. R. (1976). Continuing education for community mental health: Person, system, and task. Los Angeles: Health Training Center.

Beutler, L. E., \& Kendall, P. C. (1995). Introduction to the Special Section: The case for training in the provision of psychological therapy. Journal of Consulting and Clinical Psychology, 63, 179-181.

Beutler, L. E., Machado, P. P., \& Neufeldt, S. (1994). Therapist variables. In S. L. Garfield \& A. E. Bergin (Eds.), Handbook of psychotherapy and behavior change ( $4^{\text {th }}$ ed., pp. 259-269). New York: Wiley.

Brestan, E. V., \& Eyberg, S. M. (1998). Effective psychosocial treatments of conduct-disordered children and adolescents: 29 years, 82 studies, and 5,272 kids. Journal of Consulting and Clinical Psychology, 66, 180-189.

Brestan, E. V., Eyberg, S. M., Boggs, S., \& Algina, J. (1997). Parent-Child Interaction Therapy: Parent perceptions of untreated siblings. Child and Family Behavior Therapy, 19, 13-28.

Brestan, E. V., Jacobs, J. R., Rayfield, A. D., \& Eyberg, S. M. (1999). A consumer satisfaction measure for parent-child treatments and its relation to measures of child behavior change. Behavior Therapy, 30, 17-30.

Calhoun, K. S., Moras, K., Pilkonis, P. A., \& Rehm, L. P. (1998). Empirically supported treatments: Implications for training. Journal of Consulting and Clinical Psychology, 66, 151-162.

Calzada, E., J. \& Eyberg, S. M. (2001). The relationship between Hispanic parenting and disruptive behavior in preschool children. Manuscript submitted for publication.

Campbell, S. B., Shaw, D. S., \& Gilliom, M. (2000). Early externalizing behavior problems: Toddlers and preschoolers at risk for later maladjustment. Development and Psychopathology, 12, 467-488.

Capage, L. C., Bennett, G., \& McNeil, C. B. (2001). A comparison between African American and Caucasian children referred for treatment of behavior problems. Child and Family Behavior Therapy, 23, 1-14. 
Carroll-Rowan, L. A., \& Miltenberger, R. G. (1994). A comparison of procedures for teaching abduction prevention to preschoolers. Education and Treatment of Children, 17, 113-128.

Casey, R. J., \& Berman, J. S. (1985). The outcome of psychotherapy with children. Psychological Bulletin, 98, 388-400.

Castonguay, L. G., Goldfried, M. R., Wiser, S., Raue, P. J., \& Hayes, A. M. (1996). Predicting the effects of cognitive therapy for depression: A study of unique and common factors. Journal of Consulting and Clinical Psychology, 64, 497-504.

Chambless, D. L., Sanderson, W. C., Shoham, V., Johnson, S. B., Pope, K. S., Crits-Christoph, P., Baker, M., Johnson, B., Woody, S. R., Sue, S., Beutler, L., Williams, D. A., \& McCurry, S. (1996). An update on empirically validated therapies. The Clinical Psychologist, 49, 5-18.

Chambless, D. L., Baker, M. J., Baucom, D. H., Beutler, L. E., Calhoun, K. S., Crits-Christoph, P., Daiuto, A., DeRubeis, R., Detweiler, J., Haaga, D. A. F., Bennett Johnson, S., McCurry, S., Mueser, K. T., Pope, K. S., Sanderson, W. C., Shoham, V., Stickler, T., Williams, D. A., \& Woody, S. R. (1998). Update on empirically validated therapies II. The Clinical Psychologist, 51, 3-15.

Chevron E., \& Rounsaville, B. J. (1983). Evaluating the clinical skills of psychotherapists: A comparison of techniques. Archives of General Psychiatry, 40, 1129-1132.

Cohen, L. H. (1979). The research readership and information source reliance of clinical psychologists. Professional Psychology, 10, 780-785.

Costello, E. J. (1989). Developments in child psychiatric epidemiology. Journal of the American Academy of Child and Adolescent Psychiatry, 28, 836-841.

Crits-Christoph, P. (1996). The dissemination of efficacious psychological treatments. Clinical Psychology: Science and Practice, 3, 260-263.

Davis, D. A., Thomson, M. A., Freemantle, N., Wolf, F. M., Mazmanian, P., \& Taylor-Vaisey, A. (1999). The impact of formal continuing medical education: Do conferences, workshops, rounds, and other traditional continuing education activities change physician behavior or health care outcomes? Journal of the American Medical Association, 282, $867-874$. 
Davis, D. A., Thomson, M. A., Oxman, A. D., \& Haynes, R. B. (1992). Evidence for the effectiveness of CME: A review of randomized controlled trials. Journal of the American Medical Association, 268, 1111-1117.

Davison, G. C. (1998). Being bolder with the Boulder Model: The challenge of education and training in empirically supported treatments. Journal of Consulting and Clinical Psychology, 66, 163-167.

Davison, G. C., \& Lazarus, A. A. (1994). Clinical innovation and evaluation: Integrating practice with inquiry. Clinical Psychology: Science and Practice, 1, 157-168.

Davison, G. C., \& Lazarus, A. A. (1995). The dialectics of science and practice. In S. C. Hayes, V. M. Follette, T. Risley, R. D. Sawes, \& K. Grady (Eds.), Scientific standards of psychological practice: Issues and recommendations (pp. 95-120). Reno, NV: Context Press.

DeRubeis, R. J., \& Freeley, M. J. V. (1990). Determinants of change in cognitive therapy for depression. Cognitive Therapy and Research, 14, 469-482.

Durbin, S. S. (1972). Obsolescence or lifelong education: A choice for the professional. American Psychologist, 27, 486-498.

Edwards, D. L., Eyberg, S. M., Rayfield, A., Jacobs, J., \& Hood, K. K. (2002). Outcomes of Parent-Child Interaction Therapy: A comparison of treatment completers and treatment dropouts one to three years later. Manuscript submitted for publication.

Eisenstadt, T. H., Eyberg, S. M., McNeil, C. B., Newcomb, K., \& Funderburk, B. (1993). ParentChild Interaction Therapy with behavior problem children: Relative effectiveness of two stages and overall treatment outcome. Journal of Clinical Child Psychology, 22, 42-51.

Eyberg, S. M. (1993). Consumer satisfaction measures for assessing parent training programs. In L. VandeCreek \& S. Knapp (Eds.), Innovations in clinical practice: A source book(Vol. 12, pp. 377-382). Sarasota, FL: Professional Resource Press.

Eyberg, S. M. (1974). Therapy Attitude Inventory. (Available from Sheila Eyberg, Department of Clinical and Health Psychology, P.O. Box 100165 HSC, University of Florida, Gainsville, FL 32610).

Eyberg, S. M., \& Calzada, E. J. (1998). Parent-Child Interaction Therapy: Procedures manual. Unpublished manuscript, University of Florida. 
Eyberg, S. M., Edwards, D. L., Boggs, S. R., \& Foote, R. (1998). Maintaining the treatment effects of parent training: The role of booster sessions and other maintenance strategies. Clinical Psychology: Science and Practice, 5, 544-554.

Eyberg, S. M., Funderburk, B. W., Hembree-Kigin, T., McNeil, C. B., Querido, J., \& Hood, K. K. (2001). Parent-Child Interaction Therapy with behavior problem children: One and two year maintenance of treatment effects in the family. Child \& Family Behavior Therapy, 23(4), 1-20.

Eyberg, S. M., \& Matarazzo, R. G. (1980). Training parents as therapists: A comparison between individual parent-child interaction training and group didactic training. Journal of Clinical Psychology, 36, 492-499.

Eyberg, S. M. \& Pincus, D. (2000). Eyberg Child behavior Inventory and Sutter-Eyberg Behavior Inventory-Revised Professional manual. Odessa, FL: Psychological Assessment Resources, Inc.

Eyberg, S. M., \& Robinson, E. A. (1982). Parent-Child Interaction Training: Effects on family functioning. Journal of Clinical Child Psychology, 11, 130-137.

Eyberg, S. M., \& Robinson, E. A. (1983). Dyadic Parent-Child Interaction Coding System: A manual. Psychological Documents, 13, Ms. No. 2582. (Available from Social and Behavior Sciences Documents, Select Press, P.O. Box 9838, San Rafael, CA 94912.).

Foley, S. H., O’Malley, S., Rounsaville, B., Prusoff, B. A., \& Weissman, M. M. (1987). The relationship of patient difficulty to performance in interpersonal psychotherapy of depression. Journal of Affective Disorders, 12, 207-217.

Fowler, R. D. (1999). Giving psychology away. The American Psychological Association Monitor, 30, 3.

Frank, E., Kupfer, D. J., Wagner, E. F., McEachran, A. B., \& Cornes, C. (1991). Efficacy of interpersonal psychotherapy as a maintenance treatment of recurrent depression: Contributing factors. Archives of General Psychiatry, 48, 1053-1059.

Funderburk, B.W., Eyberg, S. M., Newcomb, K., McNeil, C. B., Hembree-Kigin, T., \& Capage, L. (1998). Parent-Child Interaction Therapy with behavior problem children: Maintenance of treatment effects in the school setting. Child and Family Behavior Therapy, 20, 17-38. 
Furtkamp, E., Giffort, D., \& Schiers, W. (1982). In-class evaluation of behavior modification knowledge: Parallel tests for use in applied settings. Journal of Behavior Therapy \& Experimental Psychiatry, 13, 131-134.

Garfield, S. L. (1996). Some problems associated with “validated”forms of psychotherapy. Clinical Psychology: Science and Practice, 3, 218-229.

Garfield, S. L. (1998). Some comments on empirically supported treatments. Journal of Consulting and Clinical Psychology, 66, 121-125.

Garvery, W. D., \& Griffith, B. C. (1971). Scientific communication: Its role in the conduct of research and creation of knowledge. American Psychologist, 26, 349-362.

Goisman, R. M., Rogers, M. P., Steketee, G. S., Warshaw, M. G., Cuneo, P., \& Keller, M. B. (1993). Utilization of behavioral methods in a multi center anxiety disorders study. Journal of Clinical Psychiatry, 54, 213-218.

Goisman, R. M., Warshaw, M. G., \& Keller, M. B. (1998). Psychosocial prescribing practices for anxiety disorders, 1991-1996: Data from a multi center anxiety disorders study. Unpublished manuscript.

Hall, R. V. (1971). Managing behavior 2. Lawrence, KS: H. \& H. Enterprises.

Hanf, C. (1969, April). A two stage program for modifying maternal controlling during motherchild interactions. Paper presented at the meeting of the Western Psychological Association, Vancouver, British Columbia, Canada.

Hawkins, K. A., \& Sinha R. (1998). Can front-line clinicians master the conceptual complexities of dialectical behavior therapy? An evaluation of a State Department on Mental Health training program. Journal of Psychiatric Research, 32, 379-384.

Hayes, S. C. (1998). Dissemination research now. the Behavior Therapist, 21, 166-169.

Head Start Bureau of the Administration on Children, Youth and Families. (2001). Preliminary report on the Head Start Teaching Center demonstration project. Retrieved April 1, 2002, from http://www2acf.dhhs.gov/programs/hsb/research/hstc.htm.

Hembree-Kigin, T. L., \& McNeil, C. B. (1995). Parent-Child Interaction Therapy. New York: Plenum Press. 
Henggeler, S. W., Melton, G. B., Brondino, M. J., \& Scherer, D. G. (1997). Multisystemic therapy with violent and chronic juvenile offenders and their families: The role of treatment fidelity in successful dissemination. Journal of Consulting and Clinical Psychology, 65, 821-828.

Henry, W. P., Schacht, T. E., Strupp, H. H., Butler, S. F., \& Binder, J. L. (1993). Effects of training in time-limited dynamic psychotherapy: Mediators of therapists responses to training. Journal of Consulting and Clinical Psychology, 61, 441-447.

Herschell, A. D., Calzada, E. J., Eyberg, S. M., \& McNeil, C. B. (2002). Research on Parent Child Interaction Therapy: Past and future. Cognitive and Behavioral Practice.

Herschell, A. D., McNeil, C. B., \& McNeil, D. W. (2002). Issues in Disseminating Empirically Supported Treatments: Comparisons between Adult and Child Clinical Psychology. Manuscript submitted for publication.

Hoagwood, K., Hibbs, E., Brent, D., \& Jensen, P. (1995). Introduction the special section: Efficacy and effectiveness in studies of child and adolescent psychotherapy. Journal of Consulting and Clinical Psychology, 63, 683-687.

Holloway, E. L., \& Neufeldt, S. A. (1995). Supervision: Its contributions to treatment efficacy. Journal of Consulting and Clinical Psychology, 63, 207-213.

Howell, D. C. (1997). Statistical methods for psychology $\left(4^{\text {th }}\right.$ ed.). Belmont, CA: Duxbury Press.

Inham, R., \& Bennett, P. (1990). Health psychology in community settings: Models and methods. In P. Bennett, J. Weinman, \& P. Spurgeon (Eds.), Current developments in health psychology (pp. 35-61). New York: Harwood.

Jacobson, N. S., Schmaling, K. B., Holtzworth-Munroe, A., Katt, J. L., Wood, L. F., \& Follette, V. M. (1989). Research structured vs. clinically flexible versions of social learning-based marital therapy. Behaviour Research and Therapy, 27, 173-180.

Kaslow, N. J., \& Thompson, M. P. (1998). Applying the criteria for empirically supported treatments to studies of psychosocial interventions for child and adolescent depression. Journal of Clinical Child Psychology, 27, 146-155.

Kazdin, A. E., Bass, D., Ayers, W. A., \& Rodgers, A. (1990). Empirical and clinical focus of child and adolescent psychotherapy research. Journal of Consulting and Clinical Psychology, 58, 729-740. 
Kazdin, A. E., Siegel, T. C., \& Bass, D. (1990). Drawing upon clinical practice to inform research on child and adolescent psychotherapy: A survey of practitioners. Professional Psychology: Research and Practice, 21, 189-198.

Kendall, P. C. (1998). Directing misperceptions: Researching the issues facing manual-based treatments. Clinical Psychology: Science and Practice, 5, 396-399.

Kolko, D. J. (1992). Characteristics of child victims of physical violence: Research findings and clinical implications. Journal of Interpersonal Violence, 7, 244-276.

Lambert, M. J. (1998). Manual-based treatment and clinical practice: Hangman of life or promising development? Clinical Psychology: Science and Practice, 5, 391-395.

Lonigan, C. J., Elbert, J. C., \& Bennett-Johnson, S. (1998). Empirically supported psychosocial interventions for children: An overview. Journal of Clinical Child Psychology, 27, 138145.

Luborsky, L. (1990). Theory and technique in dynamic psychotherapy - Curative factors and training therapists to maximize them. Psychotherapy and Psychosomatics, 53, 50-57.

Lumley, V. A., Miltenberger, R. J., Long, E. S., Rapp, J. T., \& Roberts, J. A. (1998). Evaluation of sexual abuse prevention program for adults with mental retardation. Journal of Applied Behavior Analysis, 31, 91-101.

Marques, C. (1998). Manual based treatment and clinical practice. Clinical Psychology: Science and Practice, 5, 400-402.

McLoughlin, C. S. (1985). Utility and efficacy of knowledge of behavioral principles as applied to children. Psychological Reports, 56, 463-467.

McNeil, C. B., Eyberg, S. M., Eisenstadt, T. H., Newcomb, K., \& Funderburk, B. W. (1991). Parent-Child Interaction Therapy with behavior problem children: Generalization of treatment effects to the school setting. Journal of Clinical Child Psychology, 20, 140-151.

Miller, W. R., Brown, J. M., Simpson, T. L., Handmaker, N. S., Bien, T. H., Luckie, L. F., Montgomery, H. A., Hester, R. K., \& Tonigan, J. S. (1995). What works? A methodological analysis of the alcohol treatment outcome literature. In R. K. Hester \& W. R. Miller (Eds.), Handbook of alcoholism treatment approaches: Effective alternatives (pp. 12-44). Boston: Allyn and Bacon. 
Morgenstern, J., Morgan, T. J., Labouvie, E., Blanchard, K., \& MacDonald, A. (1999, November). Disseminating cognitive behavioral treatment to community substance abuse practitioners: A test of the psychotherapy technology model. In S. B. Berns (Chair), Beyond the ivory tower: Research on the dissemination and implementation of treatments in the "real world." Symposium conducted at the meeting of the Association for Advancement of Behavior Therapy, Toronto, Canada.

Morow-Bradley, C., \& Elliott, R. (1986). Utilization of psychotherapy research by practicing psychotherapists. American Psychologist, 41, 188-197.

Najavitis, L. M., \& Strupp, H. H. (1994). Differences in the effectiveness of psychodynamic therapists: A process-outcome study. Psychotherapy, 31, 114-123.

Nixon, R. D. V. (2000). Parent-Child Interaction Therapy: A comparison of standard and abbreviated treatments of oppositional defiant preschoolers. Unpublished doctoral dissertation, University of Sydney, NSW, Australia.

Norris, E. L., \& Larsen, J. K. (1976). Critical issues in mental health service delivery: What are the priorities? Hospital and Community Psychiatry, 27, 561-566.

O’Bryne, K. K., Peterson, L., \& Saldana, L. (1997). Survey of pediatric hospitals preparation programs: Evidence of the impact of health psychology research. Health Psychology, 16, 147-154.

O’Dell, S. L., Tarler-Benlolo, L., \& Flynn, J. M. (1979). An instrument to measure Knowledge of Behavioral Principles As Applied to Children. Journal of Behavior Therapy and Experimental Psychiatry, 10, 29-34.

O’Donohue, W. T., Curtis, S. D., \& Fisher, J. E. (1985). Use of research in the practice of community mental health: A case study. Professional Psychology: Research and Practice, 16, 710-718.

Ollendick, T. H., \& King, N. J. (1998). Empirically supported psychosocial treatments for children with phobic and anxiety disorders. Journal of Clinical Child Psychology, 27, 156-167.

Patterson, G. R. (1971). Families. Champaign, IL: Research Press.

Patterson, G. R., \& Guillon, M. E. (1968). Living with children. Champaign, IL: Research Press.

Pelham, W. E., Jr. (1999). President's message: Evidence based treatments for childhood disorders: Section initiatives. Clinical Child Psychology Newsletter, 14, 1-3. 
Pelham, W. E., Jr, Wheeler, T., \& Chronis, A. (1998). Empirically supported psychosocial treatments for attention deficit hyperactivity disorder. Journal of Clinical Child Psychology, 27, 190-205.

Persons, J. B. (1995). Why practicing psychologists are slow to adopt empirically-validated treatments. In S. C. Hayes, V. M. Follette, R. M. Dawes, \& K. E. Grady (Eds.), Scientific standards of psychological practice: Issues and recommendations (pp. 141-157). Reno, NV: Context Press.

Persons, J. B. (1997). Dissemination of effective methods: Behavior therapy's next challenge. Behavior Therapy, 28, 465-471.

Persons, J. B., Bostrom, A. \& Bertagnolli, A. (1999). Results of randomized controlled trials of cognitive therapy for depression generalize to private practice. Cognitive Therapy and Research, 23, 535-548.

Peterson, L. (1997). Behavior therapy's promise for child treatment: Where we've been, where we may be going. Behavior Therapy, 28, 531-541.

Robinson, E. A., \& Eyberg, S. M. (1981). The Dyadic Parent-Child Interaction Coding System: Standardization and validation. Journal of Consulting and Clinical Psychology, 49, 245250 .

Rousaville, B. J., Chevron, E. S., \& Weissman, M. M. (1984). Specification of techniques in interpersonal psychotherapy. In J. B. W. Williams \& R. L. Spitzer (Eds.), Psychotherapy research: Where are we and where should we go? (pp. 160-172). New York: Guilford Press.

Rushton, H. G. (1989). Nocturnal enuresis: Epidemiology, evaluation, and currently available treatment options. The Journal of Pediatrics, 114, 691-696.

Sanderson, W. C., \& Woody, S. (1995). Manuals for empirically validated treatments: A project of the Task Force on Psychological Interventions. The Clinical Psychologist, 48, 3-23.

Satcher, D. (2000). Mental health: A report of the Surgeon General - executive summary. Professional Psychology: Research and Practice, 31, 5-13.

Schuhmann, E., Foote, R., Eyberg, S. M., Boggs, S., \& Algina, J. (1998). Parent-Child Interaction Therapy: Interim report of a randomized trial with short-term maintenance. Journal of Clinical Child Psychology, 27, 34-45. 
Schulte, D., Kunzel, R., Pepping, G., \& Schulte-Bahrenberg, T. (1992). Tailor-made versus standardized therapy of phobic patients. Advanced Behavior Research Therapy, 14, 6792.

Shaw, B. F. (1984). Specification of the training and evaluation of cognitive therapists for outcome studies. In J. B. W. Williams \& R. L. Spitzer (Eds.), Psychotherapy research: Where are we and where should we go? (pp. 173-188). New York: Guilford Press.

Shrout, P. E., \& Fleiss, J. L. (1979). Intraclass correlations: Uses in assessing rater reliability. Psychological Bulletin, 86, 420-428.

Silverman, W. H. (1996). Cookbooks, manuals, and paint-by-numbers: Psychotherapy in the 90's. Psychotherapy, 33, 207-215.

Schmidt, F., \& Taylor, T. K. (2002). Putting empirically supported treatments into practice: Lessons learned in a children's mental health center. Professional Psychology: research and Practice, 33, 483-489.

Stein, D. M., \& Lambert, M. J. (1995). Graduate training in psychotherapy: Are therapy outcomes enhanced? Journal of Consulting and Clinical Psychology, 63, 182-196.

Strosahl, K. (1995). Behavior therapy 2000: A perilous journey. the Behavior Therapist, 18, 130133.

Strosahl, K. (1998). The dissemination of manual-based psychotherapies in managed care: Promises, problems, and prospects. Clinical Psychology: Research and Practice, 5, 382386.

Strosahl, K. D., Hayes, S. C., Bergan, J., \& Romano, P. (1998). Assessing the filed effectiveness of Acceptance and Commitment Therapy: An example of the manipulated training research method. Behavior Therapy, 29, 35-64.

Sturmey, P., Newton, T., Milne, D., \& Burdett, C. (1987). Parallel forms of the Knowledge of Behavioral Principles As Applied to Children Questionnaire: An independent, multicentered, British replication. Journal of Behavior Therapy and Experimental Psychiatry, 18, 223-227.

Sue, S. (1999). Science, ethnicity, and bias: Where have we gone wrong? American Psychologist, 54, 1070-1077. 
Task Force on Promotion and Dissemination of Psychological Procedures. (1995). Training in and dissemination of empirically-validated psychological treatments. The Clinical Psychologist, 48, 3-23.

Tynan, D. W., \& Chew, C. (1999, November). Empirically supported treatments for children in managed care settings. In T. H. Ollendick (Chair), Implementing empirically supported treatments for children in applied settings. Symposium conducted at the annual meeting of the Association for Advancement of Behavior Therapy, Toronto, Ontario.

Urquiza, A. J., \& McNeil, C. B. (1996). Parent-Child Interaction Therapy: Potential applications for physically abusive families. Child Maltreatment, 1, 134-144.

VandeCreek, L., Knapp, S., \& Brace, K. (1990). Mandatory continuing education for licensed psychologists: Its rationale and current implications. Professional Psychology: Research and Practice, 21, 135-140.

Wade, W. A., Treat, T. A., \& Stuart, G. L. (1998). Transporting an empirically supported treatment for panic disorder to a service clinic setting: A benchmarking strategy. Journal of Consulting and Clinical Psychology, 66, 231-239.

Wagner, W. G., \& Hicks-Jimenez, K. (1986). Clinician's knowledge and attitudes regarding the treatment of childhood nocturnal enuresis. the Behavior Therapist, 9, 77-78.

Webster-Stratton, C. (1990). Enhancing the effectiveness of self-administered videotape parent training for families with conduct-problem children. Journal of Abnormal Child Psychology, 18, 479-492.

Webster-Stratton, C. (1994). Advancing videotape parent training: A comparison study. Journal of Consulting and Clinical Psychology, 62, 583-593.

Webster-Stratton, C., Reid, J. M., Hammond, M. (2001). Preventing conduct problems, promoting social competence: A parent and teacher training partnership in Head Start. Journal of Clinical Child Psychology, 30, 283-302.

Weisz, J. R. (2000). President's message: Lab and clinic differences and what we can do about them: Linking research and practice to enhance our public impact. Child Clinical Psychology Newsletter, 15(2), 1-4.

Weisz, J. R., Weiss, B., Alicke, M. D., \& Klotz, M. L. (1987). Effectiveness of psychotherapy with children and adolescents: A meta-analysis for clinicians. Journal of Consulting and Clinical Psychology, 55, 542-549. 
Weisz, J. R., Weiss, B., Han, S. S., Granger, D. A., \& Morton, T. (1995). Effects of psychotherapy with children and adolescents revisited: A meta-analysis of treatment outcome studies. Psychological Bulletin, 117, 450-468.

Werba, B. Eyberg, S. M., Boggs, S. R., \& Algina, J. (2001). Predicting outcome in Parent-Child Interaction Therapy: Success and attrition. Manuscript submitted for publication.

Wilson, G. T. (1996a). Empirically validated treatments: Realities and resistance. Clinical Psychology: Science and Practice, 3, 241-244.

Wilson, G. T. (1996b). Manual-based treatments: The clinical application of research findings. Behavior Research and Therapy, 34, 295-315.

Wilson, G. T. (1997a). Treatment manuals in clinical practice. Behavior Research and Therapy, 35, 205-210.

Wilson, G. T. (1997b). Dissemination of cognitive behavioral treatments: Commentary on “Dissemination of effective methods: Behavior therapy's next challenge." Behavior Therapy, 28, 473-475.

Wilson, G. T. (1998). Manual-based treatment and clinical practice. Clinical Psychology: Science and Practice, 5, 363-375.

Wolf, M. M. (1978). Social validity: The case for subjective measurement or how applied behavior analysis is finding its heart. Journal of Applied Behavior Analysis, 11, 203-214.

Wolf, M. M., Braukmann, C. J., \& Ramp, K. A. (1987). Serious delinquent behavior as part of a handicapping condition: Cures and supportive environments. Journal of Applied Behavior Analysis, 20, 347-359.

Wolfe, D. A. (1987). Child abuse: Implications for child development and psychopathology. Newbury Park, CA: Sage.

Woody, S. R., \& Sanderson, W. C. (1998). Manuals for empirically supported treatments: 1998 update. Retrieved April 26, 2002, from http://www.apa.org/divisions/div12/est/est.html. 
Appendix A

\section{Training Activities/Functions/Expectations}

for

\section{Contracts Related to Parent Child Interaction Therapy Training}

\section{Overview}

In response to the need for providing high quality and empirically-supported interventions for child maltreatment, the Governor's Office of Criminal Justice Planning (OCJP) developed and distributed a 'Call for Papers' to all of the child abuse treatment agencies which were receiving funding by them. The intent of this 'Call for Papers' was to have these child abuse treatment agencies develop a Parent-Child Interaction Therapy (PCIT) treatment program. This 'Call for Papers' was designed to provide funding for training staff, acquiring technical assistance, equipment acquisition, and other training-related activities (e.g., travel, participation at an annual conference). PCIT training for each agency was to be provided by the University of California Davis Medical Center, Child and Adolescent Abuse, Resource and Evaluation Center (UCDMC CAARE Center).

In July 2000, the Governor's Office of Criminal Justice Planning awarded grants to 13 child abuse treatment agencies located throughout the state of California. Funds for each of these training grants will be made available on October $1^{\text {st }}, 2000$. As part of the contract between the child abuse treatment agencies and OCJP, funds will be provided to the UCDMC CAARE Center for conducting training with each of these agencies. Each child abuse treatment agency (i.e., OCJP grantee) will compensate UCDMC CAARE Center (i.e., University of California Regents) $\$ 27,600$ for training related to PCIT.

Described below are the definitions, and activities/functions for both UCDMC CAARE Center and the child abuse treatment agency/OCJP Grantee.

\section{Definitions}

UCDMC CAARE Center: University of California Davis Medical Center, Child and Adolescent Abuse, Resource and Evaluation Center.

PCIT: Parent-Child Interaction Therapy. This is a dyadic treatment/intervention for families at risk for child maltreatment.

OCJP: The Governor's Office of Criminal Justice Planning.

OCJP Treatment Agency: There are 13 existing institutions/agencies which have been awarded a grant by OCJP to receive PCIT training. Training for each of these 13 agencies/institutions will be provided by the UCDMC CAARE Center.

TOT: Training of Trainers. These are individuals selected to participate in the fundamental training of PCIT, then to develop a skill/ability in training other agency staff in PCIT.

\section{To be completed/performed by UCDMC/CAARE Center:}

1. Phase One - Program Development (site visit, telephone, mail, e-mail, fax) Develop initial contact, distribute, review, and consultation on training plan and curriculum. Identify OCJP Treatment Agency 'point person'. Determine number of people to be present at PCIT Fundamentals training. Collaborate with agency administration and trainees in developing training and agency treatment/training objectives. Conduct a technical assistance meeting to provide information about training overview, basic training, advanced training, development of 
clinical PCIT supervisors. Conduct initial assessment of PCIT trainers. Identify and develop screening and referral procedures. Identify TOT staff. Develop client intake inclusion/exclusion criteria. Review and consultation of facility and video/room equipment acquisition and installation. Identify and develop screening, referral, assessment, and confidentiality procedures. Provide technical assistance regarding the purchase of PCIT compatible audiovisual recording equipment. Provide technical assistance regarding one-way mirror purchase and installation. Provide technical assistance regarding toy and furniture acquisition.

2. Phase Two - PCIT Fundamentals (site visit/regional - two days) Conduct PCIT training of CDI Concepts, including: Provide description of theoretical aspects of PCIT and the relationship between PCIT and interventions for high-risk families, DPICS coding, teach basic PCIT-CDI coaching techniques, and initiate/supervise role-plays of parent-child interactions. Work to bring staff to a level of CDI Mastery in CDI skills. Provide comprehensive information regarding use of standardized assessment measures (e.g., Eyberg Child Behavior Inventory, Child Behavior Checklist). Conduct written and videotaped pre-training assessments of basic PCIT knowledge, coding, and CDI coaching to TOT and other staff; provide feedback to agency/staff regarding these assessments.

3. Phase Three - PCIT Intensive Skill-Building (UCDMC Donner Site or agency/regional site two days) Conduct PCIT coaching training. Enhance trainees CDI skills, provide extensive description and training on PDI, teach PDI coaching training. Observation, coaching, and practice of all PCIT coaching skills. Continued training in use and interpretation of PCIT client assessment measures. Work with selected staff to maintain CDI Mastery Skills and acquire PDI Mastery Skills. Conduct written and videotaped training assessments of PDI/PCIT knowledge, and PDI coaching to TOT and other staff; provide feedback to agency/staff regarding these assessments.

4. Phase Four - Advanced TOT Training (site visit, telephone, videotape, or UCDMC Donner Site - two days) Continued advanced training in PCIT service delivery. Teach identified TOT staff all PCIT coaching theoretical concepts, skills, exercises, and procedures. Provide supervision to staff regarding specific cases in PCIT assessment and/or PCIT treatment. Provide live coaching of TOT staff and clients. Conduct written and videotaped training assessments of Advanced PCIT knowledge and coaching to TOT and other staff; provide feedback to agency/staff regarding these assessments. Work with TOT personnel to successfully achieve PCIT Mastery skills before progressing on to Phase Five.

5. Phase Five - PCIT Consultation/Supervision/Training (OCJP Treatment Agency/UCDMC Donner site/Regional Agency - two-three days) Review of intake procedures, screening and assessment procedures, treatment planning, coding procedures, baseline, mid-treatment, post, and follow-up procedures. Provide opportunity for observation, role-play, live PCIT treatment observation/supervision and feedback. Provide opportunity for clinical consultation on difficult cases, changing program needs, management of procedures related to PCIT. Provide guidance and information regarding the selection of trainees. Teach skills related to teaching and supervising basic level PCIT therapists. Conduct advanced observation, coaching, and practice of all PCIT coaching and supervision skills. Provide information regarding all assessment procedures to be used to assessing PCIT therapist progress (i.e., performance-based training 
assessments). Work with selected TOT staff to maintain CDI/PDI Mastery Skills, and acquire PCIT Training Mastery Skills. Conduct written and videotaped training assessments of PCIT consultation/supervision knowledge related to training other agency staff in PCIT skills; provide feedback to agency/staff regarding these assessments.

6. PCIT Quality Assurance (Type and amount of training to be dependent on OCJP Treatment Agency needs. It is expected that QA will be conducted throughout the course of the training) Review of all PCIT procedures, therapist and TOT staff skill, and use of outcome measurements/procedures. Participate in a review of all PCIT case records in conjunction with agency staff.

7. Quarterly TOT Training (To meet quarterly at UCDMC or at a Regional Agency) Meet with all agency TOT training staff and continue advanced skill-building and development of PCIT training skills. Provide opportunity for observation, role play, live PCIT treatment observation/supervision and feedback. Provide opportunity for clinical consultation on difficult cases, changing program needs, management of procedures related to PCIT. Work with selected TOT staff to maintain CDI/PDI/Training Mastery Skills.

8. PCIT Final All-Project Conference Convene an all-project meeting concurrently with Second Annual PCIT conference in Sacramento, Spring/Summer 2001. Project meeting will provide advanced consultation with national experts. Conference will provide information for individuals at both the basic and advanced level, provide current clinical research related to PCIT, and provide information describing current best practices.

\section{To be completed/performed by OCJP Treatment Agency:}

1. Phase One - Program Development (site visit, telephone, mail, e-mail, fax) Contact with UCDMC/CAARE Center staff. Provide information regarding current program (i.e., facilities, population, staff experience, mission, procedures, and staff capabilities). Identify OCJP Treatment Agency 'point person'. Provide information regarding the number of people to be present at PCIT Fundamentals training. Collaborate in developing treatment/training objectives. Collaborate with UCDMC/CAARE Center staff to acquire information about training overview, basic training, advanced training, development of clinical PCIT supervisors. Provide information about existing and planned screening and referral procedures. Collaborate with UCDMC/CAARE Center staff in developing confidentiality procedures. Identify TOT staff. Collaborate in developing client intake inclusion/exclusion criteria. Provide information regarding an initial assessment of TOT and other staff to be trained in PCIT. Distribute training material to TOT staff and other staff to be trained in PCIT; insure that all training material is read before the start of Phase Two.

Collaborate with UCDMC/CAARE Center staff regarding the purchase of PCIT compatible audiovisual recording equipment. Provide information to aid technical assistance regarding oneway mirror purchase and installation. Provide information to aid technical assistance regarding toy and furniture acquisition. Purchase and install PCIT compatible audiovisual recording equipment. Purchase and install PCIT compatible one-way mirror. Purchase PCIT-specific toys and furniture. Insure that PCIT treatment room, observation room, and all audiovideo equipment is installed and operational. 
2. Phase Two - PCIT Fundamentals (site visit/regional - two days) Provide space and staff for PCIT training of CDI Concepts, DPICS coding. Participate in two-day training related to CDI Concepts, including: theoretical aspects of PCIT and the relationship between PCIT and interventions for high-risk families, DPICS coding, and basic PCIT-CDI coaching techniques. Participate in supervised role-plays of parent-child interactions to achieve a level of CDI Mastery in CDI skills. Participate in training related to the use of standardized assessment measures (e.g., Eyberg Child Behavior Inventory, Child Behavior Checklist). Participate in written and videotaped pre-training assessments of basic PCIT knowledge, coding, and CDI coaching.

3. Phase Three - PCIT Intensive Skill-Building (UCDMC Donner Site or agency/regional site two days) Send selected TOT staff to UCDMC Donner Site (or agency/regional site) for Intensive Skill Building training. Selected TOT staff to participate in PCIT coaching training, acquire additional CDI coaching skills, participate in training on PDI concepts and acquire basic PDI coaching skills. Selected TOT staff to participate in observation, coaching, and practice of all PCIT coaching skills. Selected TOT staff to acquire comprehensive understanding of the administration, scoring, and interpretation of all PCIT client assessment outcomes. Selected staff to maintain CDI Mastery Skills and acquire PDI Mastery Skills. Participate in written and videotaped training assessments of PDI/PCIT knowledge and PDI coaching.

4. Phase Four - Advanced TOT Training (site visit, telephone, videotape, or UCDMC Donner Site - two days) Selected TOT staff to participate in advanced training in PCIT service delivery. Participate in continued advanced training in PCIT service delivery. Identified TOT staff will participate in training related to all PCIT coaching theoretical concepts, skills, exercises, and procedures. Selected TOT staff will maintain CDI/PDI Mastery Skills, and acquire PCIT Training Mastery Skills. Participate in supervision to staff regarding specific cases in PCIT assessment and/or PCIT treatment. Participate in live coaching with clients. Participate in written and videotaped training assessments of Advanced PCIT knowledge and skills. TOT personnel will successfully achieve PCIT Mastery skills before progressing on to Phase Five.

\section{Phase Five - PCIT Consultation/Supervision/Training (OCJP Treatment Agency/UCDMC} Donner site/Regional Agency - two-three days) Provide information for review of intake procedures, screening and assessment processes treatment planning, coding procedures, baseline, mid-treatment, post, and follow-up procedures. Participate in observation, role play, live PCIT treatment observation/supervision. Participate in clinical consultation on difficult cases, changing program needs, management of procedures related to PCIT. Participate in training related to the selection of additional staff/trainees. Participate in acquisition of knowledge and skills related to teaching and supervising basic level PCIT therapists. Participate in advanced observation, coaching, and practice of all PCIT coaching and supervision skills. Work with CAARE Center training staff to maintain CDI/PDI Mastery Skills, and acquire PCIT Training Mastery Skills. Participate in written and videotaped training assessments of PCIT consultation/supervision knowledge related to training other agency staff in PCIT skills. 
6. PCIT Quality Assurance (Type and amount of training to be dependent on OCJP Treatment Agency needs. It is expected that QA will be conducted throughout the course of the training) Participate in a review of all PCIT procedures, therapist and TOT staff skill, and use of outcome measurements/procedures. Participate in a review of all PCIT case records in conjunction with UCDMC/CAARE training staff.

7. Quarterly TOT Training (To meet quarterly at UCDMC or at a Regional Agency) Meet with UCDMC/CAARE Center staff and other OCJP Treatment Agencies. Participate in continued TOT training and advanced skill-building and development of PCIT training skills. Participate in observation, role play, live PCIT treatment observation/supervision. Participate and collaborate in clinical consultation on difficult cases, changing program needs, and management of procedures related to PCIT.

8. PCIT Final All-Project Conference Send TOT staff (and other selected PCIT-trained staff if desired) to Second Annual PCIT conference in Sacramento, Spring/Summer 2001. Conference will provide information for individuals at both the basic and advanced level, provide current clinical research related to PCIT, and provide information describing current best practices. 


\section{Appendix B}

Demographic Information Survey

\section{THANK YOU}

Thank you for agreeing to participate in this project. It is our hope that this assessment will add to your training experience as well as provide valuable information for future trainings. As a first step, we would like to get to know you and your prior experiences better. You can help us do this by completing the following questionnaires. You will notice that this is the only page with your name on it and an accompanying number. On subsequent pages, only a number appears. Some of the information you provide may be sensitive, or something you prefer to remain confidential. Identifying responses by a participant number is our way of ensuring that a number instead of your name is linked to your responses. Individual persons answers will not be identified. Instead, information will be considered from the entire group of training participants (approximately 75-85 people). Hopefully, this will help you to feel free to answer as openly, honestly, and precisely as possible.

The attached questions should take approximately 30 minutes to complete. We appreciate your time and effort!

Name (Please print)

\section{Participant Number}

Please tear this page from the rest of your packet and return it separately. 


\section{Some information about you:}

Your birth date:

$\begin{array}{lll}\text { Ethnicity: } & \text { Month/day/year } & \text { Asian American } \\ & \text { European American } & \text { Hispanic } \\ & \text { Native American } & \text { Other, please specify }\end{array}$

Do you speak a second language? Yes

If yes, please indicate your first language and what second language

Gender: $\quad$ Male $\quad$ Female

\section{Training background:}

What is your highest degree obtained:

At what university did you receive your graduate training?

$$
\text { Name of university }
$$

What graduate program within that university awarded your degree?

Name of program

Was that graduate program accredited by the American Psychological Association? Yes No

Was the graduate program accredited by another accrediting agency (e.g., California $\begin{array}{lll}\text { Psychological Association, APPIC) Yes No } & \text { Ye }\end{array}$

If, yes, which accrediting agency?

How useful was your graduate training in preparing you for working with children and families?

\begin{tabular}{|c|c|c|c|c|}
\hline Not at all useful & Somewhat & & $\begin{array}{c}\text { Extremely } \\
\text { useful }\end{array}$ \\
\hline 1 & 2 & 3 & 4 & 5 \\
\hline
\end{tabular}

(please circle one) 
What was the predominant theoretical orientation of your graduate training? If more than one theoretical orientation was adhered to, please place a " 1 " by the orientation in which you received the most training, a " 2 " by the orientation in which you received slightly less training, and a " 3 "by the orientation in which you received even less training. Please number all orientations that are applicable.

Behavioral
Cognitive/Behavioral
Existential/Humanistic
Family Systems

Interpersonal Psychodynamic/analytic Social Learning

How many hours of supervision would you estimate you have received? (please circle one)

$\begin{array}{ll}500-1000 & 1001-2000 \\ 2001-3000 & 3001-4000 \\ 4001-5000 & 5000+\end{array}$

How many years has it been since you obtained your graduate degree?

How many years have you worked with clinical populations?

How many years have you worked with children who exhibit disruptive behavior disorders?

How many years have you worked with children who have experienced abuse and/or neglect?

How many hours of postgraduate training would you estimate you have received?

Post-doctoral internship/fellowship

Continuing education credits

Have you obtained postgraduate training in any of the following areas? (Please circle all that apply)

Child development

Child maltreatment

Other, please specify
Disruptive behavior disorders

Empirically supported treatments 
In which type(s) of formats have you received postgraduate training? (Please indicate yes or no for each type of training mentioned, as well as the number you have received, and how useful each has been to you)

\begin{tabular}{|c|c|c|c|c|c|c|c|}
\hline & & & How usef & as 1 & training fo & & \\
\hline Have you attended & & How & Not at all & & Somewha & & Extremely \\
\hline $\begin{array}{l}\text { Additional graduate } \\
\text { course(s) }\end{array}$ & $\begin{array}{l}\text { Yes } \\
\text { No }\end{array}$ & & 1 & 2 & 3 & 4 & 5 \\
\hline Workshop - half-day & $\begin{array}{l}\text { Yes } \\
\text { No }\end{array}$ & & 1 & 2 & 3 & 4 & 5 \\
\hline Workshop - full day & $\begin{array}{l}\text { Yes } \\
\text { No }\end{array}$ & & 1 & 2 & 3 & 4 & 5 \\
\hline Presentation & $\begin{array}{l}\text { Yes } \\
\text { No }\end{array}$ & & 1 & 2 & 3 & 4 & 5 \\
\hline $\begin{array}{l}\text { Other, please } \\
\text { specify }\end{array}$ & $\begin{array}{l}\text { Yes } \\
\text { No }\end{array}$ & & 1 & 2 & 3 & 4 & 5 \\
\hline
\end{tabular}

What was the predominant theoretical orientation of your postgraduate training? If more than one theoretical orientation was adhered to, please place a "1" by the orientation in which you received the most training, a " 2 " by the orientation in which you received slightly less training, and a " 3 "by the orientation in which you received even less training. Please number all orientations that are applicable.

Behavioral Cognitive/Behavioral Existential/Humanistic Family Systems
Interpersonal

Psychodynamic/analytic

Social Learning 
For the next two questions, please indicate your top three choices by numbering them in the space provided. $1=$ top choice, $2=$ second choice, $3=$ third, and least preferred choice.

In general, what specific learning techniques have you found to be most useful?

Lectures

Video tapes

Case presentations or descriptions

Role-plays conducted by trainers in which trainees observe and do not participate Role-plays in which trainees participate

In general, what specific learning techniques have you found to be most enjoyable?

Lectures

Video tapes

Case presentations or descriptions

Role-plays conducted by trainers in which trainees observe and do not participate Role-plays in which trainees participate

\section{Professional experiences and interests:}

How many hours per week are you currently engaged in clinical activities (i.e., direct client contact)? hours

What is your predominant professional activity?

Direct patient contact

Teaching (primary/secondary)

Teaching (College/University)

Research

Consulting

Administrative

Other, please specify

What types of interventions do you currently use for treating families with children who are exhibiting disruptive behavior after experiencing abuse and/or neglect?

How useful have these interventions been?

\begin{tabular}{|c|c|c|c|c|}
\hline Not at all useful & Somewhat & & $\begin{array}{c}\text { Extremely } \\
\text { useful }\end{array}$ \\
\hline 1 & 2 & 3 & 4 & 5 \\
\hline
\end{tabular}

(please circle one) 
What is your predominant theoretical orientation? If you use more than one theoretical orientation, please place a " 1 " by the orientation which you most often use, a " 2 " by the orientation you use slightly less, and a " 3 "by the orientation that you use even less often. Please number all orientations that are applicable.

$\begin{array}{ll}\text { Behavioral } & \text { Interpersonal } \\ \text { Cognitive/Behavioral } & \text { Psychodynamic/analytic } \\ \text { Existential/Humanistic } & \text { Social Learning } \\ \text { Family Systems } & -\end{array}$

What percentage of your yearly caseload is:

Infants/Toddlers

Adolescents

Elderly

What percentage of your yearly caseload is:

African American

European American

Native American
Children

Adults
Asian American

Hispanic

Other,

please specify "other"

\section{Ideas about the upcoming training:}

Have you completed any reading regarding PCIT? Yes No

Have you had any previous training in PCIT? Yes No

How useful do you think participating in the PCIT training will be for you? Don't

\begin{tabular}{|c|c|c|c|c|}
\hline not at all useful & & somewhat useful & & know \\
\hline 1 & 2 & 3 & 4 & 5 \\
\hline
\end{tabular}

How much time will you devote to the things you are learning in training? hours 
Experience with Treatment Manuals: (Please circle one response for each of following question)

Have you ever heard of psychotherapy treatment manuals? Yes No

How clear an idea do you have of what a psychotherapy treatment manual is?

Totally unclear Somewhat unclear $\quad$ Reasonably clear $\quad$ Very clear

How much thought have you given to the use of treatment manuals in clinical practice?

$\begin{array}{llll}\text { None at all } & \text { A little bit } & \text { Some } & \text { A fair amount }\end{array}$

How strong are your attitudes/feelings about the role of treatment manuals in clinical practice?

$\begin{array}{llll}\text { Not at all strong } & \text { Somewhat strong } & \text { Strong } & \text { Very strong }\end{array}$

How would you describe your first experience with treatment manuals?

Positive Neutral Negative

How often do you use treatment manuals in your clinical (non-research) work?

Never Rarely $\quad$ Sometimes Often Almost exclusively

How often do you use treatment manuals in your research?

I don't do research Never Rarely Sometimes Often Almost exclusively

How many treatment manuals do you use on a semi-regular basis?

None $\quad 1-2 \quad 3-4 \quad$ More than 4

Have you ever helped create a treatment manual? $\quad$ Yes No

\begin{tabular}{|l|c|c|c|c|}
\hline $\begin{array}{l}\text { How well does each item } \\
\text { characterize a behaviorally } \\
\text { oriented therapy? }\end{array}$ & $\begin{array}{c}\text { Not at all } \\
\text { characteristic }\end{array}$ & $\begin{array}{c}\text { Somewhat } \\
\text { characteristic }\end{array}$ & Characteristic & $\begin{array}{c}\text { Very } \\
\text { characteristic }\end{array}$ \\
\hline 1.Is very practical & 1 & 2 & 3 & 4 \\
\hline $\begin{array}{l}\text { 2. Presents a comprehensive } \\
\text { view of psychopathology }\end{array}$ & 1 & 2 & 3 & 4 \\
\hline 3. Is objective & 1 & 2 & 3 & 4 \\
\hline 4. Tends to be rigid & 1 & 2 & 3 & 4 \\
\hline $\begin{array}{l}\text { 5. Emphasizes individual case } \\
\text { conceptualization }\end{array}$ & 1 & 2 & 3 & 4 \\
\hline 6. Is directive & 1 & 2 & 3 & Very \\
\hline $\begin{array}{l}\text { How well does each item } \\
\text { characterize a behaviorally } \\
\text { oriented therapy? }\end{array}$ & $\begin{array}{c}\text { Not at all } \\
\text { characteristic }\end{array}$ & $\begin{array}{c}\text { Somewhat } \\
\text { characteristic }\end{array}$ & Characteristic & \\
\hline
\end{tabular}




\begin{tabular}{|l|c|c|c|c|}
\hline $\begin{array}{l}\text { 7. Emphasizes the importance of } \\
\text { the therapeutic relationship }\end{array}$ & 1 & 2 & 3 & 4 \\
\hline 8. Is impersonal & 1 & 2 & 3 & 4 \\
\hline $\begin{array}{l}\text { 9. Provides a "cookbook" } \\
\text { approach of therapeutic } \\
\text { techniques }\end{array}$ & 1 & 2 & 3 & 4 \\
\hline 10. Is scientific & 1 & 2 & 3 & 4 \\
\hline $\begin{array}{l}\text { 11. Overly simplifies complex } \\
\text { processes }\end{array}$ & 1 & 2 & 3 & 4 \\
\hline
\end{tabular}

\section{Additional comments:}

What additional information might help us better understand your previous experiences and training background? 


\section{Appendix C}

Attitudes Towards Treatment Manuals

\begin{tabular}{|c|c|c|c|c|c|}
\hline \multirow[t]{2}{*}{ Item } & \multicolumn{5}{|c|}{ Please circle one response for each item } \\
\hline & $\begin{array}{l}\text { Strongly } \\
\text { disagree }\end{array}$ & Disagree & Neutral & Agree & $\begin{array}{l}\text { Strongly } \\
\text { agree }\end{array}$ \\
\hline $\begin{array}{l}\text { 1. Manuals make therapists more like } \\
\text { technicians than caring human beings. }\end{array}$ & 1 & 2 & 3 & 4 & 5 \\
\hline $\begin{array}{l}\text { 2. Manuals force individual clients into } \\
\text { arbitrary categories. }\end{array}$ & 1 & 2 & 3 & 4 & 5 \\
\hline $\begin{array}{l}\text { 3. Using a treatment manual makes a } \\
\text { therapist think more about sticking to } \\
\text { the manual than the needs of the } \\
\text { individual client. }\end{array}$ & 1 & 2 & 3 & 4 & 5 \\
\hline $\begin{array}{l}\text { 4. Using a treatment manual keeps } \\
\text { therapists from using his or her intuition } \\
\text { in responding to a client. }\end{array}$ & 1 & 2 & 3 & 4 & 5 \\
\hline $\begin{array}{l}\text { 5. Treatment manuals ignore the unique } \\
\text { contributions of individual therapists. }\end{array}$ & 1 & 2 & 3 & 4 & 5 \\
\hline $\begin{array}{l}\text { 6. Using treatment manuals detracts } \\
\text { from the authenticity of the therapeutic } \\
\text { interaction. }\end{array}$ & 1 & 2 & 3 & 4 & 5 \\
\hline $\begin{array}{l}\text { 7. Using a clinical treatment manual } \\
\text { undermines creativity and artistry. }\end{array}$ & 1 & 2 & 3 & 4 & 5 \\
\hline $\begin{array}{l}\text { 8. Treatment manuals are appropriate } \\
\text { for research clients but not "real-world" } \\
\text { clients. }\end{array}$ & 1 & 2 & 3 & 4 & 5 \\
\hline $\begin{array}{l}\text { 9. Treatment manuals over-emphasize } \\
\text { therapeutic techniques. }\end{array}$ & 1 & 2 & 3 & 4 & 5 \\
\hline $\begin{array}{l}\text { 10. Manuals force a therapist to } \\
\text { conform to one theoretical orientation. }\end{array}$ & 1 & 2 & 3 & 4 & 5 \\
\hline $\begin{array}{l}\text { 11. Treatment manuals help clinicians } \\
\text { to utilize only interventions which have } \\
\text { been demonstrated to be effective. }\end{array}$ & 1 & 2 & 3 & 4 & 5 \\
\hline $\begin{array}{l}\text { 12. Following a treatment manual will } \\
\text { enhance therapeutic outcomes by }\end{array}$ & 1 & 2 & 3 & 4 & 5 \\
\hline
\end{tabular}




\begin{tabular}{|c|c|c|c|c|c|}
\hline $\begin{array}{l}\text { insuring that the treatment being used is } \\
\text { supported by research. }\end{array}$ & & & & & \\
\hline $\begin{array}{l}\text { 13. Treatment manuals, if used } \\
\text { appropriately, will enhance the average } \\
\text { outcomes of clients treated in } \\
\text { psychotherapy. }\end{array}$ & 1 & 2 & 3 & 4 & 5 \\
\hline $\begin{array}{l}\text { 14. Treatment manuals can help keep } \\
\text { therapists on track during therapy. }\end{array}$ & 1 & 2 & 3 & 4 & 5 \\
\hline $\begin{array}{l}\text { 15. If a treatment has shown } \\
\text { scientifically to be effective, then the } \\
\text { therapist is ethically obligated to use } \\
\text { that treatment as opposed to one that } \\
\text { has not been studied. }\end{array}$ & 1 & 2 & 3 & 4 & 5 \\
\hline $\begin{array}{l}\text { 16. Using a treatment manual helps a } \\
\text { therapist to evaluate and improve his or } \\
\text { her clinical skills. }\end{array}$ & 1 & 2 & 3 & 4 & 5 \\
\hline $\begin{array}{l}\text { 17. The field of psychotherapy will } \\
\text { eventually move towards almost } \\
\text { exclusively manual-based practice. }\end{array}$ & 1 & 2 & 3 & 4 & 5 \\
\hline
\end{tabular}




\section{Appendix D}

Sample Scoring of CDI Skill Acquisition

\begin{tabular}{|c|c|c|c|c|}
\hline Skill & $\begin{array}{l}\text { Mastery } \\
\text { Criteria }\end{array}$ & $\begin{array}{c}\text { Therapist } 1 \\
\text { (score on DPICS) } \\
\text { Points toward } \\
\text { total score }\end{array}$ & $\begin{array}{l}\text { Therapist } 2 \\
\text { (score on DPICS) } \\
\text { Points toward } \\
\text { total score }\end{array}$ & $\begin{array}{c}\text { Therapist } 3 \\
\text { (score on DPICS) } \\
\text { Points toward } \\
\text { total score }\end{array}$ \\
\hline $\begin{array}{l}\text { Descriptions } \\
\text { and Reflections }\end{array}$ & $25-50$ & (28) 1 & (12) 0 & (26) 1 \\
\hline Reflections & $\begin{array}{l}1 / 2 \text { of child's } \\
\text { verbalizations }\end{array}$ & $(3 / 4) 1$ & $(1 / 4) 0$ & $(1 / 2) 1$ \\
\hline $\begin{array}{l}\text { Praise } \\
\text { (Unlabeled and } \\
\text { Labeled) }\end{array}$ & 15 & (6) 0 & (15) 1 & (18) 1 \\
\hline Labeled praise & 8 & (7) 0 & (1) 0 & (10) 1 \\
\hline \multicolumn{5}{|c|}{ No more that three of the following: } \\
\hline Commands & 0 & (0) 1 & (8) 0 & (0) 1 \\
\hline Questions & 0 & (3) 1 & (3) 0 & (0) 1 \\
\hline Criticism & 0 & (0) 1 & (0) 1 & (0) 1 \\
\hline Total Score & & 5 & 2 & 7 \\
\hline
\end{tabular}




\section{Appendix E}

Dyadic Parent-Child Interaction Coding System (DPICS) Abbreviated Definitions

Descriptive statement: A declarative statement or phrase that gives an account of the objects or people in the situation or the activity occurring during the interaction (e.g., You're building a pickup truck, You're sitting quietly)

Reflective statement: A declarative phrase or statement that immediately repeats the child's verbalization. The reflection may be exactly the same words the child said, may contain synonymous words, or may contain some elaboration on the child's statement, but the basic content must be the same as the child's message (e.g., CHILD: I made a big square. PARENT: You made a big square inside this big circle).

Unlabeled praise: A nonspecific verbalization that expresses a favorable judgment of an activity, product, or attribute of the child (e.g..,. Great, Nice, Good work, Perfect!).

Labeled praise: Any specific verbalization that expresses a favorable judgment of an activity, product, or attribute of the child (e.g., That's a terrific house you made; You have a beautiful smile).

Question: A descriptive or reflective comment expressed in question form. Some questions are differentiated from statements by voice inflection (e.g., That's the baby?)

Critical statement: A verbalization that finds fault with the activities, products, or attributes of the child (e.g., You're being naughty; That's a sloppy picture).

Direct command: A clearly stated order, demand, or direction in declarative form. The statement must be sufficiently specific as to indicate the behavior that is expected from the child (e.g., Put you hands in your lap; Please put that block here).

Indirect command: An order, demand, or direction for a behavioral response that is implied, nonspecific, or stated in question form (e.g., Put it here, OK?; Johnny!: Let's take out the red blocks).

Note. These definitions were taken directly from Hembree-Kigin \& McNeil (1995), pp. 149-150. 


\section{Appendix F}

Confederate Procedures and Situations

\section{PROCEDURES}

The confederate will interact with each participant for 5 minutes, 30 seconds. During each minute the confederate will engage in specified behaviors so that ample opportunity is provided for participants to demonstrate each skill. This also will ensure a degree of equality across roleplays. The order of situations will be randomized. Order and time will be prompted by an observer via a bug-in-the-ear device.

\begin{tabular}{|c|l|l|}
\hline Situation & Confederate Action & Therapist Skill to be elicited \\
\hline $\begin{array}{c}\text { Warm-up } \\
(30 \text { sec. })\end{array}$ & engage in all appropriate behaviors & $\begin{array}{l}\text { Allow participant to adjust to role- } \\
\text { play situation }\end{array}$ \\
\hline $\begin{array}{c}1 \\
(1 \mathrm{~min})\end{array}$ & $\begin{array}{l}\text { verbalization should be frequent and } \\
\text { allow sufficient time in between for } \\
\text { participant to respond }\end{array}$ & Reflection \\
\hline $\begin{array}{c}2 \\
(1 \mathrm{~min})\end{array}$ & $\begin{array}{l}\text { engage in lower level misbehavior. A } \\
\text { misbehavior that clearly could be } \\
\text { considered annoying and/or obnoxious } \\
(\text { e.g., whining, bossiness, refusing to } \\
\text { share })\end{array}$ & Active Ignoring \\
\hline $\begin{array}{c}\text { (1 min }) \\
\text { Verbalizations should be few while } \\
\text { confederate appropriately plays with a } \\
\text { toy }\end{array}$ & $\begin{array}{l}\text { Engage in exceptionally polite and } \\
\text { appropriate behaviors above what one } \\
\text { might expect of a child (e.g., sharing } \\
\text { valuable toys, labeled praising parent })\end{array}$ & Description \\
\hline $\begin{array}{c}\text { (1 min } \\
(1 \mathrm{~min})\end{array}$ & $\begin{array}{l}\text { Make some errors (e.g., mislabel colors, } \\
\text { unsuccessfully attempt academic tasks })\end{array}$ & Avoid criticism \\
\hline
\end{tabular}

\section{INSTRUCTIONS TO BE PROVIDED TO THERAPISTS}

"In this situation tell Eric that he may play whatever he chooses. Let him choose any activity he wishes. You just follow his lead and play along with him as if he were a child." 
Appendix G

Procedures and Instructions for Coding Coaching Statements

\section{PROCEDURES}

1. Set up videotape and audiotape for participant

2. Provide instructions to participants as detailed below - reading verbatim the instructions.

3. For each video, the taped interaction will be interrupted for a few seconds by a blank screen after the 30 second warm-up period. This will serve as a consistent cue to participants to begin coaching once the tape resumes.

4. Leave the room once therapist has begun coaching.

5. Return in five minutes, thank the therapist, and label the audiotape.

\section{INSTRUCTIONS TO BE PROVIDED TO THERAPISTS}

"In this situation, you will view a videotape of an adult (Amy Herschell) using CDI skills with a child. Amy will do some things that are right and some things that are wrong. Your job is to coach her in the correct use of the CDI skills just as you would a mother with her son. As the tape begins, you'll have 30 seconds to observe Amy's interaction with the child on the tape. After that time is over, the screen will go blank for a few seconds. Once the tape resumes, I'll let you know that you can begin coaching. Please try to speak clearly and loudly into the microphone. Once you begin coaching, I will leave the room and return in five minutes. If you need anything during that time or if the equipment doesn't seem to be working, I'll be (inform therapist of where you will be.) Do you have any questions?"

\section{INSTRUCTIONS FOR CODING SCORING}

Definitions of target behaviors (praise, refection, imitations, description, commands, questions, and criticisms) are consistent with DPICS (Eyberg \& Robinson, 1983). Also consistent with DPICS is that each unit of verbal should be coded using the "one-sentence" rule.

Each potential coaching statement will receive a score of -1 to +3 as follows:

\section{Score of -1 for the following:}

The coach directed a critical statement at the parent. A critical statement is defined as any verbalization that finds fault with the activities, products, attributes, or verbalizations of a parent. Examples

"You aren't praising him enough."

"That was the wrong thing to say to him."

"You shouldn't be playing with the blocks while he is playing with the play-doh."

The coach directed the parent to do something in the avoid category of CDI skills including questioning, commanding, or criticizing the child.

Examples

"Ask Josh to give you some playdoh." (Directing the parent to question)

"Tell Josh to put the crayons in the box." (Directing the parent to command) 
"He just said the blue block was red. Tell him that's wrong." (Directing the parent to criticize)

OR The coach praises the parent for an inappropriate behavior.

Examples

"Great question" (After the parent asks the child a question.)

"Nice command" (After the parent gives the child an indirect command.)

OR The coach points out the parent's errors

"That was another question."

"You keep giving commands - try to avoid those."

\section{Score of 0 for the following:}

There was a clear opportunity to coach, and the therapist made no attempt to provide feedback to the parent. In other words, parent provided a verbalization and the therapist did not make an attempt to respond within 3 seconds of the end of the parent's verbalization.

Also scored as a 0 are acknowledgments as specified in the DPICS (e.g., yes, yeah, um-hum, okay) and incomplete sentences.

\section{Score of 1 for the following:}

Therapist labeled parent behavior. No attempts at elaboration were made. Credit should not be given if therapist incorrectly labeled the parent's behavior (e.g., therapist - "Nice labeled praise" after parent provided a description as specified in the DPICS).

Examples

"Nice description." (After parent describes child's behavior)

"That was a reflection." (After parent reflects child's verbalization)

"Good labeled praise." (After parent labeled praises child's behavior)

OR Therapist tells parent exactly what to do.

Examples

"Tell Joshua, I like it when you share."

"Tell him - your playdoh is really squishy."

OR Therapist gives the parent a suggestion.

"I wonder if you could tell Johnny that you are really enjoying this time with him."

"You might want to praise him for sitting."

OR Therapist describes the situation

"Looks like those toys are going to be tough to clean up."

"The play doh container is at the edge of the table." 


\section{Score of 2 for the following:}

Therapist correctly labeled the parent behavior and mentioned a rationale associated with the skill.

Examples

"Great labeled praise. Because you praised that specific behavior, you'll see it more often"

"Nice description. You're really allowing him to stay in the lead."

OR Therapist attempts to generalize child's positive behavior to a different environment.

Examples

"Go ahead and say - Other kids will really like it when you share like that."

"Wow. He was really polite there. You might want to tell him how other adults will really appreciate it when he uses such good manners."

OR Therapist comments on the child's behavior.

"He's playing really calmly."

"Wow - he's been playing with the same toy for a long time."

\section{Score of 3 for the following:}

Therapist provided feedback to parent that involved the interaction between the parent and child. Examples

"I noticed that when you are really polite with him, he is also really polite with you."

"You can see how he really wants to please you. He draws part of the picture and immediately looks to you for your approval."

OR Therapist provides feedback that comments on a qualitative aspect of parent behavior or a positive parent behavior not included in the CDI skills.

Examples

"I really like the way you are leaning in towards him. That really helps to make this special time warm and positive."

"Your voice tone is really warm. He can tell how much you care and that you mean what you say by the tone of your voice."

OR Therapist provides information on how the playtime affects the parent-child relationship. Examples

"I noticed that you really seem to enjoy this time with Josh. Seems like it is really improving the quality of your relationship."

"He seems to be responding to you very positively. I think his attitude toward you and your relationship is changing." 
Appendix $\mathrm{H}$

\section{KNOWLEDGE OF BEHAVIORAL PRINCIPLES AS APPLIED TO CHILDREN}

\section{FORM A}

\section{Directions}

Please read each question and each of its four possible answers. Sometimes more than one answer could be correct under certain circumstances; however, you should select the best answer or the answer that is most generally true. Completely circle the letter beside the answer.

\section{Example:}

Probably the most important influence in a young child's life is his
a. toys.
b. television.
c. parents.
d. friends.

\section{Please do not consult others while deciding how to answer the question. Be sure to answer every question even if you must guess.}

1. Desirable and undesirable behavior are most alike in that they are
a. the result of emotions and feelings.
b. habits and therefore difficult to change.
c. ways the child expresses himself.
d. the result of learning.

2. Most problem behavior in young children is probably
a. a reaction to deeper emotional problems.
b. due to lack of communication in the home.
c. accidentally taught by the child's family.
d. due to a stage which the child will outgrow.

3. Which of the following is most important for parents in controlling their child's behavior?
a. the rules the parents make about behavior.
b. the parents' understanding of the child's feelings.
c. the behaviors to which the parents attend.
d. being strict, but also warm and gentle. 
4. Which of the following is the least likely way for children to react to the person who punishes them?
a. the child will try to avoid the punisher.
b. the child will have admiration and respect for the punisher.
c. the child may copy the punishers methods and do similar things to playmates.
d. the child will associate punishment with the punisher.

5. If you are trying to teach a child to talk, you should first:
a. reward the child after speaking a sentence.
b. Reward the child for saying a word.
c. Reward the child for any vocalization.
d. Punish the child if he does not speak.

6. A child has been rewarded each time he cleans his room. In order to keep the room clean without having to use a reward, the next step should probably be to:
a. Have a talk about how pleased you are and then stop giving the reward.
b. Give the reward about one out of five times.
c. Give the reward almost every time.
d. You must always reward it every time.

7. When should a child who is just learning to dress himself be praised the first time?
a. When he gets his foot through the first hole in his underware.
b. When he gets his underware completely on.
c. When he asks to do it himself.
d. When he has completely dressed himself.

8. Three of the following responses refer to terms of punishment which are mild and effective. Which one is not?
a. Ignoring the undesirable behavior.
b. Sending the child to a dull room for a few minutes.
c. Taking away something the child likes (such as dessert after supper).
d. Scolding.

9. Which of the following is the most effective form of punishment in the long run for reducing a child's undesirable behavior?
a. Scolding him every time he does it.
b. Occasionally spanking him when he does it.
c. Sending him to his room for five minutes every time he does it.
d. Sending him to his room all afternoon every time he does it. 
10. A good rule to remember is:
a. Do not reward with money if possible.
b. Catch a child doing something right.
c. Reward good behavior and always punish bad behavior.
d. Punishment is always unnecessary.

11. Which of the following is true about punishment?
a. Punishment teaches respect.
b. Punishment should be delayed until it can be carefully determined that it is really necessary.
c. Punishment can teach a child new behaviors.
d. Some punishments can result in a child becoming aggressive.

12. A boy loves football. What is most likely to happen if, each time he is playing nicely with his sister, his father invites him to play football?
a. He will always be asking his father to play football.
b. He will play nicely with his sister more often.
c. He will be annoyed with his father for interfering with his activities.
d. He will be encouraged to teach his sister to play football.

13. A father is teaching his son to hit a thrown ball with a bat. Which of the following methods will probably most help his son to learn to hit?
a. Let him try to hit the ball without saying anything, so the child can learn on his own.
b. Occasionally tell him what he is doing wrong.
c. Occasionally tell him what he is doing right.
d. Tell him almost every time he does something right.

14. Punishment, as a way to get rid of undesirable behavior, is best used when:
a. You are very upset.
b. You want to teach the child the right way to behave.
c. The behavior may be dangerous
d. Scolding does not seem to be effective.

15. If you want your child to develop proper study habits, you should:
a. Encourage him to do his homework.
b. Help him to see school as pleasant.
c. Reward him whenever he studies.
d. Give him good reasons why he will need school. 
16. A child often cries over any small matter that bothers her. How should her parents react to best reduce her crying.

a. Reward when she reacts without crying.

b. Use a mild punishment when she cries.

c. Try to find out what is really troubling the child and deal with that.

d. Provide her with something interesting so she will stop crying.

17. If you want your child to say "please" and "thank you" at the table, it probably is most important to:

a. Reprimand him when he forgets to say them.

b. Explain why good manners are important.

c. Remember to compliment him when he remembers to say them.

d. Praise other members of the family when they use these words.

18. A major problem has been getting Leon to bed in the evening. His mother has decided to change this and wants to measure relevant behaviors. Which is the best way for her to do this?

a. Each evening record whether or not he goes to bed on time.

b. Chart his behavior all day long, up to and including bedtime to try to find out what causes his not wanting to go to bed.

c. Each week, make a note of how easy or difficult it has been to get him to bed.

d. Ask Leon to keep his own record each week.

19. A father tells a child she cannot go to the store with him because she didn't clean her room like she promised. She reacts by shouting, crying, and promising she will clean the room when she gets home. What should the father do?

a. Ignore her and go to the store.

b. Take her to the store but make her clean her room when they return.

c. Calm her down and go help her clean her room together.

d. Talk to her and find out why she doesn't take responsibility.

20. In changing a behavior it is most important to use:

a. Methods which have been tested by others.

b. Consequences which are rewarding to the child.

c. Consequences which are punitive to the child.

d. Rewards which do not bribe the child.

21. Stan is doing a number of things that greatly disturb his parents. It would be best for them to:

a. Try to quickly eliminate all of these undesirable behaviors at once.

b. Select just a few behaviors to deal with at first.

c. Select the single behavior they find the most disruptive and concentrate on changing that.

d. Wait for 28 to 30 days before beginning to try to change his behaviors to make sure they are stable and persistent. 
22. Listed below are four methods to change behavior. Which is usually the best technique to get Frank to stop sucking his thumb?
a. Punish the undesired behavior.
b. Ignore the behavior.
c. Reward him for desirable behavior in the situation in which he usually misbehaves.
d. Explain to the child why the behavior is undesirable.

23. If you want to make a behavior a long-lasting habit, you should:
a. Reward it every time.
b. First reward it every time and then reward it occasionally.
c. Promise something the child wants very much.
d. Give several reasons why it is important and remind the child of the reasons often.

24. The most likely reason a child misbehaves is because:
a. He is expressing angry feelings which he often holds inside.
b. He has learned to misbehave.
c. He was born with a tendency to misbehave.
d. He has not been properly told that his behavior is wrong.

25. A baby often screams for several minutes and gets his parent's attention. Which of the following is probably the best way for his parents to reduce the screaming?
a. If there is nothing physically wrong with the child, ignore his screaming even though the first few times he screams even louder.
b. Distract the child with something he finds interesting whenever he screams.
c. Ignore all the noises and sounds the child makes.
d. None of the above. Babies usually have good reasons for screaming.

\section{KEY - FORM A}

$\begin{array}{lllll}\text { 1. } \mathrm{D} & \text { 6. } \mathrm{C} & 11 . \mathrm{D} & 16 . \mathrm{A} & 21 . \mathrm{C} \\ \text { 2. C } & \text { 7. } \mathrm{A} & 12 . \mathrm{B} & 17 . \mathrm{C} & 22 . \mathrm{C} \\ \text { 3. C } & \text { 8. } \mathrm{D} & 13 . \mathrm{D} & 18 . \mathrm{A} & 23 . \mathrm{B} \\ \text { 4. } \mathrm{B} & 9 . \mathrm{C} & 14 . \mathrm{C} & 19 . \mathrm{A} & 24 . \mathrm{B} \\ \text { 5. C } & 10 . \mathrm{B} & 15 . \mathrm{C} & 20 . \mathrm{B} & 25 . \mathrm{A}\end{array}$




\section{KNOWLEDGE OF BEHAVIORAL PRINCIPLES AS APPLIED TO CHILDREN}

\section{FORM B}

\section{Directions}

Please read each question and each of its four possible answers. Sometimes more than one answer could be correct under certain circumstances; however, you should select the best answer or the answer that is most generally true. Completely circle the letter beside the answer.

\section{Example:}

Probably the most important influence in a young child's life is his
a. toys.
b. television.
c. parents.
d. friends.

\section{Please do not consult others while deciding how to answer the question. Be sure to answer every question even if you must guess.}

1. Probably the most important idea to keep in mind when first changing behavior is
a. to use both reward and punishment.
b. to reward every time the desired behavior occurs.
c .to be flexible about whether or not you reward.
d. to be sure the child understands why you want the behavior to change.

2. A child begins to whine and cry when his parents explains why he can't go outside. How should the parent react?
a. ask the child why going outside is important to him.
b. explain that it is a parent's right to make such decisions.
c. explain again why he should not go outside.
d. ignore the whining and crying.

3. In changing a child's behavior a parent should try to use
a. about one reward for every punishment.
b. about one reward for every five punishments.
c. about five rewards for every punishment.
d. practically all rewards.

4. Which of the following statements is most true?

a. People usually fully understand the reasons for their actions.

b. People are often unaware of the reasons for their actions.

c. People's actions are mostly based on logic.

d. It is necessary to understand the reason for a person's behavior before trying to change the behavior. 
5. If punishment is used for a behavior such as playing football in the house, which one is probably best to use?
a. Make the child do extra homework.
b. Clearly express you disapproval.
c. Remove the child to a boring situation each time.
d. A reasonable spanking.

6. Parents who use lots of rewards for good behavior and few punishments will probably tend to have children who
a. Do not understand discipline.
b. Will not cooperate unless they are "paid."
c. Take advantage of their parents.
d. Are well-behaved and cooperative.

7. Which of the following is most effective in getting a child to do homework?
a. "When you finish your homework, you can watch TV."
b. "You can watch this show on TV if you promise to do your homework when the show is over."
c. "If you don't do your homework tonight, you can't watch TV at all tomorrow."
d. Explain the importance of school work and the dangers of putting things off.

8. Each time Mother starts to read, Billy begins making a lot of noise which prevents her from enjoying her reading time. The best way for Mother to get Billy to be quiet while she reads is to:

a. Severely reprimand him when this occurs.

b. Pay close attention and praise and hug him when he plays quietly while she is reading and ignore his noisy behavior.

c. Call him to her and explain carefully how important it is hor her to have a quiet time for herself each time this occurs.

d. Tell him that he won't get a dessert for dinner if he continues.

9. A young child often whines and cries when he is around his mother. In trying to find out why he cries, his mother should first consider the possibility that:
a. He is trying to tell her something.
b. He needs more of her attention.
c. She is somehow rewarding his crying.
d. She is not giving him enough attention.

10. If a child gradually receives rewards less and less often for a behavior, what is most likely to happen?
a. He will soon stop the behavior.
b. He will be more likely to behave that way foe a long time.
c. He will not trust the person giving the reward.
d. None of the above. 
11. In a reading group, the teacher gives each child candy plus praise for each correct answer. Which of the following statements is most true?
a. The candy is a bribe and doesn't belong in a school setting.
b. At first, children work to earn the candy and may later work for the praise alone.
c. Children shouldn't be "paid" for doing their school work.
d. If probably doesn't make much difference whether or not candy is used because the children who want to learn to read will do so and the others won't.

12. To record, graph, and note the direction of the change of a behavior is:
a. A minor, optional step in a behavior change program.
b. An important step in a behavior change program.
c. A procedure employed only by scientists for research.
d. Time consuming and complicated. Therefore, these procedures should only be used in special cases.

13. Which of the following is most true about physical punishment?
a. It should immediately follow the undesired behavior and at full intensity.
b. It should be mild and immediately follow the undesirable behavior.
c. It should begin in a mild form and if that doesn't work, intensity should be increased.
d. It is ineffective and inappropriate.

14. Which of the following is not an important step in a behavior-change program?
a. Make certain the child feels ashamed for his misbehavior.
b. Decide on a particular behavior that you want to change.
c. If necessary, break the selected behavior into smaller steps.
d. Select a proper time and situation for measuring the behavior.

15. Two brothers fight constantly. Their parents decide to praise them when they play together nicely. However, they still continue to fight. Punishment may be necessary. What is probably happening?
a. They don't want their parents' praise.
b. The benefits of fighting are stronger to them than their parents' praise.
c. They have too much anger toward each other to control.
d. They are at a stage they will grow out of.

16. Mrs. Thomas found out that spanking her seven-year-old son, Bob, did not seem to stop him from using "naughty" words. A friend suggested that rather than spanking him, she should send him to be by himself. The room he is sent to should be:
a. His own room, so he will still have something to do.
b. Small and dark.
c. As uninteresting as possible.
d. A large room. 
17. Which reward is probably best to help a 12 -year-old child improve his arithmetic skills?

a. A dollar for each evening he studies.

b. A dime for each problem he works correctly.

c. Ten dollars for each A he receives on his report card in arithmetic.

d. A bicycle for passing arithmetic for the rest of the year.

18. Mr. Jones agreed to pay his son, Mike, $.25 \notin$ each time he carries out the trash. If Mr. Jones forgets to give him the money for a few days, what is likely to happen?

a. Mike will continue to take out the trash because he realizes how important it is.

b. Mike will stop taking out the trash.

c. Mike will begin to do extra chores, as well as take out the trash so his father will notice how well he's doing and remember to give Mike the money.

d. Mile will start to misbehave to take out his anger about not being paid.

19. The first step to changing a problem behavior is to:

a. Reward the child when he is behaving nicely.

b. Punish the child for misbehavior.

c. Carefully observe the behavior.

d. Seek help from someone who is more objective.

20. Johnny has just torn up a new magazine. Of the following choices, which is the best way for his mother to discipline him?

a. Tell him he will be spanked from his father when he gets home.

b. Punish him then and there.

c. Explain to Johnny about the wrongness of his action.

d. Angrily scold Johnny so that he will learn that such an act is bad and upsetting to his mother.

21. Which would be the best example of an appropriate way to praise Mary?
a. Good girl, Mary.
b. I love you Mary.
c. I like the way you helped me put the dishes away.
d. I'll tell your father how nice you were when he comes home.

22. Jimmy sometimes says obscene words, but only in from of his mother. She has been shocked and makes her feelings clear to him. How should she react when he uses obscene words?

a. Wash his mouth out with soap.

b. Ignore him when he uses obscene words.

c. Tell him how bad he is and how she doesn't like him when he uses those words.

d. Explain to him the reason such words are not used. 
23. Punishment will not be effective unless you:

a. Prevent the child from escaping while you punish him.

b. Throw all of your emotions into the punishment.

c. Follow it with a careful explanation of your reasons for the punishment.

d. Have tried everything else.

24. Which of the following is probably the most important in helping a child behave in desirable ways?
a. To teach him the importance of self-discipline.
b. To help him understand right and wrong.
c. Providing consistent consequences for his behavior.
d. Understanding his moods and feelings as a unique person.

25. How often a behavior occurs is probably mostly controlled by:

a. The person's attitude about his behavior.

b. What happens to him at the same time the behavior occurs.

c. What happens to him just before the behavior occurs.

d. What happens to him just after the behavior occurs.

\section{KEY - FORM B}

1. B

2. D

3. D

4. B

5. $\mathrm{C}$
6. D

7. A

8. B

9. $\mathrm{C}$

10. B
11. B

12. B

13. A

14. A

15. B
16. $\mathrm{C}$

17. B

18. B

19. C

20. B
21. C

22. B

23. A

24. C

25. D 


\section{Appendix I}

CDI \& DPICS Knowledge Questionnaire and Answers - Form A

\section{Knowledge}

1. Please list three reasons why you would praise appropriate behavior.

- Causes the behavior to increase

- Lets the child know what you like

口 Increases self-esteem

- Adds to the warmth of the relationship

- Makes both parent and child feel good

2. Please list three reasons why you would avoid commands during special playtime.

口 Doesn't allow the child to lead

- Can cause unpleasantness

口 Child compliance will be taught later

3. List three things you might mention to a parent regarding the rationale for conducting five minutes of special playtime each day at home.

口 Generalization of skills from home to clinic

- Helps parents practice skills

- Provides child an opportunity to receive positive attention from the parent

4. What do Hembree-Kigin and McNeil (1995) recommend for completion of special playtime homework when parents have more than one child?

- Special playtime should be conducted with siblings if at all possible

- Time should be individual

5. How many days per week are parents asked to conduct "special playtime" with their child?

7

6. During a coaching session, a child begins to whine and say, "That's my toy. You just took it." As a coach, what might your response be?

Ignore and redirect

7. Hembree-Kigin and McNeil (1995) mention five advantages of direct coaching, please list three.

口 Parental errors can be corrected promptly

- Every child presents unique challenges, coaching allows parent to adapt skills to individual needs

- Many parents lack the confidence to use new skills without the initial encouragement and support of therapist 
- Faster learning

- Parents are not always good reporters - therapist can observe the in-session behavior

8. Please list five child behaviors as a coach to which you might instruct the parent to pay particular attention to (i.e., reward or reinforce).

口 Polite manners

- Playing gently with the toys

a Staying seated at the table

口 Talking softly

๑ Helping

a Sharing

Trying

9. Which CDI skill should you coach first?

a Those that are easier

- Description

10. List three categories of qualitative aspects of the parent-child interaction you might want to coach. (Hembree-Kigin and McNeil mention five.)

- Physical closeness and touching

- Contact, facial expressions, and vocal qualities

口 Turn-taking, sharing, and polite manners

- Developmentally sensitive teaching

a Task persistence and frustration tolerance

\section{DPICS Knowledge}

Please code the parent verbalizations in the following parent-child interaction.

11. Child: "May I have the playdoh?."

12. Parent: "That was great asking." (Labeled praise)

13. Parent: I'll hand you the playdoh because you asked so nicely." (Labeled Praise or Description)

Child: "I'm going to make a playdoh snake."

14. Parent "You're going to make a really scary playdoh snake." (Reflection)

15. Parent: "I'm going to make a snake just like you" (Description)

\section{Please provide DPICS definitions for the following terms:}

16. Reflective statement

- A declarative phrase or statement that immediately repeats the child's verbalization.

The reflection may be exactly the same words the child said, may contain synonymous words, or may contain some elaboration on the child's statement, but the basic content must be the same as the child's message. 
17. Critical statement

- A verbalization that finds fault with the activities, products, or attributes of the child.

18. Noncompliance

a Child does not begin obeying a direct or indirect parental command within three-five seconds.

Please provide an example consistent with DPICS definitions for each of the following:

19. Unlabeled praise

口 Great.

口 Nice.

a Good work.

a Perfect.

20. Direct Command

- Put you hands in your lap.

a Please put that block here. 
CDI \& DPICS Knowledge Questionnaire and Answers - Form B

\section{Knowledge}

1 Please list three reasons why you would describe appropriate behavior.

a Allows the child to lead

- Shows child you're interested

- Teaches concepts

a Models speech

a Holds the child's attention

口 Organizes child's thoughts about play

2. Please list three reasons why you would avoid questions during special playtime.

a Leads the conversation instead of following

- Many are commands that require an answer

口 May seem like you aren't listening or disagree with the child

3. Why is labeled praise considered better than unlabeled praise?

a More specific

- Tells the child exactly what is expected

a More likely to increase targeted behavior

4. What are the two steps for strategic attention?

- Identify target behaviors

a Provide attention to targeted behaviors

5. Hembree-Kigin and McNeil (1995) mention six assessment measures as being part of core assessment procedures for PCIT. Please list 4 of these measures

a Semi-structured intake interview

a $\mathrm{CBCL}$

- ECBI

๑ SESBI

a PSI

口 DPICS

6. Please list five parent behaviors as a coach to which you might strategically attend.

a Praise

a Reflection

a Imitation

口 Descriptions

口 Enthusiasm 
7 and 8. Hembree-Kigin and MeNeil make 8 recommendations for coaching ("tips for therapists"). Please list 6 of those recommendations.

a Make coaching brief and precise

- Coach after nearly every parent verbalization

- Give more praise than correction

- Coach easier skills before harder ones

- Use special exercises for difficult skills

a Use observations to highlight effects

a Make use of humor

a Progress from more directive to less directive coaching.

9. During a coaching session, a child turns to his mother and says, "I made a tall tower." As a coach, what might you instruct the parent to say?

व Reflection

- Labeled praise

10. Please list three reasons a parent might not respond to enthusiastic coaching.
a Resistance
口 Depression
- Substance use
- Chronic fatigue

\section{DPICS Knowledge}

Please code the parent verbalizations in the following parent-child interaction.

11. Parent: "Please put the toys away?" (Direct or Indirect command)

Child: "I'm not done drawing yet."

12. Parent: "It's time for us to go home." (Description)

13. Parent: Let's pick up the toys." (Indirect command)

Child: [slowly begins to put toys away.]

14. Parent "Thanks." (Acknowledgment)

15. Parent: "When we get home it will be time for lunch."(Description)

\section{Please provide DPICS definitions for the following terms:}

16. Labeled praise

- Any verbalization that expresses a favorable judgement upon an activity, product, or attribute.

17. Indirect command

- An order, demand, or direction for a behavioral response that is implied, nonspecific, or stated in question form. 
18. Compliance

- Child obeys, begins to obey, or attempts to obey a direct or indirect parental command within three- five seconds.

Please provide an example consistent with DPICS definitions for each of the following:

19. Descriptive statement

口 You're building a pickup truck.

口 You're sitting quietly.

20. Child disruptive behavior

a Gets out of chair

口 Screaming "No!" when asked to do something

a Smacks mother. 
CDI \& DPICS Knowledge Questionnaire and Answers - Form C

\section{Knowledge}

1. Please list three reasons why you would reflect appropriate speech.

a Doesn't control the conversation

- Shows the child you're really listening

- Demonstrates acceptance and understanding of the child

- Improves the child's speech

- Increases verbal communication

2. Please list three reasons why you would avoid criticism during special playtime.

\ Doesn't work to decrease difficult behaviors

- Often increases the criticized behavior

- May lower the child's self-esteem

- Creates an unpleasant interaction

3. What type of toys (not examples of toys) are appropriate for CDI?

a Those that are creative and constructive

- Avoid toys that encourage tough, aggressive play or require limit-setting, and rules

- Avoid toys that discourage conversations or have child pretend they are someone else

4. What is the appropriate age range for PCIT according to Hembree-Kigin \& McNeil (1995)?

a 2-7

5. How many labeled, unlabeled, and combined (labeled + unlabeled) praises are parents required to demonstrate in a 5-minute period before advancing to the second phase of PCIT?

๑ 7 unlabeled, 8 labeled, 15 total

6. Please list five child behaviors as a coach to which you might selectively ignore.

a Bossiness

a Banging toy on the tables

a Leaving seat during play

a Whining

a Yelling

口 Dropping toys on the floor

7. List two reasons why coaching should progress from more directive to less directive.

口 Empower parents

a Parents able to generate own statements 
8. List four specific ways to provide a gentle correction.

口 Oops, a question

口 Sounds a little critical

- Might be better to say....

a Was that a command?

9. If a parent does not respond to coaching, what do Hembree-Kigin and McNeil (1995) recommend?

a A heart-to-heart chat

10. Please fill in the appropriate time that should be allotted for each coaching session involving one parent:

a Check-in and review of homework (10 minutes)

- Recording of CDI skills (5 minutes)

a Coaching of CDI skills (35 minutes)

a Feedback on progress and homework assignment (10 minutes)

\section{DPICS Knowledge}

Please code the parent verbalizations in the following parent-child interaction.

11. Parent: "Let's draw a cloud in the sky." (Indirect command)

Child: "I don't know how to draw clouds."

12. Parent: "You're not trying." (Criticism)

13. Parent: "This time I'll show you how to do it." (Description)

Child: [attempts to draw a cloud]

14. Parent "I knew you could do it." (Unlabeled praise)

15. Parent: "You're a pretty smart kid - aren't ya'." (Unlabeled praise)

\section{Please provide DPICS definitions for the following terms:}

16. Descriptive statement

- A declarative statement or phrase that gives an account of the objects or people in the situation or the activity occurring during the interaction.

17. Question

- A descriptive or reflective comment expressed in question form. Some questions are differentiated from statements by voice inflection.

18. Disruptive behavior

- Any cry (inarticulate utterance of distress), yell (loud screech, scream, shout, or loud crying), whine (words uttered in a slurring, nasal, high-pitched, falsetto voice), smart talk (impudent or disrespectful speech), destructive (destroys, damages, or attempts to damage any object, such as throwing blocks at wall, banging Lincoln Log on table; kicking toy box), or physical negative (bodily attack or attempt to attack the parent; kicking; pulling hair; twisting finger; standing on toe). 
Please provide an example consistent with DPICS definitions for each of the following:

19. Reflective statement

a CHILD: I made a big square.

a PARENT: You made a big square inside this big circle.

20. Critical statement

口 You're being naughty.

口 That's a sloppy picture. 
CDI \& DPICS Knowledge Questionnaire and Answers - Form D

\section{Knowledge}

1. Please list the 5 critical words parents are asked to avoid in CDI.

- No, Don't, Stop, Quit, Not

2. Please list three reasons why you would imitate appropriate behavior.

a Let's the child lead

- Approves of the child's choice of play

a Shoes the child that you are involved

- Teaches the child how to play with others

- Tends to increase the child's imitation of what you do

3. List three reasons why parents are instructed to ignore inappropriate behavior (unless dangerous or destructive).

- Avoids increasing difficult behaviors

- Decreases some behaviors

- Helps child notice difference between your responses to good and bad behavior

4. How many descriptions plus reflections are parents required to demonstrate in a 5-minute period before advancing to the second phase of PCIT?

व $25-50$

5. Stage one of PCIT focuses on_(relationship building/enhancement), whereas stage two of PCIT focuses on (discipline).

6. Please list three parent behaviors as a coach to which you might initially selectively ignore as a first step in trying to change the behaviors.

๑ Commands

๑ Questions

口 Subtle criticisms

7. Name one exercise that could be used to help a parent acquire a particularly difficult skill.

口 "I want to try a little experiment. I want to see how many times in the next minute you can praise Timmy, OK? Are you ready? Begin." During that minute count aloud the number of praises

- Ask parents to reflect all appropriate child verbalizations in a two-minute period

8. List two reasons why a therapist might want to coach after each parent verbalization?

- More opportunities to teach

- More feedback for parent - faster skill acquisition

口 Develop coaching rhythm 
9. If dangerous or destructive play occurs during CDI coaching in the clinic, what is one thing mentioned in Hembree-Kigin \& McNeil (1995) that a coach could instruct the parent to do?

a Wrist restraint

10. Please fill in the appropriate time that should be allotted for each coaching session involving two parents:
a Check-in and review of homework
(10 minutes)
- Recording of first parent's CDI skills
(5 minutes)
a Coaching of first parent's CDI skills
(15 minutes)
- Recording of second parent's CDI skills
(5 minutes)
- Coaching of second parent's CDI skills
(15 minutes)
- Feedback too both parents on progress and homework assignment
(10 minutes)

\section{DPICS Knowledge}

Please code the parent verbalizations in the following parent-child interaction.

11. Parent: "We can play with whatever you want." (Description)

Child: "I want to play with the dogs."

12. Parent: "Are you pretending to take the dog for a walk?" (Question)

13. Parent: "Your dog is going for a walk." (Description)

Child: "He's going to visit his friends."

14. Parent "Yes, he is going to visit his friends." (Reflection)

15. Parent: "He must have lots of friends just like you do because he is kind to others just like you are." (Labeled praise)

\section{Please provide DPICS definitions for the following terms:}

16. Descriptive statement

- A declarative statement or phrase that gives an account of the objects or people in the situation or the activity occurring during the interaction.

17. Direct command

- A clearly stated order, demand, or direction in declarative form. The statement must be sufficiently specific as to indicate the behavior that is expected from the child.

18. Reflective statement

- A declarative phrase or statement that immediately repeats the child's verbalization. The reflection may be exactly the same words the child said, may contain synonymous words, or may contain some elaboration on the child's statement, but the basic content must be the same as the child's message. 
Please provide an example consistent with DPICS definitions for each of the following:

19. Labeled praise

a That's a terrific house you made.

- You have a beautiful smile.

20. Indirect Command

Put it here, OK?

a Johnny!

- Let's take out the red blocks. 


\section{Appendix J}

Pilot Study on CDI and DPICS Knowledge Questionnaires

Procedures, Results, and Discussion

Procedures

\section{Setting and Participants}

At the time of data collection, the CAARE Center had 17 therapists and trainees who meet one hour weekly for supervision in PCIT. Typically these meetings were reserved for supervision and case management activities; however, during the meetings on 11/8/00 and 11/15/00 staff members were asked to complete developed CDI and DPICS Knowledge Questionnaires. If this two hour period was insufficient for completion of all forms, it was recommended that the individual complete them during office hours and return the forms to Amy Herschell. Four forms of the CDI and DPICS Knowledge Questionnaires (i.e., Forms A, B, C, \& D) were presented to participants in random order to control for order effects.

Four staff members were excluded from completion due to three people being absent from both meetings, and one person developing the forms. Of 13 staff members invited to participate in the pilot study, 10 completed and returned the forms by 12/4/00.

Participants who completed the questionnaires had a wide range of exposure to and experience with PCIT varying from one participant who has been using PCIT with multiple clients weekly and training pre- and post-doctoral interns in PCIT to a trainee who had very limited exposure to PCIT (e.g., had read only one research review article and never observed a PCIT case). When asked to classify themselves as expert, moderate, or novice PCIT therapists, 1 person rated him or herself as an expert, 1 person rated him or herself as moderate, and 8 people rated themselves as novice PCIT therapists.

Participants were asked to identify questions with awkward or confusing language. They also were asked to provide any suggestions for possible improvements to the forms. Almost all participants provided this type of feedback. In fact, one participant provided a separate, detailed list of ideas for improvements, some of which were incorporated as will be discussed later in this brief report.

Scoring

After collection of completed questionnaires, the primary researcher (Amy Herschell) sorted individual questionnaire packets by form letter (A, B, C, or D). To facilitate scoring consistency, questionnaires were scored by form so that all of Form As were scored prior to advancing to scoring form $\mathrm{B}$, and so on.

\section{Results and Discussion}

In the table below scores for each participant on each form are presented as well as averages for each form and each participant. When scores were averaged across all participants, the average score on Form A was equal to $69 \%$, the average score on Form B was equal to $56 \%$, the average score on Form $\mathrm{C}$ was equal to $65 \%$, and the average score on Form $\mathrm{D}$ was equal to $74 \%$. An inspection of the group mean suggested that Form B was more difficult that the other forms; however, an examination of individual scores revealed that participant eight had a particularly low score. That participant left almost all items blank on Questionnaire B and it was not clear why the items were skipped. If participant eight's score is excluded, the average total score is equal to 62, the average CDI score is 64, and the average DPICS score is 70 which are similar to the average scores on Forms A and C. 
From the group means, it also appeared that Form D was slightly easier than the other three forms. An examination of individual data confirmed this, particularly on the DPICS section of the form. Therefore, items on this form were changed and the revised DPCIS section of the form (10 items) were administered to the same participants on 12/6/00. Scoring of these items yielded an average score of 72, which was comparable to DPICS scores on Forms A, B, and C (77, 66, and 60 respectively).

Inspection of individual results indicated a wide range of scores across participants. Some participants averaged low scores (e.g., 30\%) whereas other participants averaged high scores (e.g., 92\%). Generally, these scores appeared to be positively associated with experience in providing PCIT. In other words, novice PCIT therapists generally scored low, and PCIT therapists with more experience scored high. One exception to this was participant nine, who had little experience providing PCIT, but had read many PCIT references, completed research projects in the area of treatment of externalizing problems in children, and who reported a main reason for employment at the CAARE Center was to gain clinical experience in PCIT.

Modifications. Several minor wording changes were made to items in an attempt to correct grammatical or typographic errors or to provide clarification. For example, Form B item 6 was changed from "Please list five parent behaviors as a coach to which you might strategically attend" to "Please list five parent behaviors as a coach to which you might strategically attend." Similarly, Form C item 10 was changed from "Please fill in the appropriate time that should be allotted for each coaching session involving one parent:" to "Please fill in the appropriate time that should be allotted for a 60 -minute coaching session involving one parent" due to some participants completing that item for a 50-minute and others for a 60 -minute therapy hour.

Additions to answer key. This pilot study also was useful in providing additional information for answer keys for each form as well as providing some completed questionnaires that was hoped would assist in training research assistants in scoring these forms.

Mastery criteria. Of the ten participants who completed the forms, five people conducted 8 to 10 weekly PCIT sessions for at least one year prior to data collection (Participants 1, 3, 4, 6, and 10). Because these participants had experience in conducting PCIT, and were believed to have mastered PCIT concepts, the average of their scores $(80 \%)$ was considered a mastery score. In other words, in the larger study, a participant who scored $80 \%$ or higher on the CDI and DPICS Knowledge Questionnaires was considered to have reached mastery criteria of PCIT knowledge. 
Table

Individual Scores and Average Scores on CDI \& DPICS Knowledge Questionnaires

\begin{tabular}{|c|c|c|c|c|c|}
\hline \multirow[b]{2}{*}{$\begin{array}{l}\text { Pilot Participant } \\
\text { Number }\end{array}$} & \multicolumn{4}{|c|}{ Questionnaire Form } & \multirow[b]{2}{*}{$\begin{array}{l}\text { Average Score of Each } \\
\text { Pilot Participant }\end{array}$} \\
\hline & A & $\mathrm{B}$ & $\mathrm{C}$ & $\mathrm{D}$ & \\
\hline \multicolumn{6}{|c|}{ TOTAL CDI and DPICS Knowledge Percentage Scores } \\
\hline 1 & 64 & 63 & 73 & 86 & 72 \\
\hline 2 & 68 & 50 & 64 & 54 & 59 \\
\hline 3 & 85 & 68 & 86 & 92 & 83 \\
\hline 4 & 79 & 95 & 89 & 76 & 85 \\
\hline 5 & 64 & 28 & 49 & 73 & 54 \\
\hline 6 & 64 & 58 & 80 & 92 & 74 \\
\hline 7 & 26 & 22 & 24 & 64 & 34 \\
\hline 8 & 55 & 9 & 12 & 22 & 25 \\
\hline 9 & 94 & 95 & 89 & 86 & 91 \\
\hline 10 & 88 & 76 & 85 & 95 & 86 \\
\hline $\begin{array}{l}\text { Average Scores on } \\
\text { each Form }\end{array}$ & 69 & 56 & 65 & 74 & 66 \\
\hline
\end{tabular}

CDI Portion of CDI \& DPICS Knowledge Questionnaires Percentage Scores

$\begin{array}{llllll}1 & 58 & 61 & 74 & 81 & 69 \\ 2 & 63 & 43 & 67 & 59 & 58 \\ 3 & 79 & 64 & 85 & 89 & 79 \\ 4 & 75 & 96 & 93 & 67 & 83 \\ 5 & 58 & 25 & 48 & 67 & 50 \\ 6 & 58 & 46 & 93 & 93 & 73 \\ 7 & 25 & 25 & 22 & 70 & 36\end{array}$


Table (continued).

\begin{tabular}{|c|c|c|c|c|c|}
\hline \multirow[b]{2}{*}{$\begin{array}{l}\text { Pilot Participant } \\
\text { Number }\end{array}$} & \multicolumn{4}{|c|}{ Questionnaire Form } & \multirow[b]{2}{*}{$\begin{array}{l}\text { Average Score of Each } \\
\text { Pilot Participant }\end{array}$} \\
\hline & A & B & $\mathrm{C}$ & $\mathrm{D}$ & \\
\hline 8 & 50 & 4 & 11 & 7 & 18 \\
\hline 9 & 96 & 96 & 85 & 85 & 91 \\
\hline 10 & 92 & 71 & 96 & 93 & 88 \\
\hline $\begin{array}{l}\text { Average Scores on } \\
\text { each Form }\end{array}$ & 65 & 53 & 67 & 71 & 64 \\
\hline \multicolumn{6}{|c|}{ DPICS Portion of CDI \& DPICS Knowledge Questionnaires Percentage Scores } \\
\hline 1 & 78 & 70 & 70 & 100 & 80 \\
\hline 2 & 83 & 70 & 65 & 40 & 65 \\
\hline 3 & 100 & 80 & 90 & 100 & 93 \\
\hline 4 & 89 & 90 & 80 & 100 & 90 \\
\hline 5 & 78 & 35 & 50 & 90 & 63 \\
\hline 6 & 78 & 90 & 45 & 90 & 76 \\
\hline 7 & 28 & 15 & 30 & 45 & 30 \\
\hline 8 & 67 & 25 & 15 & 60 & 42 \\
\hline 9 & 89 & 90 & 100 & 90 & 92 \\
\hline 10 & 78 & 90 & 55 & 100 & 81 \\
\hline $\begin{array}{l}\text { Average Scores on } \\
\text { each Form }\end{array}$ & 77 & 66 & 60 & 82 & 71 \\
\hline
\end{tabular}




\section{Appendix K}

\section{Modified Therapy Attitude Inventory (Modified TAI)}

Directions: Please circle the response for each questions which best expresses how you honestly feel.

1. Compared to other approaches I have used, regarding techniques of discipline, I feel I have learned:

1. Nothing

2. Very little
3. A few new techniques
4. Several useful techniques
5. Very many useful techniques

2. Compared to other approaches I have used, regarding techniques for teaching children new skills, I feel I have learned
1. Nothing
2. Very little
3. A few new techniques
4. Several useful techniques useful techniques
5. Very many

3. Compared to other approaches I have used, regarding the relationship between parents and children, I feel I can help them get along

\begin{tabular}{|c|c|c|c|c|}
\hline $\begin{array}{l}\text { 1. Much worse } \\
\text { than before }\end{array}$ & $\begin{array}{l}\text { 2. Somewhat } \\
\text { worse than } \\
\text { before }\end{array}$ & $\begin{array}{c}\text { 3. The same as } \\
\text { before }\end{array}$ & $\begin{array}{c}\text { 4. Somewhat } \\
\text { better than } \\
\text { before }\end{array}$ & $\begin{array}{l}\text { 5. Very much } \\
\text { better than } \\
\text { before }\end{array}$ \\
\hline
\end{tabular}

4. Compared to other approaches I have used, regarding my confidence in my ability to help parents discipline their children, I feel
1. Much less
2. Somewhat
3. The same
4. Somewhat
more confident
5. Much more confident

5. Compared to other approaches I have used, I feel that the major child behavioral problems presented before the program started after treatment will be
1. Considerably
2. Somewhat
3. Neutral
4. Somewhat improved
5. Greatly worse improved

6. Compared to other approaches I have used, I feel that child compliance after treatment will be
1. Considerably
2. Somewhat
3. Neutral
4. Somewhat
5. Greatly
worse
worse
improved
improved 
7. Compared to other approaches I have used, I feel that general child behavior after treatment will be

$\begin{array}{cccc}\begin{array}{c}\text { 1. Considerably } \\ \text { worse }\end{array} & \begin{array}{c}\text { 2. Somewhat } \\ \text { worse }\end{array} & \begin{array}{c}\text { 3. Neutral } \\ \text { improved }\end{array} & \begin{array}{c}\text { 4. Somewhat } \\ \text { improatly }\end{array}\end{array}$

8. Compared to other approaches I have used, to what degree do you think the treatment program will help with general personal or family problems not directly related to the child in the program

$\begin{array}{ccccc}\begin{array}{c}\text { 1. Will hinder } \\ \text { much more than } \\ \text { help }\end{array} & \begin{array}{c}\text { 2. Will hinder } \\ \text { slightly }\end{array} & \begin{array}{c}\text { 3. Neither help } \\ \text { nor hinder }\end{array} & \begin{array}{c}\text { 4. Help } \\ \text { somewhat }\end{array} & \begin{array}{c}\text { 5. Help very } \\ \text { much }\end{array}\end{array}$

9. Compared to other approaches I have used, I feel this type of program (PCIT) will help me improve the behavior of children is
1. Very poor
2. Poor
3. Adequate
4. Good
5. Very good

10. Compared to other approaches I have used, my general feel about this program is
1. I dislike it
2. I dislike it
3. I feel neutral
4. I like it
5. I like it very very much somewhat somewhat
much 


\section{Appendix L}

\section{Satisfaction with Training}

Directions: Please circle the response for each questions which best expresses how you honestly feel.

\begin{tabular}{|c|c|c|c|c|c|}
\hline Question & $\begin{array}{l}\text { Strongly } \\
\text { Disagree }\end{array}$ & Disagree & $\begin{array}{l}\text { Neither } \\
\text { Agree } \\
\text { nor } \\
\text { Disagree }\end{array}$ & Agree & $\begin{array}{l}\text { Strongly } \\
\text { Agree }\end{array}$ \\
\hline \multicolumn{6}{|l|}{ The content of training: } \\
\hline $\begin{array}{l}\text { 1. Will be useful to me in my work } \\
\text { assignment }\end{array}$ & 1 & 2 & 3 & 4 & 5 \\
\hline 2.Was consistent with stated objectives & 1 & 2 & 3 & 4 & 5 \\
\hline 3. Was practical & 1 & 2 & 3 & 4 & 5 \\
\hline $\begin{array}{l}\text { 4. Provided new and innovative } \\
\text { information }\end{array}$ & 1 & 2 & 3 & 4 & 5 \\
\hline $\begin{array}{l}\text { 5. My overall rating of the content of } \\
\text { training so far would be... }\end{array}$ & $\begin{array}{c}\text { Poor } \\
1\end{array}$ & $\begin{array}{c}\text { Below } \\
\text { Average } \\
2\end{array}$ & $\begin{array}{c}\text { Average } \\
3\end{array}$ & $\begin{array}{c}\text { Above } \\
\text { Average } \\
4\end{array}$ & $\begin{array}{c}\text { Excellent } \\
5\end{array}$ \\
\hline Question & $\begin{array}{l}\text { Strongly } \\
\text { Disagree }\end{array}$ & Disagree & $\begin{array}{c}\text { Neither } \\
\text { Agree } \\
\text { nor } \\
\text { Disagree }\end{array}$ & Agree & $\begin{array}{l}\text { Strongly } \\
\text { Agree }\end{array}$ \\
\hline \multicolumn{6}{|l|}{ The format of training: } \\
\hline 6. Facilitated learning & 1 & 2 & 3 & 4 & 5 \\
\hline 7. Held my attention & 1 & 2 & 3 & 4 & 5 \\
\hline $\begin{array}{l}\text { 8. Prepared me to implement presented } \\
\text { strategies }\end{array}$ & 1 & 2 & 3 & 4 & 5 \\
\hline $\begin{array}{l}\text { 9. Facilitated a supportive and } \\
\text { comfortable learning environment }\end{array}$ & 1 & 2 & 3 & 4 & 5 \\
\hline $\begin{array}{l}\text { 10. My overall rating of the format of } \\
\text { training so far would be... }\end{array}$ & $\begin{array}{c}\text { Poor } \\
1\end{array}$ & $\begin{array}{c}\text { Below } \\
\text { Average } \\
2\end{array}$ & $\begin{array}{c}\text { Average } \\
3\end{array}$ & $\begin{array}{c}\text { Above } \\
\text { Average } \\
4\end{array}$ & $\begin{array}{c}\text { Excellent } \\
5\end{array}$ \\
\hline
\end{tabular}




\begin{tabular}{|l|c|c|c|c|c|}
\hline Question & $\begin{array}{c}\text { Strongly } \\
\text { Disagree }\end{array}$ & Disagree & $\begin{array}{c}\text { Neither } \\
\text { Agree } \\
\text { nor } \\
\text { Disagree }\end{array}$ & Agree & $\begin{array}{c}\text { Strongly } \\
\text { Agree }\end{array}$ \\
\hline \multicolumn{1}{|l|}{ The trainers: } & 1 & 2 & 3 & 4 & 5 \\
\hline $\begin{array}{l}\text { 11. Communicated ideas and } \\
\text { information }\end{array}$ & 1 & 2 & 3 & 4 & 5 \\
\hline 12. Showed enthusiasm for the subject & 1 & 2 & 3 & 4 & 5 \\
\hline $\begin{array}{l}\text { 13. Showed respect and concern for } \\
\text { therapists }\end{array}$ & 1 & 2 & 3 & 4 & 5 \\
\hline $\begin{array}{l}\text { 14. Presented materials in an interesting } \\
\text { way }\end{array}$ & Poor & $\begin{array}{c}\text { Below } \\
\text { Average } \\
\text { 15. My overall rating of the trainers so } \\
\text { far would be... }\end{array}$ & $\begin{array}{c}\text { Average } \\
\text { Above } \\
\text { Average } \\
4\end{array}$ & Excellent \\
\hline
\end{tabular}

16. Which of the training methods have you found to be most helpful in terms of helping you to learn the skills? (Please circle one)

Didactic Presentations (i.e., Lectures)

Incorporation of case examples

Videos

Role-plays in which the presenters were the participants

Role-plays in which the workshop attendees were the participants

Assessment of participants' skills

17. Which of the training methods used did you enjoy the most?(Please circle one)

Didactic Presentations (i.e., Lectures)

Incorporation of case examples

Videos

Role-plays in which the presenters were the participants

Role-plays in which the workshop attendees were the participants

Assessment of participants' skills

18. What suggestions do you have for improving our training?

19. What in particular did you like about our training? 


\section{Appendix M}

\section{Training Integrity PCIT Fundamentals Day 1}

Tape Number Agency Date of Training

Observer

Date of scoring Trainers

\begin{tabular}{|c|c|}
\hline & Please circle one \\
\hline \multicolumn{2}{|l|}{ Content - MORNING } \\
\hline $\begin{array}{l}\text { 1. A video of a child (Harley) and mother was shown which highlighted a coercive } \\
\text { parent-child interaction pattern - Slide } 4\end{array}$ & True False \\
\hline $\begin{array}{l}\text { 2. A developmental progression of conduct disordered behavior was presented - } \\
\text { Slide } 6\end{array}$ & True False \\
\hline $\begin{array}{l}\text { 3. The relationship between physical abuse and conduct problems was highlighted } \\
\text { - Slide } 7\end{array}$ & True False \\
\hline 4. Parent factors associated with child maltreatment were reviewed - Slide 8 & True False \\
\hline 5. Child factors associated with child maltreatment were discussed - Slide 9 & True False \\
\hline $\begin{array}{l}\text { 6. Parent factors, child factors, and a coercive cycle between parents and their } \\
\text { children were discussed in relation to PCIT Slide } 10 \text { - Coercive cycle }\end{array}$ & True False \\
\hline $\begin{array}{l}\text { 7. Information on behavioral principles was provided (in theoretical discussion } \\
\text { either through slides or case discussion and/or later around slide 24) }\end{array}$ & True False \\
\hline 8. Training model was discussed - Slides 11-14 & True False \\
\hline $\begin{array}{l}\text { 9. Factors which are unique to PCIT relative to other treatment approaches were } \\
\text { identified Slide } \mathbf{1 5}-\text { What is PCIT }\end{array}$ & True False \\
\hline 10. Pre/Post Treatment tapes were shown - Slides 16-18 & True False \\
\hline $\begin{array}{l}\text { 11. Assessment of parent-child dyads using structured behavior observation } \\
\text { (DPICS) was mentioned - Slide } 17\end{array}$ & True False \\
\hline 12. PCIT treatment outcome research was discussed - Slide 19 & True False \\
\hline 13. Limitations and caveats were reviewed - Slide 20 & True False \\
\hline 14. Pulse videotape was shown - Slide 21 & True False \\
\hline
\end{tabular}




\begin{tabular}{|c|c|}
\hline \multicolumn{2}{|l|}{ Format-MORNING } \\
\hline 1. The presentation was conducted similar to a lecture format. & True False \\
\hline $\begin{array}{l}\text { 2. All role-plays were conducted by the trainers. Participants were not included in } \\
\text { the role-plays. }\end{array}$ & True False \\
\hline 3. Case review discussions were lead by the trainers. & True False \\
\hline 4. Participant questions were answered, but did not become the focus of training & True False \\
\hline 5. Participants were not asked to break into small groups & True False \\
\hline \multicolumn{2}{|l|}{ Content - AFTERNOON } \\
\hline $\begin{array}{l}\text { 15. A description was provided for the theoretical foundations of PCIT including } \\
\text { information relevant to developmental theory - Slide } 23\end{array}$ & True False \\
\hline $\begin{array}{l}\text { 16. Information was provided regarding social learning theory Slide } 24 \text { - Coercive } \\
\text { cycle }\end{array}$ & True False \\
\hline $\begin{array}{l}\text { 17. Assessment of parent-child dyads using parent report measures was discussed } \\
\text { (e.g., } \boldsymbol{C B C L} \text { - Slide 29; ECBI-Slide 30; PSI -Slide 31; TAI - Slide 32) }\end{array}$ & True False \\
\hline $\begin{array}{l}\text { 18. Assessment of parent-child dyads using structured behavior observation was } \\
\text { mentioned (DPICS - Slides 33-34) }\end{array}$ & True False \\
\hline $\begin{array}{l}\text { 19. Guidelines for coding parent-child interactions using DPICS were presented - } \\
\text { Slide } 41\end{array}$ & True False \\
\hline 20. A sample client plan was reviewed - Slide 39 & True False \\
\hline 21. An overview of the two phases of PCIT was discussed - Slide 41 & True False \\
\hline $\begin{array}{l}\text { 22. The CDI Skill Using Praise was identified and described. Also, a rationale and } \\
\text { accompanying examples were provided for that skill.- Slides } 43-44\end{array}$ & True False \\
\hline $\begin{array}{l}\text { 23. The CDI Skill Using Reflection was identified and described. Also, a rationale } \\
\text { and accompanying examples were provided for that skill.- Slide } 45\end{array}$ & True False \\
\hline $\begin{array}{l}\text { 24. The CDI Skill Using Imitation was identified and described. Also, a rationale } \\
\text { and accompanying examples were provided for that skill. - Slide } 46\end{array}$ & True False \\
\hline $\begin{array}{l}\text { 25. The CDI Skill Using Description was identified and described. Also, a } \\
\text { rationale and accompanying examples were provided for that skill.- Slide } 47\end{array}$ & True False \\
\hline $\begin{array}{l}\text { 26. The CDI Skill Using Enthusiasm was identified and described. Also, a } \\
\text { rationale and accompanying examples were provided for that skill.- Slide } 48\end{array}$ & True False \\
\hline
\end{tabular}




\begin{tabular}{|c|c|}
\hline $\begin{array}{l}\text { 27. A rationale was provided for use of strategic attention and active ignoring - } \\
\text { Slide } 49\end{array}$ & True False \\
\hline $\begin{array}{l}\text { 28. The CDI Skill Avoiding commands was identified and described. Also, a } \\
\text { rationale and accompanying examples were provided for that skill.- Slide } \mathbf{5 0}\end{array}$ & True False \\
\hline $\begin{array}{l}\text { 29. The CDI Skill Avoiding question was identified and described. Also, a } \\
\text { rationale and accompanying examples were provided for that skill.- Slide } 51\end{array}$ & True False \\
\hline $\begin{array}{l}\text { 30. The CDI Skill Avoiding criticism was identified and described. Also, a } \\
\text { rationale and accompanying examples were provided for that skill.- Slide } 52\end{array}$ & True False \\
\hline $\begin{array}{l}\text { 31. Toys appropriate for use during special playtime were identified and discussed } \\
\text { (e.g., constructive and creative toys such as legos, lincoln logs, play doh)- Slide } 53\end{array}$ & True False \\
\hline $\begin{array}{l}\text { 32. The two rules of special playtime were identified (i.e., play gently with the } \\
\text { toys, stay in your seat)- through videos }\end{array}$ & True False \\
\hline 33. The structure of special playtime in the clinic was discussed - through videos & True False \\
\hline 34. The structure of special playtime in the home was discussed -through videos & True False \\
\hline \multicolumn{2}{|l|}{ Content Score (Total number of content “trues"/34 * 100) } \\
\hline \multicolumn{2}{|l|}{ Format - AFTERNOON } \\
\hline 1. The presentation was conducted similar to a lecture format. & True False \\
\hline $\begin{array}{l}\text { 2. All role-plays were conducted by the trainers. Participants were not included in } \\
\text { the role-plays. }\end{array}$ & True False \\
\hline 3. Case review discussions were lead by the trainers. & True False \\
\hline 4. Participant questions were answered, but did not become the focus of training & True False \\
\hline 5. Participants were not asked to break into small groups & True False \\
\hline \multicolumn{2}{|l|}{ Format Score (Total number of process "trues"/10*100) } \\
\hline Total treatment integrity score (Total number of "trues"/44*100) & \\
\hline
\end{tabular}




\section{Appendix N}

\section{Training Integrity PCIT Fundamentals Day 2 EXPERIENTIAL GROUP}

Tape Number Agency Date of Training

Observer Date of scoring Trainers

\begin{tabular}{|c|c|}
\hline & $\begin{array}{l}\text { Please circle } \\
\text { one }\end{array}$ \\
\hline \multicolumn{2}{|l|}{ Content } \\
\hline 1. Information covered on the previous day briefly was reviewed & True False \\
\hline $\begin{array}{l}\text { 2. Use of praise skill was highlighted. Very specific situations in which the skill } \\
\text { might be used were reviewed. }\end{array}$ & True False \\
\hline $\begin{array}{l}\text { 3. Use of imitation skill was highlighted. Very specific situations in which the skill } \\
\text { might be used were reviewed. }\end{array}$ & True False \\
\hline $\begin{array}{l}\text { 4. Use of description skill was highlighted. Very specific situations in which the } \\
\text { skill might be used were reviewed. }\end{array}$ & True False \\
\hline $\begin{array}{l}\text { 5. Use of reflection skill was highlighted. Very specific situations in which the skill } \\
\text { might be used were reviewed. }\end{array}$ & True False \\
\hline $\begin{array}{l}\text { 6. Use of enthusiasm skill was highlighted. Very specific situations in which the } \\
\text { skill might be used were reviewed. }\end{array}$ & True False \\
\hline $\begin{array}{l}\text { 7. Avoiding commands was highlighted. Very specific situations in which the skill } \\
\text { might be used were reviewed. }\end{array}$ & True False \\
\hline $\begin{array}{l}\text { 8. Avoiding questions was highlighted. Very specific situations in which the skill } \\
\text { might be used were reviewed. }\end{array}$ & True False \\
\hline $\begin{array}{l}\text { 9. Avoiding criticism was highlighted. Very specific situations in which the skill } \\
\text { might be used were reviewed. }\end{array}$ & True False \\
\hline $\begin{array}{l}\text { 10. Selective attention/strategic ignoring was highlighted. Very specific situations } \\
\text { in which the skill might be used were reviewed. }\end{array}$ & True False \\
\hline 11. DPICS coding definitions were reviewed & True False \\
\hline 12. Specific situations in which DPICS codes would be applied were highlighted & True False \\
\hline 13. Hard copies of DPICS Coding sheets were provided & True False \\
\hline Content Score (Total number of content "trues"/13*100) & \\
\hline
\end{tabular}




\begin{tabular}{|l|l|}
\hline \multicolumn{2}{|c|}{ Format } \\
\hline 1. Participants were required to generate answers to questions & True False \\
\hline 2. Participants were required to participate in role-plays & True False \\
\hline 3. Participants received feedback from trainers & True False \\
\hline 4. Participants practiced coding videotapes or did live coding & True False \\
\hline 5. Participants were active in the training process & True False \\
\hline 6. Participants broke into smaller groups & True False \\
\hline Process Score (Total number of process "trues"/6*100) & \\
\hline Total treatment integrity score (Total number of "trues"/19*100) & \\
\hline
\end{tabular}


Appendix $\mathrm{O}$

Training Integrity PCIT Fundamentals Day 2

DIDACTIC GROUP

Tape Number Agency Date of Training

Observer

Date of scoring Trainers

\begin{tabular}{|c|c|}
\hline & Please circle one \\
\hline \multicolumn{2}{|l|}{ Content } \\
\hline 1. Information covered on the previous day briefly was reviewed & True False \\
\hline $\begin{array}{l}\text { 2. Use of praise skill was highlighted. Very specific situations in which the skill } \\
\text { might be used were reviewed. }\end{array}$ & True False \\
\hline $\begin{array}{l}\text { 3. Use of imitation skill was highlighted. Very specific situations in which the } \\
\text { skill might be used were reviewed. }\end{array}$ & True False \\
\hline $\begin{array}{l}\text { 4. Use of description skill was highlighted. Very specific situations in which the } \\
\text { skill might be used were reviewed. }\end{array}$ & True False \\
\hline $\begin{array}{l}\text { 5. Use of reflection skill was highlighted. Very specific situations in which the } \\
\text { skill might be used were reviewed. }\end{array}$ & True False \\
\hline $\begin{array}{l}\text { 6. Use of enthusiasm skill was highlighted. Very specific situations in which the } \\
\text { skill might be used were reviewed. }\end{array}$ & True False \\
\hline $\begin{array}{l}\text { 7. Avoiding commands was highlighted. Very specific situations in which the } \\
\text { skill might be used were reviewed. }\end{array}$ & True False \\
\hline $\begin{array}{l}\text { 8. Avoiding questions was highlighted. Very specific situations in which the } \\
\text { skill might be used were reviewed. }\end{array}$ & True False \\
\hline $\begin{array}{l}\text { 9. Avoiding criticism was highlighted. Very specific situations in which the skill } \\
\text { might be used were reviewed. }\end{array}$ & True False \\
\hline $\begin{array}{l}\text { 10. Selective attention/strategic ignoring was highlighted. Very specific } \\
\text { situations in which the skill might be used were reviewed. }\end{array}$ & True False \\
\hline 11. DPICS coding definitions were reviewed & True False \\
\hline 12. Specific situations in which DPICS codes would be applied were highlighted & True False \\
\hline 13. Hard copies of DPICS Coding sheets were provided & True False \\
\hline Content Score (Total number of content "trues"/13*100) & \\
\hline
\end{tabular}




\begin{tabular}{|l|l|}
\hline \multicolumn{2}{|c|}{ Format } \\
\hline 1. The presentation was conducted similar to a lecture format. & True False \\
\hline $\begin{array}{l}\text { 2. All role-plays were conducted by the trainers. Participants were not included } \\
\text { in the role-plays. }\end{array}$ & True False \\
\hline 3. Case review discussions were lead by the trainers. & True False \\
\hline 4. Participant questions were answered, but did not become the focus of training & True False \\
\hline 5. Participants were not asked to break into small groups & True False \\
\hline Process Score (Total number of process "trues"/5*100) & \\
\hline Total treatment integrity score (Total number of "trues"/18*100) & \\
\hline
\end{tabular}


Appendix P

Sample Reminder Letter to Participants

December 18, 2000

Lucky Participant

Community Mental Health Agency

Somewhere, CA 95634

Dear Participant:

Hello again. I am writing in regard to our PCIT Fundamentals Training that is coming up on January $4^{\text {th }}$ and $5^{\text {th }}$. I am really looking forward to meeting with you again and have been preparing materials to share with you. I am hoping that you will be prepared as well. As mentioned in our initial site visit, it would be wonderful if you could read pages 1-69 of the book Parent-Child Interaction Therapy (Hembree-Kigin \& McNeil, 1995) and the provided DPICS manual prior to beginning PCIT Fundamentals Training on January $4^{\text {th }}$. Also, please record any questions or concerns on the provided reading log and bring that to training. I will collect you reading $\log$ at the beginning of the day, photocopy it, and return it to you. This will allow us to address your specific questions and concerns regarding the reading during the training.

If you have any questions or concerns about the reading that need to be addressed prior to January $4^{\text {th }}$, please don't hesitate to contact me. My contact information is as follows: (916) 7346648 (phone); (916) 734-6652 (fax); amy.herschell@ucdmc.ucdavis.edu (email).

I hope you have a wonderful holiday season, and I will look forward to seeing you early in the new year.

Best regards,

Amy Herschell, M.A. 
Table 1

Participating Agencies Information Summary

\begin{tabular}{|c|c|c|}
\hline Agency & Regional division & Relevant information \\
\hline Agency 1 & Northern California & $\begin{array}{l}\text { One center offering multiple types of service (e.g., in-home, clinic-based, school consultation) } \\
\text { Predominate population - rural Caucasian, English speaking } \\
\text { Therapists - all masters-level }\end{array}$ \\
\hline Agency 2 & Northern California & $\begin{array}{l}\text { Centers in North Auburn, Roseville, and Forresthill } \\
\text { Of the approximately } 1800 \text { child known to suffer from physical abuse in Placer County, fewer } \\
\text { than } 200 \text { are known to receive treatment of any kind } \\
\text { integrating PCIT into home service; proposed } 2 \text { PCIT facilities }\end{array}$ \\
\hline Agency 3 & Northern California & $\begin{array}{l}\text { last year provided services to } 1400 \text { children and parents - highest proportion of children preschool } \\
\text { or latency age } \\
\text { has always considered abuse dynamics within a dysfunctional family system, and included parents } \\
\text { in the treatment process } \\
\text { ethically diverse, low income population }\end{array}$ \\
\hline
\end{tabular}


Table 1 (continued).

Agency Regional division Relevant information

Agency $4 \quad$ Northern California

July 1999-June 2000 handled 279 cases involving children between 2-7, referred primarily by

Child Protective Services, local law enforcement's juvenile divisions, and pediatricians

Agency is part of a larger children's hospital

Agency $5 \quad$ Southern California

rural farm-working community, predominately Spanish speaking, majority of parents are

immigrants from Mexico and Latin America, migrant farm workers, generational discrepancy,

corporal punishment,

Agency 6

Southern California

Multiple services (in-home, individual, group, multi-family therapy)

Spanish speaking staff

Currently serving 187 clients between 0 and 12

Agency 7

Southern California

Approximately 100 of Center's more than 800 child abuse victims are ethnically, socio-

economically and otherwise diverse children between the ages of 2 and 7 
Table 1 (continued).

\begin{tabular}{|c|c|c|}
\hline Agency & Regional division & Relevant information \\
\hline Agency 8 & Southern California & $\begin{array}{l}\text { Serves Central LA } \\
\text { at risk population characterized by a high incidence of child abuse and neglect, domestic } \\
\text { violence, and other social, emotional, and behavioral problems } \\
\text { poverty }\end{array}$ \\
\hline Agency 9 & Southern California & $\begin{array}{l}\text { Used a Family-Focused Parallel Therapy model in which both the abused child and parent } \\
\text { (or primary caregiver) participate in a combination of individual therapy and dyadic } \\
\text { family counseling for } 6 \text { months to one year } \\
20 \% \text { of kids in program have physical abuse or neglect as one of their primary presenting } \\
\text { problems } \\
73 \text { children } 2-7 \text { ( } 36 \text { boys and } 37 \text { girls) received services in a one year period } 7 / 1 / 99 \text { - } \\
6 / 30 / 00\end{array}$ \\
\hline Agency 10 & Southern California & $\begin{array}{l}\text { Serves Native American child abuse victims in San Bernardino, Riverside, and San Diego } \\
\text { counties }\end{array}$ \\
\hline Agency 11 & Southern California & $\begin{array}{l}\text { Program to be established at the South bay office of the Child Abuse Treatment Services } \\
\text { located in Chula Vista - Majority of clients are Spanish speaking }\end{array}$ \\
\hline
\end{tabular}


Table 2

Dependent Variable Summary

Dependent Variables

Attitudes Towards Treatment Manuals - Negative

Process

Attitudes Towards Treatment Manuals - Positive

Outcome

CDI Skills assessment

Coaching score

Knowledge of Behavioral Principles as Applied to Children

CDI and DPICS Knowledge Questionnaire

Modified Therapy Attitude Inventory

Training Satisfaction Questionnaire
Reliability assessment

Not applicable

Not applicable

$25 \%$ of data double coded

Reliability assessed by percent agreement

$25 \%$ of data double coded

Reliability assessed by intraclass correlation coefficients

Not applicable

$25 \%$ of data double coded

Reliability assessed by intraclass correlation coefficients

Not applicable

Not applicable 
Table 3

Participants' Attitudes Toward Behaviorally Oriented Therapies

\begin{tabular}{|c|c|c|c|c|}
\hline \multirow[b]{2}{*}{$\begin{array}{l}\text { How well does each item characterize a } \\
\text { behaviorally oriented therapy? }\end{array}$} & \multirow[b]{2}{*}{ M } & \multirow[b]{2}{*}{$\mathrm{SD}$} & \multicolumn{2}{|c|}{ Factor loadings $^{\mathrm{a}}$} \\
\hline & & & $\begin{array}{l}\text { Negative } \\
\text { Ideas } \\
(\alpha=.75) \\
\end{array}$ & $\begin{array}{l}\text { Positive Ideas } \\
\quad(\alpha=.68)\end{array}$ \\
\hline $\begin{array}{l}\text { 2. Presents a comprehensive view of } \\
\text { psychopathology }\end{array}$ & 1.59 & .64 & & .71 \\
\hline 3. Is objective & 2.92 & .90 & & .55 \\
\hline 4. Tends to be rigid & 2.51 & .84 & .67 & \\
\hline 5. Emphasizes individual case conceptualization & 2.23 & .93 & & .74 \\
\hline 6. Is directive & 3.28 & .72 & .75 & \\
\hline $\begin{array}{l}\text { 7. Emphasizes the importance of the therapeutic } \\
\text { relationship }\end{array}$ & 1.95 & .72 & & .49 \\
\hline 8. Is impersonal & 1.92 & .70 & .59 & -.49 \\
\hline Rotated due to negative loading & 3.08 & .70 & & \\
\hline $\begin{array}{l}\text { 9. Provides a "cookbook" approach of } \\
\text { therapeutic techniques }\end{array}$ & 2.38 & .80 & .81 & \\
\hline 11. Overly simplifies complex processes & 2.43 & .77 & & -.46 \\
\hline Rotated due to negative loading & 2.57 & .77 & & \\
\hline
\end{tabular}
Note. $1=$ Not at all characteristic, $2=$ Somewhat characteristic, $3=$ Characteristic, $4=$ Very characteristic. ${ }^{\mathrm{a}}$ Factor loadings less than .45 are excluded from this table. 
Table 4

Training Integrity Percentages for each Training Day and Format

\begin{tabular}{lcc}
\hline & Mean Percent Adherence & Range \\
\hline Day One & & \\
Content & $97 \%$ & $91 \%-100 \%$ \\
Format & $100 \%$ & $100 \%$ \\
Total & $98 \%$ & $92 \%-100 \%$ \\
Day Two & & \\
Didactic & & \\
Content & $96 \%$ & $100 \%$ \\
Format & $100 \%$ & $92 \%-100 \%$ \\
Total & $97 \%$ & $100 \%$ \\
Experiential & & $94 \%-100 \%$ \\
Content & $100 \%$ & \\
Format & $100 \%$ & $100 \%$ \\
Total & $100 \%$ & \\
\hline
\end{tabular}


Table 5

Basic Demographic Characteristics of Combined, Didactic, and Experiential Groups

\begin{tabular}{|c|c|c|c|c|c|}
\hline Characteristic & Combined & Didactic & Experiential & Significance test & $\begin{array}{c}\mathrm{p} \\
\text { (two-tailed) }\end{array}$ \\
\hline Gender & & & & $\chi^{2}(1, N=42)=3.11$ & .08 \\
\hline Female & 36 & 20 & 16 & & \\
\hline Male & 6 & 1 & 5 & & \\
\hline Age & & & & $t(38)=.57$ & .57 \\
\hline Mean & 40.50 & 39.47 & 41.43 & & \\
\hline $\mathrm{SD}$ & 10.74 & 10.74 & 10.93 & & \\
\hline Ethnicity & & & & $\chi^{2}(4, N=41)=3.11$ & .54 \\
\hline African-American & 1 & 0 & 1 & & \\
\hline Asian-American & 0 & 0 & 0 & & \\
\hline European American & 27 & 14 & 13 & & \\
\hline Hispanic & 11 & 5 & 6 & & \\
\hline Indian & 1 & 1 & 0 & & \\
\hline Native American & 1 & 0 & 1 & & \\
\hline Prefer not to disclose & 1 & 1 & 0 & & \\
\hline Speak a second language & 19 & 10 & 9 & $\chi^{2}(3, N=19)=2.06$ & .56 \\
\hline English & 8 & 4 & 4 & & \\
\hline French & 1 & 1 & 0 & & \\
\hline Hindi & 1 & 1 & 0 & & \\
\hline Spanish & 9 & 4 & 5 & & \\
\hline
\end{tabular}


Table 6

Educational and Training Experience Characteristics of Combined, Didactic, and Experiential Groups

\begin{tabular}{|c|c|c|c|c|c|}
\hline Characteristic & Combined & Didactic & Experiential & Significance test & $\begin{array}{c}\mathrm{p} \\
\text { (two-tailed) }\end{array}$ \\
\hline Educational Level & & & & $\chi^{2}(4, N=42)=.21$ & .99 \\
\hline Ph.D. & 2 & 1 & 1 & & \\
\hline M.A. & 15 & 7 & 8 & & \\
\hline M.S. & 7 & 4 & 3 & & \\
\hline M.S.W. & 14 & 7 & 7 & & \\
\hline B.A. & 4 & 2 & 2 & & \\
\hline \multicolumn{4}{|c|}{$\begin{array}{l}\text { Predominant theoretical orientation of graduate } \\
\text { program }\end{array}$} & $\chi^{2}(6, N=39)=5.45$ & .49 \\
\hline Behavioral & 4 & 3 & 1 & & \\
\hline Cognitive behavioral & 4 & 3 & 1 & & \\
\hline Existential/Humanistic & 3 & 1 & 2 & & \\
\hline Family Systems & 18 & 9 & 9 & & \\
\hline Interpersonal & 2 & 0 & 2 & & \\
\hline Psychodynamic & 7 & 3 & 4 & & \\
\hline Social learning & 1 & 1 & 0 & & \\
\hline Don't Know & 3 & 2 & 1 & & \\
\hline \multicolumn{4}{|c|}{ Years since degree was earned $(n=39)$} & $t(36)=1.11$ & .24 \\
\hline Mean & 8.03 & 6.63 & 9.35 & & \\
\hline SD & 7.69 & 7.41 & 7.90 & & \\
\hline
\end{tabular}


Table 6 (continued).

\begin{tabular}{|c|c|c|c|c|c|}
\hline Characteristic & Combined & Didactic & Experiential & Significance test & $\begin{array}{c}\mathrm{p} \\
\text { (two-tailed) }\end{array}$ \\
\hline \multicolumn{4}{|c|}{ Hours of supervision received } & $\chi^{2}(5, \mathrm{~N}=39)=3.76$ & .58 \\
\hline $500-1000$ & 16 & 9 & 7 & & \\
\hline $1001-2000$ & 3 & 1 & 2 & & \\
\hline $2001-3000$ & 4 & 2 & 2 & & \\
\hline $3001-4000$ & 8 & 4 & 4 & & \\
\hline $4001-5000$ & 3 & 0 & 3 & & \\
\hline $5000+$ & 5 & 3 & 2 & & \\
\hline Missing & 3 & 2 & 1 & & \\
\hline \multicolumn{4}{|c|}{ Number of continuing education credits $(n=31)$} & $t(29)=1.12$ & .27 \\
\hline Mean & 259.58 & 186.83 & 305.53 & & \\
\hline SD & 289.88 & 231.16 & 318.81 & & \\
\hline
\end{tabular}

Postgraduate trainings attended on the following topics

$\begin{array}{lccccc}\text { Child development } & 10 & 6 & 4 & \chi^{2}(1, \mathrm{~N}=41)=.67 & .41 \\ \text { Child maltreatment } & 29 & 16 & 13 & \chi^{2}(1, \mathrm{~N}=41)=1.62 & .20 \\ \text { Disruptive behavior } & 11 & 4 & 7 & \chi^{2}(1, \mathrm{~N}=41)=.93 & .34 \\ \text { ESTs } & 11 & 8 & 3 & \chi^{2}(1, \mathrm{~N}=41)=3.45 & .06 \\ \text { Years worked with clinical populations }(\mathrm{n}=39) & & t(37)=1.27 & .21 \\ \text { Mean } & 9.54 & 8.00 & 11.00 & & \\ \text { SD } & 7.46 & 7.98 & 6.81 & \end{array}$


Table 6 (continued).

\begin{tabular}{|c|c|c|c|c|c|}
\hline Characteristic & Combined & Didactic & Experiential & Significance test & $\begin{array}{c}\mathrm{p} \\
\text { (two-tailed) }\end{array}$ \\
\hline \multicolumn{4}{|c|}{$\begin{array}{l}\text { Years worked with disruptive behavior disorder populations } \\
(\mathrm{n}=39)\end{array}$} & $t(37)=-.14$ & .89 \\
\hline Mean & 8.67 & 8.84 & 8.50 & & \\
\hline sn & 752 & 016 & 581 & & \\
\hline \multicolumn{4}{|c|}{ Years worked with child maltreatment populations $(n=39)$} & $t(37)=-.23$ & .82 \\
\hline Mean & 7.69 & 7.95 & 7.45 & & \\
\hline SD & 6.60 & 8.39 & 4.51 & & \\
\hline
\end{tabular}


Table 7

Current Professional Characteristics of Combined, Didactic, and Experiential Groups

\begin{tabular}{|c|c|c|c|c|c|}
\hline Characteristic & Combined & Didactic & Experiential & Significance test & $\begin{array}{c}\mathrm{p} \\
\text { (two-tailed) }\end{array}$ \\
\hline Predominant professional activity & & & & $\chi^{2}(4, N=40)=2.55$ & .64 \\
\hline Direct patient contact & 28 & 13 & 15 & & \\
\hline Teaching - primary/secondary & 1 & 1 & 0 & & \\
\hline Research & 1 & 1 & 0 & & \\
\hline Administrative & 8 & 3 & 5 & & \\
\hline Other & 2 & 1 & 1 & & \\
\hline $\begin{array}{l}\text { Hours per week of direct client } \\
\text { contact }(n=41)\end{array}$ & & & & $t(39)=1.49$ & .15 \\
\hline Mean & 18.85 & 16.10 & 21.48 & & \\
\hline SD & 11.75 & 9.20 & 13.45 & & \\
\hline \multicolumn{3}{|c|}{ Current Predominant theoretical orientation } & & $\chi^{2}(7, \mathrm{~N}=40)=5.46$ & .60 \\
\hline Behavioral & 1 & 0 & 1 & & \\
\hline Cognitive behavioral & 14 & 5 & 9 & & \\
\hline Existential/Humanistic & 2 & 1 & 1 & & \\
\hline Family Systems & 10 & 6 & 4 & & \\
\hline Interpersonal & 1 & 0 & 1 & & \\
\hline Psychodynamic/analytic & 10 & 5 & 5 & & \\
\hline Social learning & 1 & 1 & 0 & & \\
\hline Post-modern/Narrative & 1 & 1 & 0 & & \\
\hline Don't Know & 2 & 2 & 0 & & \\
\hline
\end{tabular}


Table 7 (continued).

Characteristic

Combined Didactic

Experiential Significance test

$\mathrm{p}$

(two-tailed)

Percentage of current caseload $(n=39)$

Infants

$\begin{array}{llll}\text { Mean } & 6.18 & 9.89 & 2.65 \\ \text { SD } & 13.66 & 18.36 & 4.03 \\ \text { Children } & & & \\ \text { Mean } & 39.64 & 42.39 & 37.05 \\ \text { SD } & 27.46 & 30.79 & 24.40\end{array}$

Adolescents

$t(37)=1.19$

.24

Mean

14.08

10.00

17.95

SD

21.00

22.77

18.91

Adults

$$
t(37)=1.58
$$

Mean

35.05

27.63

42.10

SD

29.10

29.34

27.76

Elderly

$$
t(37)=1.75
$$

.10

Mean

.13

0

.25

SD

.47

0

.64

African-American

$$
t(37)=-.53
$$

Mean

14.15

16.00

12.49

SD

20.89

24.49

17.26

Asian-American

Mean

1.31

1.79

$t(37)=-1.01$

.32

$\mathrm{SD}$

2.91

3.33

.85

2.46 
Table 7 (continued).

Characteristic

Combined Didactic Experiential Significance test

$\mathrm{p}$

(two-tailed)

\begin{tabular}{|c|c|c|c|c|c|}
\hline European American & & & & $t(37)=-.33$ & .74 \\
\hline Mean & 35.15 & 37.00 & 33.40 & & \\
\hline SD & 33.74 & 37.32 & 30.84 & & \\
\hline Hispanic & & & & $t(37)=.75$ & .46 \\
\hline Mean & 42.62 & 38.26 & 46.75 & & \\
\hline $\mathrm{SD}$ & 34.93 & 38.27 & 31.88 & & \\
\hline Native American & & & & $t(37)=-.03$ & .98 \\
\hline Mean & 5.69 & 5.79 & 5.60 & & \\
\hline SD & 22.30 & 22.87 & 22.33 & & \\
\hline $\begin{array}{l}\text { Usefulness of current } \\
\text { interventions used }\end{array}$ & & & & $\chi^{2}(2, N=39)=.86$ & .65 \\
\hline 3 -Somewhat & 13 & 5 & 8 & & \\
\hline 4 & 19 & 10 & 9 & & \\
\hline 5 - Extremely & 7 & 4 & 3 & & \\
\hline Missing & 3 & 2 & 1 & & \\
\hline
\end{tabular}


Table 8

Interest in Upcoming PCIT training of Combined, Didactic, and Experiential Groups

\begin{tabular}{|c|c|c|c|c|c|}
\hline Interest Variable & Combined & Didactic & Experiential & Significance test & $\begin{array}{c}\mathrm{p} \\
\text { (two-tailed) }\end{array}$ \\
\hline \multicolumn{4}{|c|}{ Completed reading about PCIT prior to pre-training assessment } & $\chi^{2}(1, \mathrm{~N}=41)=.75$ & .39 \\
\hline Yes & 8 & 5 & 3 & & \\
\hline No & 33 & 15 & 18 & & \\
\hline Missing & 1 & 1 & 0 & & \\
\hline \multicolumn{4}{|c|}{ Attended a PCIT workshop prior to pre-training assessment } & $\chi^{2}(1, N=41)=1.08$ & .30 \\
\hline Yes & 1 & 1 & 0 & & \\
\hline No & 40 & 19 & 21 & & \\
\hline Missing & 1 & 1 & 0 & & \\
\hline \multicolumn{4}{|c|}{ Expected Usefulness of PCIT } & $\chi^{2}(2, N=35)=1.51$ & .47 \\
\hline 3 - Somewhat & 4 & 2 & 2 & & \\
\hline 4 & 14 & 8 & 6 & & \\
\hline 5 - Extremely & 17 & 6 & 11 & & \\
\hline Missing $\backslash$ Don't know & 7 & 5 & 2 & & \\
\hline \multicolumn{2}{|c|}{ Expected hours to devote to PCIT $(n=9)$} & $(n=6)$ & $(n=3)$ & $t(7)=-.54$ & .61 \\
\hline Mean & 17.56 & 21.67 & 15.50 & & \\
\hline $\mathrm{SD}$ & 15.44 & 17.56 & 15.59 & & \\
\hline \multicolumn{4}{|c|}{ Read PCIT manual between assessments one and two } & $\chi^{2}(1, \mathrm{~N}=42)=.11$ & .74 \\
\hline Yes & 29 & 15 & 14 & & \\
\hline No & 13 & 6 & 7 & & \\
\hline Missing & 0 & 0 & 0 & & \\
\hline
\end{tabular}


Table 8 (continued).

Interest Variable

Combined Didactic

Experiential

Significance test

$\mathrm{p}$

(two-tailed)

Read DPIC manual between assessments one and two

$$
\chi^{2}(1, \mathrm{~N}=42)=1.56
$$

Yes

18

11

7

No

24

10

14

Missing

0

0

0

Turned in reading log before assessment two

$\chi^{2}(1, \mathrm{~N}=42)=1.71$ .19

Yes

14

9

5

No

28

12

16

Missing 
Table 9

Experience with Treatment Manuals of Combined, Didactic, and Experiential Groups

\begin{tabular}{|c|c|c|c|c|c|}
\hline Experience Variable & Combined & Didactic & Experiential & $\chi^{2}$ & $\mathrm{p}$ \\
\hline \multicolumn{4}{|c|}{ Ever heard of psychotherapy treatment manuals? } & .41 & .52 \\
\hline Yes & 38 & 18 & 20 & & \\
\hline No & 3 & 2 & 1 & & \\
\hline Missing & 1 & 1 & 0 & & \\
\hline \multicolumn{4}{|c|}{ How clear an idea do you have of what a psychotherapy treatment manual is? } & 1.18 & .74 \\
\hline Totally unclear & 1 & 0 & 1 & & \\
\hline Somewhat unclear & 13 & 6 & 7 & & \\
\hline Reasonably clear & 19 & 10 & 9 & & \\
\hline Very clear & 7 & 3 & 4 & & \\
\hline Missing & 2 & 2 & 0 & & \\
\hline \multicolumn{4}{|c|}{$\begin{array}{l}\text { How much thought have you given to the use of treatment manuals in clinical } \\
\text { practice? }\end{array}$} & .99 & .91 \\
\hline None at all & 5 & 3 & 2 & & \\
\hline A little bit & 13 & 6 & 7 & & \\
\hline Some & 12 & 5 & 7 & & \\
\hline A fair amount & 7 & 3 & 4 & & \\
\hline A lot & 3 & 2 & 1 & & \\
\hline Missing & 2 & 2 & 0 & & \\
\hline
\end{tabular}


Table 9 (continued).

\begin{tabular}{|c|c|c|c|c|c|}
\hline Experience Variable & Combined & Didactic & Experiential & $\chi^{2}$ & $\mathrm{p}$ \\
\hline \multicolumn{4}{|c|}{$\begin{array}{l}\text { How strong are your attitudes/feelings about the role of treatment manuals in } \\
\text { clinical practice? }\end{array}$} & 3.74 & .29 \\
\hline Not at all strong & 21 & 9 & 12 & & \\
\hline Somewhat strong & 10 & 4 & 6 & & \\
\hline Strong & 8 & 6 & 2 & & \\
\hline Very strong & 1 & 0 & 1 & & \\
\hline Missing & 2 & 2 & 0 & & \\
\hline \multicolumn{4}{|c|}{ How would you describe your first experience with treatment manuals? } & .22 & .64 \\
\hline Positive & 0 & 0 & 0 & & \\
\hline Neutral & 22 & 10 & 12 & & \\
\hline Negative & 15 & 8 & 7 & & \\
\hline Missing & 5 & 3 & 2 & & \\
\hline \multicolumn{4}{|c|}{ How often do you use treatment manuals in your clinical (non-research) work? } & 2.97 & .56 \\
\hline Never & 8 & 2 & 6 & & \\
\hline Rarely & 15 & 8 & 7 & & \\
\hline Sometimes & 14 & 7 & 7 & & \\
\hline Often & 2 & 1 & 1 & & \\
\hline Almost exclusively & 1 & 1 & 0 & & \\
\hline Missing & 2 & 2 & 0 & & \\
\hline
\end{tabular}


Table 9 (continued).

\begin{tabular}{|c|c|c|c|c|c|}
\hline Experience Variable & Combined & Didactic & Experiential & $\chi^{2}$ & $\mathrm{p}$ \\
\hline \multicolumn{4}{|c|}{ How often do you use treatment manuals in your research? } & 6.14 & .19 \\
\hline I don't do research & 32 & 12 & 20 & & \\
\hline Never & 2 & 2 & 0 & & \\
\hline Rarely & 1 & 1 & 0 & & \\
\hline Sometimes & 3 & 2 & 1 & & \\
\hline Often & 0 & 0 & 0 & & \\
\hline Almost exclusively & 1 & 1 & 0 & & \\
\hline Missing & 3 & 3 & 0 & & \\
\hline \multicolumn{4}{|c|}{ How many treatment manuals do you use on a semi-regular basis? } & 3.18 & .37 \\
\hline None & 15 & 5 & 10 & & \\
\hline $1-2$ & 20 & 11 & 9 & & \\
\hline $3-4$ & 3 & 2 & 1 & & \\
\hline$>4$ & 1 & 1 & 0 & & \\
\hline Missing & 3 & 2 & 1 & & \\
\hline \multicolumn{4}{|c|}{ Have you ever helped create a treatment manual? } & .07 & .79 \\
\hline Yes & 7 & 3 & 4 & & \\
\hline No & 33 & 16 & 17 & & \\
\hline Missing & 2 & 2 & 0 & & \\
\hline
\end{tabular}


Table 10

Attitudes toward Behaviorally Oriented Treatments of Combined, Didactic, and Experiential Groups

\begin{tabular}{|c|c|c|c|c|c|}
\hline Attitude Variable & Combined & Didactic & Experiential & $\chi^{2}$ & $\mathrm{p}$ \\
\hline Is very practical & & & & .79 & .85 \\
\hline Not at all characteristic & 2 & 1 & 1 & & \\
\hline Somewhat characteristic & 7 & 4 & 3 & & \\
\hline Characteristic & 19 & 9 & 10 & & \\
\hline Very characteristic & 11 & 4 & 7 & & \\
\hline Missing \Don’t Know & 3 & 3 & 0 & & \\
\hline \multicolumn{3}{|c|}{ Presents a comprehensive view of psychology } & & 1.96 & .38 \\
\hline Not at all characteristic & 19 & 7 & 12 & & \\
\hline Somewhat characteristic & 17 & 10 & 7 & & \\
\hline Characteristic & 3 & 1 & 2 & & \\
\hline Very characteristic & 0 & 0 & 0 & & \\
\hline Missing \Don't Know & 3 & 3 & 0 & & \\
\hline Is objective & & & & 3.08 & .38 \\
\hline Not at all characteristic & 2 & 1 & 1 & & \\
\hline Somewhat characteristic & 11 & 4 & 7 & & \\
\hline Characteristic & 14 & 9 & 5 & & \\
\hline Very characteristic & 12 & 4 & 8 & & \\
\hline Missing \Don’t Know & 3 & 3 & 0 & & \\
\hline
\end{tabular}


Table 10 (continued).

\begin{tabular}{|c|c|c|c|c|c|}
\hline Attitude Variable & Combined & Didactic & Experiential & $\chi^{2}$ & $\mathrm{p}$ \\
\hline Tends to be rigid & & & & 1.65 & .65 \\
\hline Not at all characteristic & 4 & 2 & 2 & & \\
\hline Somewhat characteristic & 14 & 6 & 8 & & \\
\hline Characteristic & 15 & 6 & 9 & & \\
\hline Very characteristic & 4 & 3 & 1 & & \\
\hline Missing \Don’t Know & 5 & 4 & 1 & & \\
\hline \multicolumn{3}{|c|}{ Emphasizes individual case conceptualization } & & 6.23 & .10 \\
\hline Not at all characteristic & 9 & 2 & 7 & & \\
\hline Somewhat characteristic & 16 & 11 & 5 & & \\
\hline Characteristic & 10 & 4 & 6 & & \\
\hline Very characteristic & 4 & 1 & 3 & & \\
\hline Missing $\backslash$ Don't Know & 3 & 3 & 0 & & \\
\hline Is directive & & & & 2.59 & .46 \\
\hline Not at all characteristic & 1 & 0 & 1 & & \\
\hline Somewhat characteristic & 3 & 1 & 2 & & \\
\hline Characteristic & 19 & 11 & 8 & & \\
\hline Very characteristic & 16 & 6 & 10 & & \\
\hline Missing \Don't Know & 3 & 3 & 0 & & \\
\hline \multicolumn{4}{|c|}{ Emphasizes the importance of the therapeutic relationship } & 2.22 & .33 \\
\hline Not at all characteristic & 11 & 3 & 8 & & \\
\hline Somewhat characteristic & 19 & 10 & 9 & & \\
\hline Characteristic & 9 & 5 & 4 & & \\
\hline Very characteristic & 0 & 0 & 0 & & \\
\hline Missing $\backslash$ Don’t Know & 3 & 3 & 0 & & \\
\hline
\end{tabular}


Table 10 (continued).

\begin{tabular}{|c|c|c|c|c|c|}
\hline Attitude Variable & Combined & Didactic & Experiential & $\chi^{2}$ & $\mathrm{p}$ \\
\hline Is impersonal & & & & 1.37 & .71 \\
\hline Not at all characteristic & 10 & 5 & 5 & & \\
\hline Somewhat characteristic & 23 & 10 & 13 & & \\
\hline Characteristic & 5 & 2 & 3 & & \\
\hline Very characteristic & 1 & 1 & 0 & & \\
\hline Missing \Don’t Know & 3 & 3 & 0 & & \\
\hline \multicolumn{4}{|c|}{ Provides a "cookbook" approach of therapeutic techniques } & 4.84 & .18 \\
\hline Not at all characteristic & 3 & 0 & 3 & & \\
\hline Somewhat characteristic & 21 & 11 & 10 & & \\
\hline Characteristic & 9 & 3 & 6 & & \\
\hline Very characteristic & 4 & 3 & 1 & & \\
\hline Missing $\backslash$ Don't Know & 5 & 4 & 1 & & \\
\hline Is scientific & & & & 1.58 & .67 \\
\hline Not at all characteristic & 1 & 0 & 1 & & \\
\hline Somewhat characteristic & 8 & 4 & 4 & & \\
\hline Characteristic & 18 & 7 & 11 & & \\
\hline Very characteristic & 11 & 6 & 5 & & \\
\hline Missing $\backslash$ Don’t Know & 4 & 4 & 0 & & \\
\hline Oversimplifies complex processes & & & & 1.67 & .64 \\
\hline Not at all characteristic & 4 & 2 & 2 & & \\
\hline Somewhat characteristic & 15 & 8 & 7 & & \\
\hline Characteristic & 16 & 5 & 11 & & \\
\hline Very characteristic & 2 & 1 & 1 & & \\
\hline Missing $\backslash$ Don’t Know & 5 & 5 & 0 & & \\
\hline Negative Ideas & & & & $t(35)=-.73$ & .47 \\
\hline Positive Ideas & & & & $t(35)=-.36$ & .47 \\
\hline
\end{tabular}


Table 11

Comparison of Pre-training Variables of Combined, Didactic, and Experiential Groups

\begin{tabular}{|c|c|c|c|c|c|}
\hline Skill Variable & $\begin{array}{c}\text { Combined } \\
(\mathrm{n}=42)\end{array}$ & $\begin{array}{l}\text { Didactic } \\
(\mathrm{n}=21)\end{array}$ & $\begin{array}{l}\text { Experiential } \\
\qquad(\mathrm{n}=21)\end{array}$ & $t$ & $\mathrm{p}$ \\
\hline Unlabeled Praise & & & & .62 & .54 \\
\hline Mean & 4.19 & 3.86 & 4.52 & & \\
\hline SD & 3.46 & 2.71 & 4.12 & & \\
\hline Labeled Praise & & & & .97 & .34 \\
\hline Mean & 1.26 & 1.05 & 1.48 & & \\
\hline $\mathrm{SD}$ & 1.43 & 1.28 & 1.60 & & \\
\hline Reflections & & & & .154 & .88 \\
\hline Mean & 2.69 & 2.62 & 2.76 & & \\
\hline SD & 2.98 & 3.09 & 2.93 & & \\
\hline Descriptions & & & & -1.28 & .21 \\
\hline Mean & 12.14 & 13.62 & 10.67 & & \\
\hline $\mathrm{SD}$ & 7.52 & 8.31 & 6.51 & & \\
\hline Questions & & & & 1.30 & .20 \\
\hline Mean & 20.86 & 18.71 & 23.00 & & \\
\hline $\mathrm{SD}$ & 9.42 & 10.77 & 10.69 & & \\
\hline Criticism & & & & -.24 & .81 \\
\hline Mean & .26 & .29 & .24 & & \\
\hline SD & .63 & .56 & .70 & & \\
\hline Indirect Commands & & & & .35 & .73 \\
\hline Mean & 1.38 & 1.28 & 1.48 & & \\
\hline SD & 1.74 & 1.68 & .83 & & \\
\hline
\end{tabular}


Table 11 (continued).

\begin{tabular}{lccccc}
\hline \multicolumn{1}{c}{ Skill Variable } & $\begin{array}{c}\text { Combined } \\
(\mathrm{n}=42)\end{array}$ & $\begin{array}{c}\text { Didactic } \\
(\mathrm{n}=21)\end{array}$ & $\begin{array}{c}\text { Experiential } \\
(\mathrm{n}=21)\end{array}$ & $t$ & $\mathrm{p}$ \\
\hline Direct Commands & & & & -1.22 & .20 \\
Mean & 1.26 & 1.67 & .86 & & \\
SD & 2.16 & 2.76 & 1.28 & & \\
CDI Mastery Score & & & & .000 & \\
Mean & .14 & .14 & .14 & & \\
SD & .35 & .36 & .36 & & \\
Total Coaching Score & $(\mathrm{n}=41)$ & $(\mathrm{n}=21)$ & $(\mathrm{n}=20)$ & -.60 & \\
Mean & 7.85 & 8.57 & 7.10 & & \\
SD & 7.83 & 8.86 & 6.72 & & \\
\hline
\end{tabular}


Table 12

Comparison of Pre-training Knowledge Variables of Combined, Didactic, and Experiential Groups

\begin{tabular}{lccccc}
\hline \multicolumn{1}{c}{ Knowledge Variable } & Combined & Didactic & Experiential & $t$ & $\mathrm{p}$ \\
\hline $\begin{array}{l}\text { Knowledge of Behavioral } \\
\text { Principles as Applied to Children }\end{array}$ & $(\mathrm{n}=42)$ & $(\mathrm{n}=21)$ & $(\mathrm{n}=21)$ & .69 & .50 \\
Mean & 15.90 & 15.52 & 16.29 & \\
SD & 3.57 & 3.61 & 3.57 & \\
Child Directed Interaction & $(\mathrm{n}=42)$ & $(\mathrm{n}=21)$ & $(\mathrm{n}=21)$ & -.41 & .69 \\
Mean & 42.25 & 43.63 & 40.87 & & \\
SD & 21.66 & 21.30 & 22.45 & & .28 \\
DPICS & $(\mathrm{n}=38)$ & $(\mathrm{n}=19)$ & $(\mathrm{n}=19)$ & 1.10 & \\
Mean & 13.19 & 9.47 & 16.90 & \\
SD & 20.85 & 21.72 & 19.82 & \\
Total PCIT Knowledge & $(\mathrm{n}=38)$ & $(\mathrm{n}=19)$ & $(\mathrm{n}=19)$ & -.11 \\
Mean & 30.77 & 31.04 & 30.50 & \\
SD & 14.79 & 15.40 & 14.57 & \\
\hline
\end{tabular}


Table 13

Balance of Trainers Across Groups

Trainer

\begin{tabular}{lllll}
\cline { 2 - 4 } Training Location & \multicolumn{1}{c}{ Nancy } & \multicolumn{1}{c}{ Jean } & \multicolumn{1}{c}{ Amy } & Anthony \\
\hline Oakland & & Didactic & Didactic & Experiential \\
Santa Barbara & Rotating & Experiential & Didactic & \\
Los Angeles & Experiential & Didactic & Rotating & \\
Long Beach & Didactic & Rotating & Experiential & \\
Redding & Rotating & Experiential & Didactic & \\
Northridge & Experiential & Rotating & Didactic & \\
Sacramento & Rotating & & Experiential & Didactic \\
San Diego & Didactic & Rotating & Experiential & \\
\hline Totals & 2-Experiential & 2-Experiential & 3-Experiential & 1-Experiential \\
& 2-Didactic & 2-Didactic & 4-Didactic & 1-Didactic \\
& 3-Rotating & 3-Rotating & 3-Rotating & 0-Rotating \\
\hline & & & & \\
\hline
\end{tabular}


Table 14

Assessment Procedures Summary

Assessment Point

Elapsed Time Since Last Assessment

Characteristics

Demographic Information Survey

Attitudes toward Treatment Manuals

Skill

CDI Skills

Coaching Skills

Knowledge

KBPAC

CDI/DPCIS Knowledge Questionnaire

Satisfaction

Modified TAI
One

$$
\begin{aligned}
& \text { (Prior to start of Day } 1 \\
& \text { PCIT Fundamentals) }
\end{aligned}
$$

Approximately 12 weeks

X

X

X

$\mathrm{X}$

X

X

X

X

X

Three
(End of Day 1 PCIT
Fundamentals)
8 hours

Four

(End of Day 2 PCIT

Fundamentals)

24 hours
X

$\mathrm{X}$

X

X

X

X

X

$$
\mathrm{X}
$$


Table 14 (continued).

\begin{tabular}{|c|c|c|c|c|}
\hline Assessment Point & One & $\begin{array}{c}\text { Two } \\
\text { (Prior to start of Day } 1 \\
\text { PCIT Fundamentals) } \\
\end{array}$ & $\begin{array}{c}\text { Three } \\
\text { (End of Day 1 PCIT } \\
\text { Fundamentals) } \\
\end{array}$ & $\begin{array}{c}\text { Four } \\
\text { (End of Day } 2 \text { PCIT } \\
\text { Fundamentals) } \\
\end{array}$ \\
\hline Satisfaction with Training & & & $\mathrm{X}$ & $\mathrm{X}$ \\
\hline Training Integrity & & & & \\
\hline $\begin{array}{l}\text { Training Integrity Checklist - PCIT } \\
\text { Fundamentals Day } 1\end{array}$ & & & $\mathrm{X}$ & \\
\hline $\begin{array}{l}\text { Training Integrity Checklist- PCIT } \\
\text { Fundamentals Day } 1 \text { Experiential Group }\end{array}$ & & & & $\mathrm{X}$ \\
\hline $\begin{array}{l}\text { Training Integrity Checklist- PCIT } \\
\text { Fundamentals Day } 1 \text { Didactic Group }\end{array}$ & & & & $\mathrm{X}$ \\
\hline $\begin{array}{l}\text { Estimated Amount of Time for } \\
\text { Assessment Completion per participant }\end{array}$ & 60 minutes & 30 minutes & 25 minutes & 50 minutes \\
\hline
\end{tabular}


Table 15

Comparison of Knowledge Scores Pre-training and After Reading the PCIT Manual

\begin{tabular}{lcccccc}
\hline & \multicolumn{2}{c}{ Pre-training } & \multicolumn{2}{c}{$\begin{array}{c}\text { After reading the } \\
\text { PCIT manual }\end{array}$} \\
\cline { 2 - 7 } Percent Scores & $\mathrm{M}$ & $\mathrm{SD}$ & $\mathrm{M}$ & $\mathrm{SD}$ & $t$ & $\begin{array}{c}\text { Significance } \\
\text { (two-tailed) }\end{array}$ \\
\hline CDI Knowledge & 43.89 & 22.76 & 49.61 & 21.47 & -1.00 & .33 \\
DPICS Knowledge & 14.66 & 21.65 & 38.96 & 33.66 & -3.86 & $.001^{*}$ \\
Total PCIT Knowledge & 31.93 & 15.58 & 47.27 & 22.05 & -3.79 & $.001^{*}$ \\
\hline
\end{tabular}

Note. ${ }^{*} \mathrm{p}<.004$ corrected for familywise error considering Bonferroni inequality. 
Table 16

Comparison of Skill Scores Pre-training and After Reading the PCIT Manual

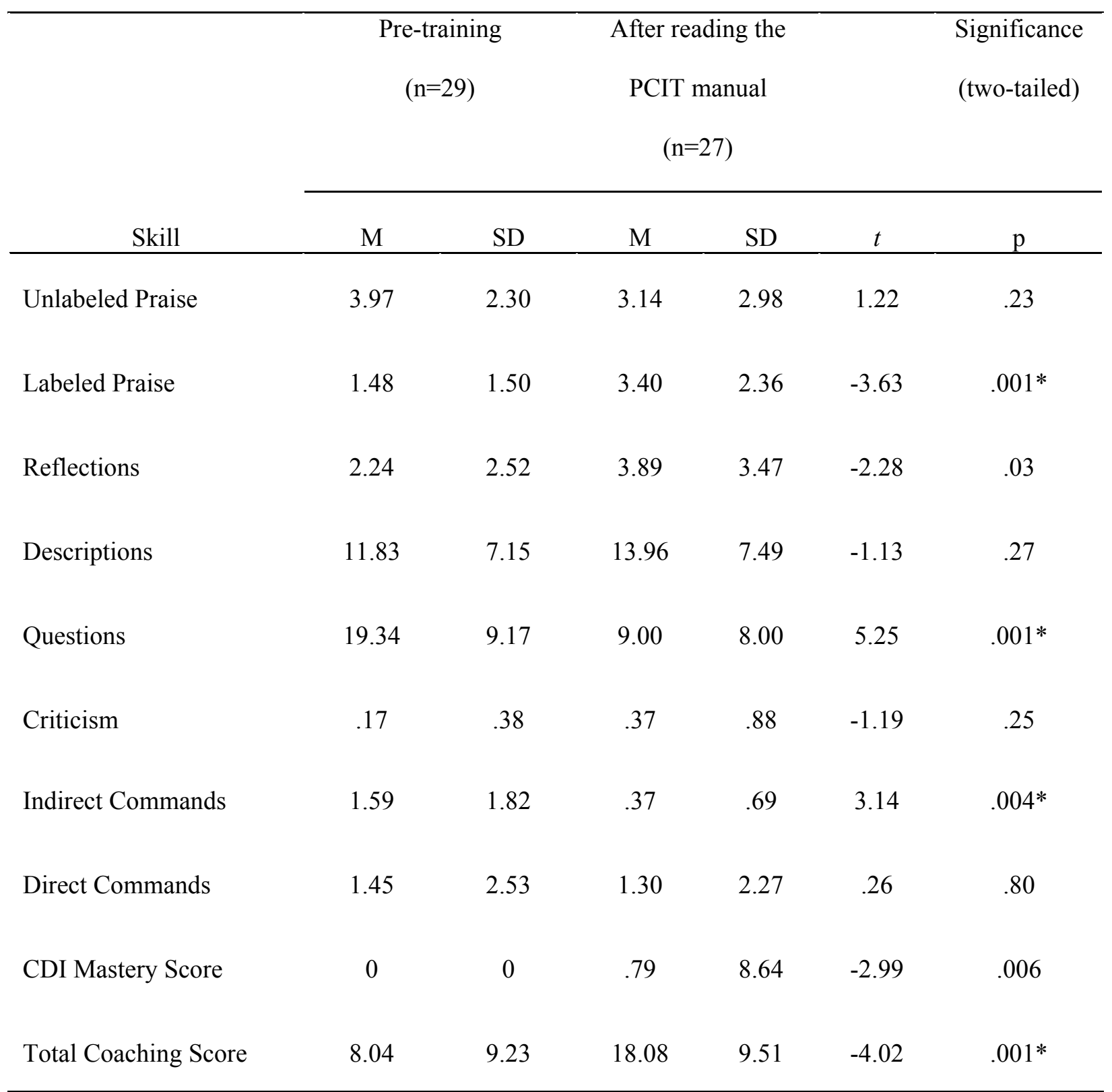

Note. ${ }^{*} \mathrm{p}<.004$ corrected for familywise error considering Bonferroni inequality. 
Table 17

Comparison of Assessment Point Three Knowledge Variables of Combined, Didactic, and Experiential Groups

\begin{tabular}{|c|c|c|c|c|c|}
\hline Knowledge Variable & $\begin{array}{c}\text { Combined } \\
(n=42)\end{array}$ & $\begin{array}{l}\text { Didactic } \\
(n=21)\end{array}$ & $\begin{array}{l}\text { Experiential } \\
\qquad(n=21)\end{array}$ & $t$ & $\mathrm{p}$ \\
\hline Child Directed Interaction & & & & .14 & .89 \\
\hline Mean & 60.17 & 59.85 & 60.49 & & \\
\hline SD & 14.95 & 14.80 & 15.47 & & \\
\hline DPICS & & & & .08 & .94 \\
\hline Mean & 50.49 & 50.16 & 50.82 & & \\
\hline SD & 25.88 & 28.53 & 23.64 & & \\
\hline Total PCIT Knowledge & & & & .13 & .90 \\
\hline Mean & 57.60 & 57.30 & 57.90 & & \\
\hline $\mathrm{SD}$ & 15.13 & 16.31 & 14.28 & & \\
\hline
\end{tabular}


Table 18

Comparison of Assessment Point Three Skill Variables of Combined, Didactic, and Experiential Groups

\begin{tabular}{|c|c|c|c|c|c|}
\hline Skill Variable & $\begin{array}{c}\text { Combined } \\
(\mathrm{n}=42)\end{array}$ & $\begin{array}{l}\text { Didactic } \\
(n=21)\end{array}$ & $\begin{array}{c}\text { Experiential } \\
(n=21)\end{array}$ & $t$ & $\mathrm{p}$ \\
\hline Unlabeled Praise & & & & 1.67 & .14 \\
\hline Mean & 6.50 & 5.38 & 7.62 & & \\
\hline $\mathrm{SD}$ & 4.45 & 2.94 & 5.41 & & \\
\hline Labeled Praise & & & & 2.01 & .01 \\
\hline Mean & 4.76 & 3.71 & 5.81 & & \\
\hline $\mathrm{SD}$ & 3.50 & 2.83 & 3.84 & & \\
\hline Reflections & & & & 2.22 & .03 \\
\hline Mean & 3.31 & 2.38 & 4.24 & & \\
\hline SD & 2.83 & 2.77 & 2.64 & & \\
\hline Descriptions & & & & 1.37 & .18 \\
\hline Mean & 17.55 & 15.67 & 19.43 & & \\
\hline SD & 9.02 & 7.75 & 9.95 & & \\
\hline Questions & & & & 1.94 & .06 \\
\hline Mean & 6.71 & 5.10 & 8.33 & & \\
\hline SD & 5.60 & 3.33 & 6.90 & & \\
\hline Criticism & & & & 1.04 & .31 \\
\hline Mean & .19 & .00 & .29 & & \\
\hline SD & .59 & .30 & .78 & & \\
\hline Indirect Commands & & & & .19 & .85 \\
\hline Mean & 1.05 & 1.10 & 1.00 & & \\
\hline SD & 1.61 & 1.79 & 1.45 & & \\
\hline
\end{tabular}


Table 18 (continued).

\begin{tabular}{lccccc}
\hline \multicolumn{1}{c}{ Skill Variable } & $\begin{array}{c}\text { Combined } \\
(\mathrm{n}=42)\end{array}$ & $\begin{array}{c}\text { Didactic } \\
(\mathrm{n}=21)\end{array}$ & $\begin{array}{c}\text { Experiential } \\
(\mathrm{n}=21)\end{array}$ & $t$ & $\mathrm{p}$ \\
\hline Direct Commands & 1.26 & 1.29 & 1.24 & .08 & \\
Mean & 1.87 & 2.15 & 1.61 & & \\
SD & & & & .94 \\
CDI Mastery Score & .98 & .71 & 1.24 & & \\
Mean & 1.18 & 1.10 & 1.22 & & \\
SD & $(\mathrm{n}=35)$ & $(\mathrm{n}=17)$ & $(\mathrm{n}=18)$ & -.28 & .78 \\
Total Coaching Score & 25.34 & 25.94 & 24.78 & & \\
Mean & 12.28 & 12.60 & 12.31 & & \\
SD & & & & \\
\hline
\end{tabular}

Note. ${ }^{*} \mathrm{p}<.004$ corrected for familywise error considering Bonferroni inequality. 
Table 19

Comparison of Training Groups on Skill Acquisition at Assessment Points Three and Four

Didactic

$(\mathrm{n}=17)$

Assessment Points

Skill

Three

Four Experiential

$$
(\mathrm{n}=17)
$$

Three Four

ANOVA $F(1,32)$

time main effect

Unlabeled Praise

.04

M

SD

Labeled Praise

M

SD

Descriptions

M

SD

Reflections

M

SD

Questions

M

SD

Criticism

M

SD

\subsection{9}

3.16

5.12

3.55

7.24

5.91

7.06

3.45

3.88

3.14

7.88

3.48

6.53

3.94

10.06

5.15

15.76

21.23

20.82

10.36

7.78

8.08

2.65

2.96

4.94

4.58

4.24

2.41

4.34

4.88

3.06

7.76

2.18

3.08

3.47

6.65

2.40

.12

.24

.56

.33

.35

.29

.86

.77
20.50 **

$9.01^{* *}$

$14.29 * *$

$17.99 * *$

.03 
Table 19 (continued).

\begin{tabular}{|c|c|c|c|c|c|}
\hline \multirow[b]{2}{*}{ Assessment Points } & \multicolumn{2}{|c|}{$\begin{array}{l}\text { Didactic } \\
(n=17)\end{array}$} & \multicolumn{2}{|c|}{$\begin{array}{l}\text { Experiential } \\
\quad(n=17)\end{array}$} & \multirow{4}{*}{$\begin{array}{l}\text { ANOVA } F(1,32) \\
\text { time main effect }\end{array}$} \\
\hline & Three & Four & Three & Four & \\
\hline \multirow[t]{2}{*}{ Skill } & & & & & \\
\hline & & & & & \\
\hline Indirect Commands & & & & & .31 \\
\hline M & 1.06 & .82 & .82 & .71 & \\
\hline SD & 1.98 & 1.07 & 1.24 & .85 & \\
\hline Direct Commands & & & & & .83 \\
\hline M & 1.41 & 2.29 & 1.41 & 1.23 & \\
\hline $\mathrm{SD}$ & 2.29 & 2.64 & 1.73 & 1.64 & \\
\hline CDI Mastery Score & & & & & $12.45^{* *}$ \\
\hline M & .82 & 2.18 & 1.47 & 2.94 & \\
\hline SD & 1.19 & 1.74 & 1.23 & 2.05 & \\
\hline Coaching & & & & & $37.81 * *$ \\
\hline M & 25.94 & 37.41 & 24.82 & 41.29 & \\
\hline SD & 12.60 & 13.62 & 12.68 & 17.50 & \\
\hline
\end{tabular}

Note. ${ }^{* *} \mathrm{p}<.01$ 
Table 20

Comparison of Training Groups on Knowledge Gain at Assessment Points Three and Four

\begin{tabular}{|c|c|c|c|c|c|}
\hline \multirow{3}{*}{ Assessment Points } & \multicolumn{2}{|c|}{$\begin{array}{l}\text { Didactic } \\
(\mathrm{n}=21)\end{array}$} & \multicolumn{2}{|c|}{$\begin{array}{l}\text { Experiential } \\
\qquad(n=20)\end{array}$} & \multirow[b]{3}{*}{$\begin{array}{l}\text { ANOVA } F(1,40) \\
\text { time main effect }\end{array}$} \\
\hline & Three & Four & Three & Four & \\
\hline & & & & & \\
\hline CDI Knowledge & & & & & $26.84 * *$ \\
\hline M & 59.85 & 73.56 & 60.49 & 70.74 & \\
\hline SD & 14.78 & 15.39 & 15.47 & 12.28 & \\
\hline DPICS Knowledge & & & & & $33.27 * *$ \\
\hline M & 50.16 & 69.15 & 50.82 & 79.79 & \\
\hline SD & 28.53 & 20.35 & 23.64 & 16.62 & \\
\hline
\end{tabular}

Note. ${ }^{* *} \mathrm{p}<.01$ 
Table 21

Comparison of Training Groups on Satisfaction at Assessment Points Three and Four

\begin{tabular}{|c|c|c|c|c|c|}
\hline \multirow[b]{2}{*}{ Assessment Points } & \multicolumn{2}{|c|}{$\begin{array}{l}\text { Didactic } \\
(n=21)\end{array}$} & \multicolumn{2}{|c|}{$\begin{array}{l}\text { Experiential } \\
\qquad(\mathrm{n}=20)\end{array}$} & \multirow[b]{3}{*}{$\begin{array}{c}\text { ANOVA } F(1,39) \text { time } \\
\text { main effect }\end{array}$} \\
\hline & Three & Four & Three & Four & \\
\hline Satisfaction Variable & & & & & \\
\hline Therapy Attitude Inventory & & & & & $14.91 * *$ \\
\hline M & 41.57 & 43.67 & 42.85 & 44.05 & \\
\hline SD & 4.45 & 4.60 & 4.02 & 3.79 & \\
\hline Satisfaction with Training & & & & & $19.93 * *$ \\
\hline M & 67.10 & 69.10 & 64.90 & 69.90 & \\
\hline SD & 6.37 & 6.53 & 6.96 & 5.34 & \\
\hline
\end{tabular}


Table 22

Intercorrelations Between Pre-training Therapist Variables and Post-training Knowledge, Skills, and Satisfaction

\begin{tabular}{|c|c|c|c|c|c|c|c|c|c|c|c|c|c|}
\hline & 1 & 2 & 3 & 4 & 5 & 6 & 7 & 8 & 9 & 10 & 11 & 12 & 13 \\
\hline 1. Age & ------ & & & & & & & & & & & & \\
\hline 2. Years since grad degree & $.56^{* *}$ & ------- & & & & & & & & & & & \\
\hline $\begin{array}{l}\text { 3. Years worked clinical } \\
\text { population }\end{array}$ & $.49 * *$ & $.75 * *$ & ------ & & & & & & & & & & \\
\hline $\begin{array}{l}\text { 4. Years worked with disruptive } \\
\text { behavior disorders }\end{array}$ & $.41 * *$ & $.48^{* *}$ & $.50 * *$ & ------- & & & & & & & & & \\
\hline $\begin{array}{l}\text { 5. Years worked with abuse and } \\
\text { neglect }\end{array}$ & $.33^{*}$ & $.47 *$ & $.47^{* *}$ & $.90 * *$ & ------ & & & & & & & & \\
\hline 6. Supervision hours & .05 & .13 & .31 & $.41^{*}$ & $.50 * *$ & ---- & & & & & & & \\
\hline 7. CE hours & .17 & $.38^{*}$ & $.48^{* *}$ & .22 & .25 & .36 & ----- & & & & & & \\
\hline $\begin{array}{l}\text { 8. Knowledge of Behavioral } \\
\text { Principles }\end{array}$ & .27 & .07 & .27 & .23 & .32 & -.13 & .25 & ----- & & & & & \\
\hline 9. Total PCIT Knowledge & -.07 & -.05 & .16 & .04 & -.01 & -.24 & .16 & $.50 * *$ & ---- & & & & \\
\hline 10. CDI Mastery score & -.26 & $-.34 *$ & $-.33 *$ & -.29 & -.25 & .13 & -.07 & .12 & .07 & ----- & & & \\
\hline 11. Coaching score & -.30 & -.15 & -.04 & -.24 & -.12 & -.05 & .15 & $.34^{*}$ & .25 & $.35^{*}$ & ----- & & \\
\hline 12. TAI & .30 & .10 & -.17 & -.01 & .02 & $-.34 *$ & -.20 & -.01 & -.06 & .06 & -.29 & ------ & \\
\hline 13. Satisfaction with Training & $.38 *$ & .29 & -.01 & .100 & .06 & $-.34 *$ & -.11 & .29 & .29 & .06 & -.21 & $.64 * *$ & --- \\
\hline
\end{tabular}


Table 23

Intercorrelations Between Pre-training Attitudes Toward and Experience with Treatment Manuals and Post-training Knowledge, Skills, and Satisfaction

\begin{tabular}{|c|c|c|c|c|c|c|c|c|c|c|c|}
\hline & 1 & 2 & 3 & 4 & 5 & 6 & 7 & 8 & 9 & 10 & 11 \\
\hline $\begin{array}{l}\text { 1.Attitude toward treatment } \\
\text { manuals - Negative Process }\end{array}$ & ----- & & & & & & & & & & \\
\hline $\begin{array}{l}\text { 2.Attitude toward treatment } \\
\text { manuals - Positive Outcome }\end{array}$ & .09 & ------ & & & & & & & & & \\
\hline $\begin{array}{l}\text { 3. Ever heard of a treatment } \\
\text { manual }\end{array}$ & -.07 & -.15 & ---- & & & & & & & & \\
\hline $\begin{array}{l}\text { 4. Frequency of treatment } \\
\text { manual use }\end{array}$ & -.24 & .17 & $.41 * *$ & -------- & & & & & & & \\
\hline $\begin{array}{l}\text { 5. Number of manuals used on a } \\
\text { regular basis }\end{array}$ & -.05 & .07 & .30 & $.82 * *$ & -------- & & & & & & \\
\hline $\begin{array}{l}\text { 6. Knowledge of Behavioral } \\
\text { Principles }\end{array}$ & -.22 & -.06 & $.33 *$ & .26 & .24 & ------- & & & & & \\
\hline 7. Total PCIT Knowledge & -.02 & -.17 & .14 & .26 & .18 & $.50 * *$ & ------ & & & & \\
\hline 8. CDI Mastery score & $-.31^{*}$ & -.06 & -.09 & .07 & -.08 & .12 & .07 & ------ & & & \\
\hline 9. Coaching score & -.23 & -.26 & .22 & .24 & .22 & $.34 *$ & .25 & $.35^{*}$ & ------ & & \\
\hline 10. TAI & -.17 & .08 & -.12 & -.17 & -.26 & -.01 & -.06 & .06 & -.29 & ------ & \\
\hline 11. Satisfaction with Training & .05 & .03 & .01 & -.11 & -.09 & .29 & .29 & .06 & -.21 & $.64 * *$ & ------ \\
\hline
\end{tabular}

Note. $* \mathrm{p}<.05, * * \mathrm{p}<.01$ 
Table 24

Intercorrelations Between Attitudes Toward Behaviorally Oriented Therapy (BOT) and Post-training Knowledge, Skills, and Satisfaction

\begin{tabular}{|c|c|c|c|c|c|c|c|c|c|c|c|}
\hline & 1 & 2 & 3 & 4 & 5 & 6 & 7 & 8 & 9 & 10 & 11 \\
\hline 1. BOTs are practical & ------- & & & & & & & & & & \\
\hline $\begin{array}{l}\text { 2.BOTs provide a } \\
\text { "cookbook" approach of } \\
\text { therapeutic techniques }\end{array}$ & .21 & -------- & & & & & & & & & \\
\hline $\begin{array}{l}\text { 3. BOTs overly simplify } \\
\text { complex processes }\end{array}$ & -.06 & .08 & -------- & & & & & & & & \\
\hline 4. Positive Ideas & .24 & -.12 & $-.52 * *$ & ------ & & & & & & & \\
\hline 5. Negative Ideas & .06 & $.74 * *$ & .21 & $-.39 *$ & ------ & & & & & & \\
\hline $\begin{array}{l}\text { 6. Knowledge of } \\
\text { Behavioral Principles }\end{array}$ & .15 & .15 & -.02 & -.13 & .21 & ------- & & & & & \\
\hline $\begin{array}{l}\text { 7. Total PCIT } \\
\text { Knowledge }\end{array}$ & -.08 & -.09 & .09 & .09 & .06 & $.50 * *$ & ------ & & & & \\
\hline 8. CDI Mastery score & -.27 & $-.37^{*}$ & $-.36^{*}$ & .17 & -.19 & .12 & .07 & ----- & & & \\
\hline 9. Coaching score & $-.45 * *$ & $-.49 * *$ & -.01 & -.19 & -.29 & $.34 *$ & .25 & $.35^{*}$ & ----- & & \\
\hline 10. TAI & .19 & .10 & -.29 & .23 & -.08 & -.01 & -.06 & .06 & -.29 & ----- & \\
\hline $\begin{array}{l}\text { 11. Satisfaction with } \\
\text { Training }\end{array}$ & .12 & .04 & -.11 & .19 & -.09 & .29 & .29 & .06 & -.21 & $.64 * *$ & ------ \\
\hline
\end{tabular}


Table 25

Intercorrelations Between Pre- and Post-training Knowledge, Skills, and Satisfaction

\begin{tabular}{|c|c|c|c|c|c|c|c|c|c|c|c|c|}
\hline & 1 & 2 & 3 & 4 & 5 & 6 & 7 & 8 & 9 & 10 & 11 & 12 \\
\hline $\begin{array}{l}\text { 1. Pre Knowledge of } \\
\text { Behavioral Principles }\end{array}$ & -------- & & & & & & & & & & & \\
\hline $\begin{array}{l}2 \text { Pre Total PCIT } \\
\text { Knowledge }\end{array}$ & $.46^{* *}$ & ------ & & & & & & & & & & \\
\hline 3. Pre CDI Mastery score & .24 & .17 & $\begin{array}{l}------ \\
-\end{array}$ & & & & & & & & & \\
\hline 4. Pre Coaching score & .14 & $.45^{* *}$ & .07 & -------- & & & & & & & & \\
\hline $\begin{array}{l}\text { 5. How useful think PCIT } \\
\text { training will be }\end{array}$ & .05 & -.10 & .14 & -.07 & ------- & & & & & & & \\
\hline $\begin{array}{l}\text { 6. Time will devote to } \\
\text { PCIT }\end{array}$ & -.29 & .06 & -.31 & .15 & -.49 & ------- & & & & & & \\
\hline $\begin{array}{l}\text { 7. Post Knowledge of } \\
\text { Behavioral Principles }\end{array}$ & $.66^{* *}$ & .17 & .18 & -.05 & .22 & .08 & ------ & & & & & \\
\hline $\begin{array}{l}\text { 8. Post Total PCIT } \\
\text { Knowledge }\end{array}$ & $.43 * *$ & .14 & -.15 & -.27 & -.02 & .03 & $.50 * *$ & ----- & & & & \\
\hline 9. Post CDI Mastery score & -.09 & -.30 & -.01 & .03 & .17 &.- .40 & .12 & .07 & ------ & & & \\
\hline 10. Post Coaching score & .13 & -.04 & -.07 & .08 & .05 & -.31 & $.34 *$ & .25 & $.35^{*}$ & ----- & & \\
\hline 11. Post TAI & -.05 & -.25 & .21 & -.24 & $.41 *$ & .00 & -.01 & -.06 & .06 & -.29 & ------- & \\
\hline $\begin{array}{l}\text { 12. Post Satisfaction with } \\
\text { Training }\end{array}$ & .14 & -.20 & .23 & $-.34 *$ & $.38 *$ & .06 & .29 & .29 & .06 & -.21 & $.64 * *$ & ------ \\
\hline
\end{tabular}

Note. $* \mathrm{p}<.05, * * \mathrm{p}<.01$ 
Table 26

Results of Logistic Regressions Predicting PCIT Knowledge Mastery by Degree Type and Theoretical Orientation

PCIT Knowledge Mastery

Step 1

Step 2

\begin{tabular}{lcccccc}
\cline { 2 - 6 } Variable & B & SE & $\beta$ & B & SE & $\beta$ \\
\hline Degree & 1.09 & .74 & 3.00 & .95 & .77 & 2.58 \\
Orientation & & & & -.94 & .82 & .39 \\
-2LL & 41.90 & & & 40.52 & & \\
Model $\chi^{2}$ & 2.25 & & 3.63 & & \\
\hline
\end{tabular}


Table 27

Results of Logistic Regressions Predicting CDI Skill Mastery by Degree Type and Theoretical Orientation

\begin{tabular}{|c|c|c|c|c|c|c|}
\hline \multirow[b]{3}{*}{ Variable } & \multicolumn{6}{|c|}{ CDI Mastery } \\
\hline & \multicolumn{3}{|c|}{ Step 1} & \multicolumn{3}{|c|}{ Step 2} \\
\hline & B & $\mathrm{SE}$ & $\beta$ & B & $\mathrm{SE}$ & $\beta$ \\
\hline Degree & 2.36 & 1.17 & $10.56^{*}$ & 2.74 & 1.27 & $15.48 *$ \\
\hline Orientation & & & & 1.21 & 1.09 & 3.34 \\
\hline$-2 L L$ & 26.19 & & & 24.91 & & \\
\hline Model $\chi^{2}$ & $5.50 *$ & & & $6.77 *$ & & \\
\hline
\end{tabular}

Note. $* \mathrm{p}<.05$ 
Table 28

List of Variables Examined in Exploratory Analyses

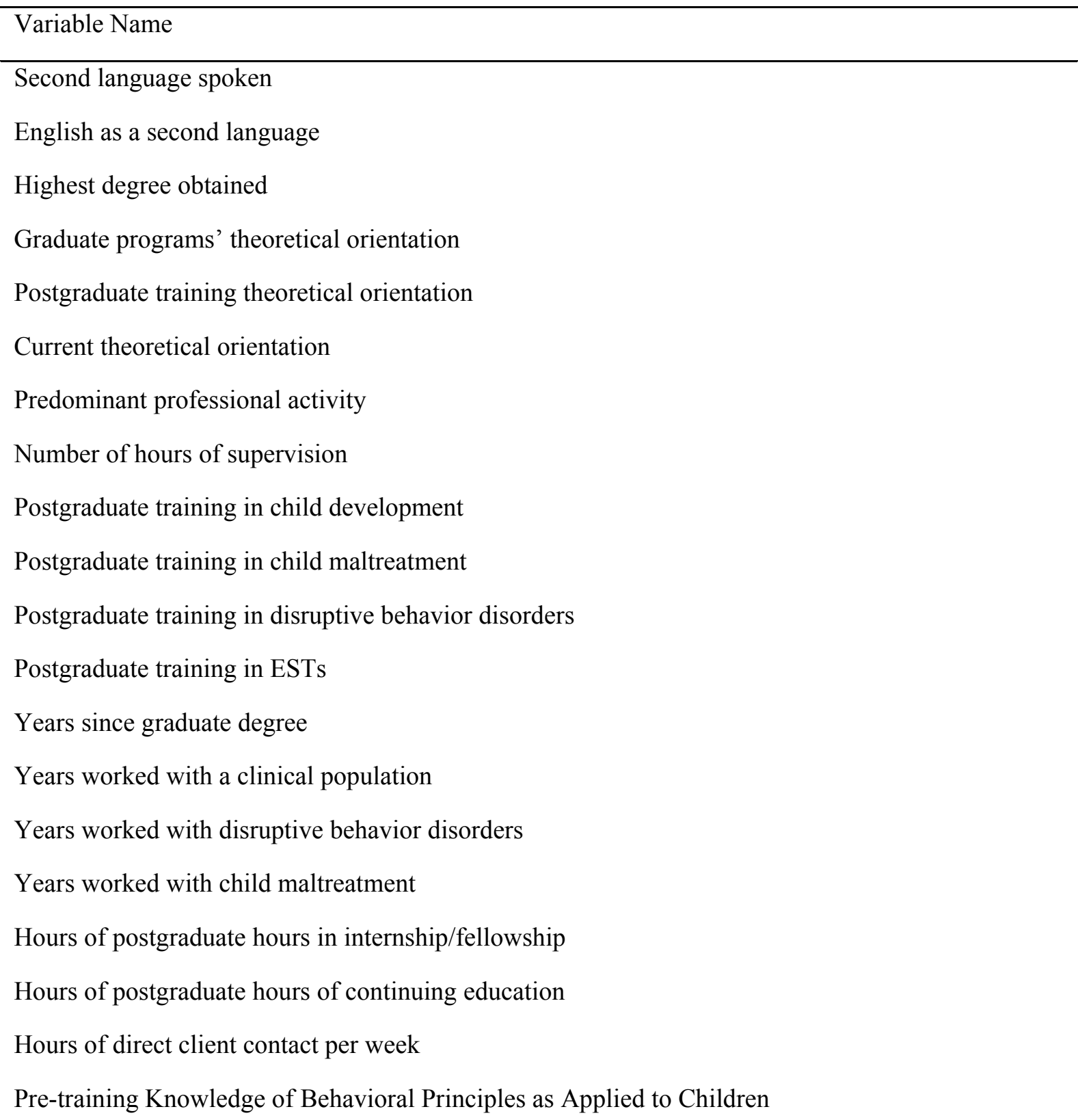


Table 28 (continued).

Variable Name

Pre-training Total PCIT Knowledge

Pre-training unlabeled praise

Pre-training labeled praise

Pre-training descriptions

Pre-training reflections

Pre-training questions

Pre-training indirect commands

Pre-training direct commands

Pre-training criticism

Pre-training total coaching score

Read PCIT treatment manual prior to assessment two

Read DPICS manual prior to assessment two

Returned reading log prior to assessment two

How useful think PCIT training will be

Anticipated time to devote to PCIT

Usefulness of previously used interventions

Attitude toward treatment manuals - negative process

Attitude toward treatment manuals - positive outcome

Attitude toward treatment manuals - items 1 through 9

Attitude toward behaviorally oriented therapies - positive ideas

Attitude toward behaviorally oriented therapies - negative ideas

Attitude toward behaviorally oriented therapies - items 1 through 11 
Table 29

Description of Participants' MSW and MA/MS Programs by Graduate School and Specialty Area

\begin{tabular}{|c|c|c|}
\hline Number & Graduate School & Specialty Area \\
\hline \multicolumn{3}{|c|}{ MSW } \\
\hline 1 & Arizona State University & Social Work \\
\hline 2 & California State University, Sacramento & Social Work \\
\hline 1 & Columbia and Boston Universities & Social Work \\
\hline 4 & Sacramento State University & Social Work \\
\hline 1 & San Diego State University & Social Work \\
\hline 2 & University of California, Berkeley & Social Welfare \\
\hline 2 & University of California, Los Angeles & Social Welfare \\
\hline 1 & University of Denver & Social Work \\
\hline \multicolumn{3}{|c|}{$\mathrm{MA} / \mathrm{MS}$} \\
\hline 1 & Anitoch University & Psychology \\
\hline 1 & California Lutheran & Counseling Psychology \\
\hline 1 & California State University, Fullerton & Counseling Psychology \\
\hline 1 & California State University, Long Beach & Marriage and Family Therapy \\
\hline 1 & California State University, Northridge & Educational Psychology \\
\hline 1 & California State University, Sacramento & Counselor Education \\
\hline 1 & Hope International & MFCC \\
\hline 1 & Hoyola Marymount University & Clinical Art Therapy \\
\hline 1 & John Jay College of Criminal Justice & Psychology \\
\hline 1 & National University & Counseling Psychology \\
\hline 1 & National University & Psychology \\
\hline 1 & National University & School of Education \\
\hline 2 & Pacifica Graduate Institute & Counseling Psychology \\
\hline 1 & Pepperdine University & Clinical Psychology \\
\hline
\end{tabular}


Table 29 (continued).

\begin{tabular}{cll}
\hline Number & Graduate School & Specialty Area \\
\hline 1 & Pepperdine University & Community Clinical Psychology \\
1 & Pepperdine University & SPE \\
1 & Sacramento State University & Counseling Education \\
1 & San Francisco State University & Counseling Psychology \\
2 & University of California, Santa Barbara & Counseling Psychology \\
1 & University of Kerala & Education \\
\hline
\end{tabular}


Evaluation of dissemination techniques 168

\section{Figure Caption}

Figure 1. Sample agency assessment schedule in relation to training phases. 
Training

phase

Assessment

Abbreviated activities

Estimated
completion
date and
time*
Time elapsed
between

One

assessments

\begin{tabular}{ll|} 
& \multicolumn{1}{c}{ PHASE ONE } \\
One & \\
& \\
& $\begin{array}{l}\text { 4 hour meeting at agency } \\
\text { regarding program } \\
\text { development }\end{array}$ \\
& $\begin{array}{l}\text { Provide PCIT and DPICS } \\
\text { manual for participants to } \\
\text { read prior to Post-1 }\end{array}$ \\
& \\
& \\
& 12/14/00 \\
12/14/00 & \\
8:00am- & \\
9:00am & \\
& \\
&
\end{tabular}

\section{PHASE TWO}

\section{DAY 1}

Two

7 hour

workshop

\section{All participants} attend the same presentation

3/11/00
8:00am-
9:00am
4 weeks

$3 / 11 / 00$

$3 / 11 / 00$

9:00am-4:00pm
3/11/00

4:00pm-

5:00pm

8 hours

\section{DAY 2}

Three

Four

7 hour workshop

Participants attend

different

presentations based

on group

assignment

(experiential versus

didactic)

\section{$3 / 12 / 00$}

9:00am-4:00pm

$3 / 12 / 00$

4:00pm-

5:00pm

24 hours

Note. ${ }^{*}$ The dates in this row are estimates and they are meant to serve as an example of a schedule for one of the 11 participating agencies. 